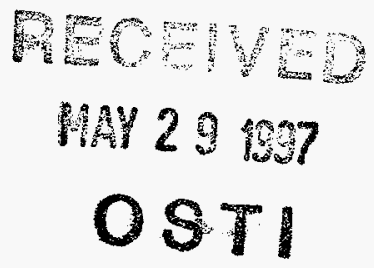

ORNL/TM-13407
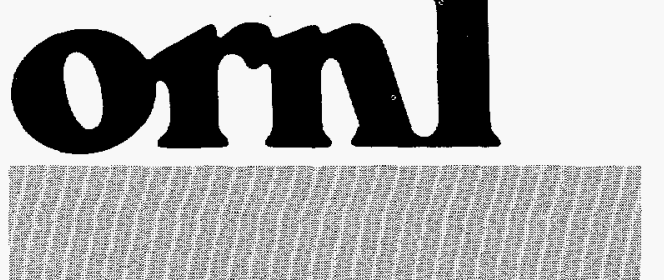

OAK RIDGE NATIONAL LABORATORY
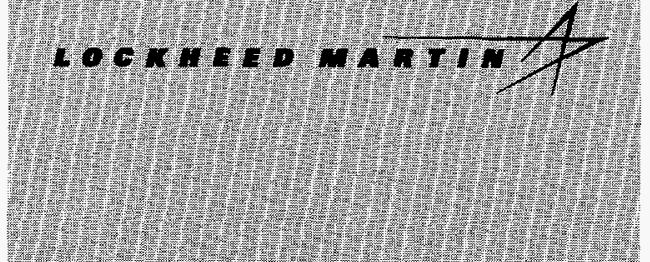

\section{ADVANCED COMPUTATIONAL SIMULATION FOR DESIGN AND MANUFACTURING OF LIGHTWEIGHT MATERIAL COMPONENTS FOR AUTOMOTIVE APPLICATIONS}

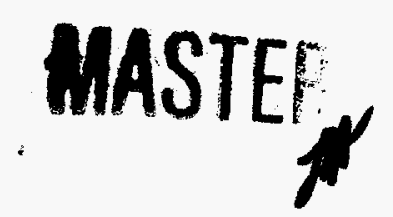

DETRIEUTION OF THIS DOCUMENT IS UNLMITED 
This report has been reproduced directly from the best available copy.

Available to DOE and DOE contractors from the Office of Scientific and Technical Information, P. O. Box 62, Oak Ridge, TN 37831; prices available from (423) 576-8401, FTS 626-8401.

Available to the public from the National Technical Information Service, U.S. Department of Commerce, 5285 Port Royal Road. Springfield. VA 22161.

This report was prepared as an account of work sponsored by an agency of the United States Government. Neither the United States Government nor any agency thereof, nor any of their employees, makes any warranty, express or implied, or assumes any legal liability or responsibility for the accuracy, completeness, or usefulness of any information, apparatus, product, or process disclosed, or represents that its use would not infringe privately owned rights. Reference herein to any specific commercial product, process, or service by trade name, trademark, manufacturer, or otherwise, does not necessarily constitute or imply its endorsement, recommendation, or favoring by the United States Government or any agency thereof. The views and opinions of authors expressed herein do not necessarily state or reflect those of the United States Government of any agency thereof. 


\section{DISCLAIMER}

Portions of this document may be illegible electronic image products. Images are produced from the best available original document. 
Metals and Ceramics Division

Engineering Materials Section

\title{
ADVANCED COMPUTATIONAL SIMULATION FOR DESIGN AND MANUFACTURING OF LIGHTWEIGHT MATERIAL COMPONENTS FOR AUTOMOTIVE APPLICATIONS
}

\author{
Srdan Simunovic, Gustavo A. Aramayo, Thomas Zacharia ${ }^{1}$ \\ Theodore G. Toridis ${ }^{2}$ \\ Faris Bandak, Carl L. Ragland ${ }^{3}$ \\ ${ }^{1}$ The Oak Ridge National Laboratory \\ 2 The George Washington University \\ ${ }^{3}$ The U.S. Department of Transportation
}

Date Published: April 1997

Research was sponsored by the U.S. Department of Energy, Assistant Secretary for Energy Efficiency and Renewable Energy, Office of Transportation Technologies, Lightweight Vehicle Materials Program.

Prepared by the OAK RIDGE NATIONAL LABORATORY

Oak Ridge, Tennessee 37831 managed by LOCKHEED MARTIN ENERGY RESEARCH CORP.

for the

U.S. DEPARTMENT OF ENERGY under Contract No. DE-AC05-96OR22464 


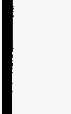




\section{CONTENTS}

1 INTRODUCTION 1

2 TECHNICAL APPROACH 3

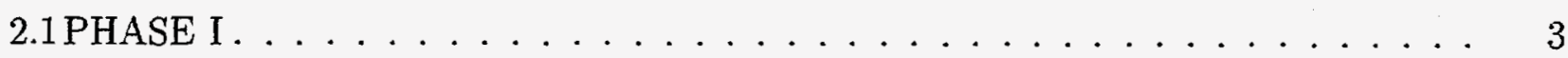

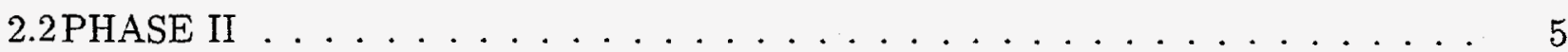

3 PROJECT RESULTS 6

3.1 ANALYSIS OF NHTSA VEHICLE DATABASE . . . . . . . . . . . . . . 6

3.2 ANALYSIS OF THE TEST VEHICLE . . . . . . . . . . . . . . . . 10

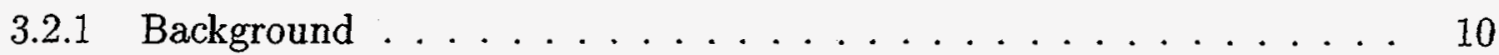

3.2 .2 Digitizing Equipment . . . . . . . . . . . . . . 11

3.2.2.1 Hardware ................... 11

3.2.2.2 Software ....................... 12

3.2 .2 .3 Certification . . . . . . . . . .... 13

3.2 .2 .4 Measurement . . . . . . . . . . . . 13

3.2.2.5 Construction ................... 14

3.2.2.6 Alignment ...................... 15

3.2.2.7 NURBS Surface Construction . . . . . . . . . . 15

3.2 .3 Measurement Setup . . . . . . . . . . . . . . . . 16

3.2 .4 Measurement Strategies .................. 18

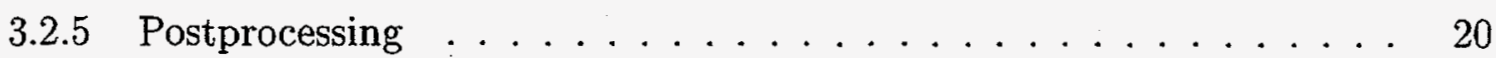

3.3 DEVELOPMENT OF VEHICLE MODEL . . . . . . . . . . . . . . . . . 20

3.3 .1 Original Model Limitations . . . . . . . . . . . . . . . 22

3.3 .2 Model Modifications . . . . . . . . . . . . . . . 23

3.3.2.1 Material Sets . . . . . . . . . . . . . 23

3.3.2.2 Number of Nodes and Elements in the Model . . . . . . 23

3.3.2.3 Contact Interfaces . . . . . . . . . . . . . 24

3.3.2.4 Nodal Constraint Sets . . . . . . . . . . . . 25 


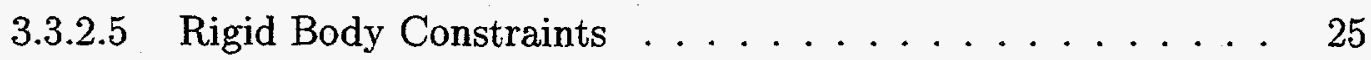

3.3.2.6 Front Suspension Components . . . . . . . . . . 25

3.3.2.7 Engine and Transmission Mounts . . . . . . . . . 37

3.3.2.8 Structural Changes . . . . . . . . . . . . . . 37

3.3.3 Consequences of the Changes in the Model . . . . . . . . . . . . 43

3.4 CONSTITUTIVE MODELS FOR LWM . . . . . . . . . . . . . . . . 59

3.5 MASSIVELY PARALLEL COMPUTING APPLICATIONS $\ldots \ldots \ldots \ldots$

4 CONCLUSIONS AND FUTURE WORK $\quad 70$

5 REFERENCES $\quad 71$

$\begin{array}{llll}\text { Appendix A } & \text { GENERAL TEST INFORMATION FOR TEST } 2075 & 73\end{array}$ 


\section{LIST OF FIGURES}

1 Vehicle Positions for Offset Frontal Oblique Test . . . . . . . . . . . 7

2 Collision Point of Test Vehicles . . . . . . . . . . . . . . . 8

3 Tested Vehicle on Rotating Fixture . . . . . . . . . . . . . 9

4 Beam and Truss Elements in Vehicle Model . . . . . . . . . . . . . . 28

5 Front Suspension Components in Vehicle Model . . . . . . . . . . . . . 29

6 Front Engine Cradle Assembly and Suspension, Technical Documentation . . 30

7 Front Engine Cradle Assembly and Suspension, Revised Model . . . . . . . . 31

8 Tension Struts, Model . . . . . . . . . . . . . . . . 32

9 Stabilizer Bar and Subframe .................... 33

10 Stabilizer Bar and Suspension Links . . . . . . . . . . . . . 34

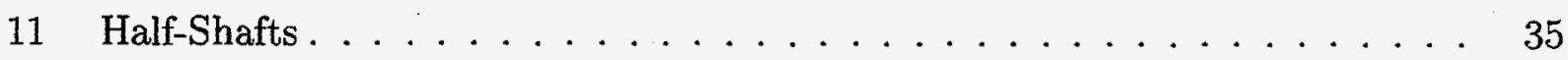

12 MacPherson Strut and Knuckle Assembly . . . . . . . . . . . . 36

13 Engine and Transmission Mounts, Top View . . . . . . . . . . . . . . . . 39

14 Engine and Transmission Mounts, Front View . . . . . . . . . . . . . 40

15 Engine Cradle, Initial Rear Cross Member . . . . . . . . . . . . . . . . 41

16 Engine Cradle, Modified Rear Cross Member . . . . . . . . . . . . . . . . 42

17 Frontal Offset Impact with Rigid Barrier, Top View . . . . . . . . . . . . 44

18 Frontal Offset Impact with Rigid Barrier, Bottom View . . . . . . . . . . 45

19 Frontal Offset Impact, Deformed Vehicle, Top View . . . . . . . . . . . . . 46

20 Frontal Offset Impact, Deformed Vehicle, Bottom View . . . . . . . . . . 47

21 Frontal Offset Impact, Deformed Vehicle, Side View . . . . . . . . . . . . . 48

22 Frontal Offset Impact, Left Subframe with Suspension . . . . . . . . . . . 49

23 Two Vehicle Frontal Oblique Offset Crash . . . . . . . . . . . . . . 51

24 Two Vehicle Crash, Deformation after $50 \mathrm{~ms} \ldots \ldots . . \ldots 52$

25 Two Vehicle Crash, Deformation after $150 \mathrm{~ms}$. . . . . . . . . . . . 53

26 Two Vehicle Crash, Suspension and Subframe . . . . . . . . . . . 54

27 Two Vehicle Crash, Test Vehicle, Bottom View . . . . . . . . . . . . 55

28 Two Vehicle Crash, Model, Bottom View . . . . . . . . . . . . . . . 56 
29 Two Vehicle Crash, Test Vehicle, Top View . . . . . . . . . . . . . . . . 57

30 Two Vehicle Crash, Model, Top View . . . . . . . . . . . . . . . . . 58

31 Tube Impact Force . . . . . . . . . . . . . . . . . . . . . . . . . 60

32 Material Model without Damage Effects . . . . . . . . . . . . . . 61

33 Material Model with Damage Effects . . . . . . . . . . . . . . . 62

34 Domain Decomposition for MPP . . . . . . . . . . . . . 66

35 CPU Time on Intel Paragon . . . . . . . . . . . . . . . . 67

36 CPU Time History on Intel Paragon . . . . . . . . . . . . . . . . 68

37 CPU Time Scalling on Intel Paragon . . . . . . . . . . . . . . . 69 


\section{ACKNOWLEDGEMENTS}

Research was sponsored by the U.S. Department of Energy, Assistant Secretary for Energy Efficiency and Renewable Energy, Office of Transportation Technologies, Lightweight Vehicle Materials Program, under contract DE-AC05-96OR22464 with Lockheed Martin Energy Research Corporation. The authors acknowledge use of the Intel Paragon XP/S 35 and XP/S 150 computers located in the Oak Ridge National Laboratory Center for Computational Sciences, funded by the Department of Energy's Office of Scientific Computing. 



\begin{abstract}
Computational vehicle models for the analysis of lightweight material performance in automobiles have been developed through collaboration between Oak Ridge National Laboratory, the National Highway Transportation Safety Administration, and George Washington University. The vehicle models have been verified against experimental data obtained from vehicle collisions. The crashed vehicles were analyzed, and the main impact energy dissipation mechanisms were identified and characterized. Important structural parts were extracted and digitized and directly compared with simulation results. High-performance computing played a key role in the model development because it allowed for rapid computational simulations and model modifications. The deformation of the computational model shows a very good agreement with the experiments. This report documents the modifications made to the computational model and relates them to the observations and findings on the test vehicle. Procedural guidelines are also provided that the authors believe need to be followed to create realistic models of passenger vehicles that could be used to evaluate the performance of lightweight materials in automotive structural components.
\end{abstract}




\section{INTRODUCTION}

Introduction of new materials in automobiles is a long process. For car designers to accept a new material or process, it is essential to have no risk associated with manufacturing and use at the time the commitment is made because changes in these areas have significant effects on both up- and downstream operations, with the potential for significant delay and negative consequences.

Requirements on processing and in-service performance are so numerous and intermingled that their enumeration and importance ranking is best left to car company executives. Perhaps the most dramatic automotive design challenge comes from vehicle collision tests. Not only do they bring perspective to everyday driving but also make one more appreciative of challenges that are facing vehicle designers. The dissipation of energy and the extent of deformation in collisions are very often critical design considerations. Material behavior must be well understood to design structures and mechanisms that protect vehicle occupants.

The high expense of impact testing and the availability of supercomputers have motivated the development of sophisticated computer programs to model such complex physical phenomena. From the standpoint of a design engineer, vehicle impact simulations must meet three essential requirements: (1) accuracy, (2) versatility, and (3) computational feasibility.

In recent years, massively parallel computer designs have emerged and presented a new technology aimed at meeting the increasing need for scalable processing speed. Massively parallel computers can combine hundreds or even thousands of processors that are able to operate concurrently on a problem. These computers currently appear to provide a viable route (although computer trend forecasting has proven to be rather unreliable in the past) for performing detailed and realistic crashworthiness simulations and consequently enabling the assessment of integrated design and performance of lightweight materials (LWM) in automotive applications.

A collaborative research effort between the U.S. Department of Transportation (DOT) and the U.S. Department of Energy (DOE) has been established supporting the presidential initiative on Partnership for a New Generation of Vehicles. DOE has the coordinating role for tripling the fuel efficiency (Goal 3 of the PNGV Initiative), and DOT has the coordinating 
role for improving the near-term fuel economy and reducing emissions, while maintaining safety (Goal 2 of the PNGV Initiative).

The participants in this project were:

1. DOE: Oak Ridge National Laboratory (ORNL)

2. DOT: National Highway Transportation and Safety Administration (NHTSA)

3. George Washington University (GWU)

A large number of model modifications and simulations have been performed for car-tocar and car-to-rigid-barrier impacts. The vehicles from crash tests were analyzed and the main impact energy dissipation mechanisms were identified. Deformed parts were digitized and compared with simulation results. The end result of this project is a comprehensive computational platform that can be used for testing and evaluating the performance and design consequences of introducing LWM into the passenger vehicles. One of the main contributions of this project is that it has linked the results and the developments from the computational model to the physical observations from the physical vehicle crash. 


\section{TECHNICAL APPROACH}

\subsection{PHASE I}

The objectives of Phase I were to provide early results as well as a smooth transition into the effective use of the emerging parallel machines working with existing finite element method (FEM) structural mechanics codes. The following tasks were stated in the original statement of work:

1. Evaluating the performance of the computational model for a series of frontal offset impact conditions, including oblique impacts, against test data.

(ORNL task-partially completed)

2. Investigating the structural response of compartment for the above configurations. (ORNL task-completed)

3. Performing appropriate impact tests to accommodate the above requirements. (NHTSA task-partially completed)

4. Collecting and analyze the experimental data. (GWU task-completed)

5. Developing post-test investigation protocol. (GWU task-partially completed)

6. Modifying vehicle model based on experimental validation. (ORNL task-completed)

7. Project report detailing accuracy of the finite element model and comparisons with experimental results. (ALL-in progress)

Because of the funding situation, the ORNL activities on the project had to be brought to a conclusion by the end of calendar year 1996. The project objectives in the original statement of work were written assuming long-term effort and were planning on continuous 
contributions from related projects to create a comprehensive study of a wide spectrum of LWM in automotive applications.

The results of the first phase of the project were to be computational models for a midsize sedan that would accurately describe deformation of the standard vehicle [the term standard pertains to the vehicle made of conventional automotive materials (i.e., mild steel)] in various collision scenarios. The impact situations that were planned to be analyzed and simulated were, in chronological order:

1. Frontal offset impact of a vehicle into a rigid barrier

2. Frontal offset impact of a vehicle into a moving deformable barrier (MDB)

3. Frontal offset impact of two vehicles

4. Frontal oblique offset impact of a vehicle into an MDB

5. Frontal oblique offset collision of two vehicles

The project collaborators from NHTSA were interested primarily in modeling collision scenario 5, and subsequently, only a vehicle from such a collision was made available for comparison with the simulation data. That has forced ORNL efforts to skip the analysis of collision scenarios 1 to 4 and work directly on scenario 5 . The model for scenario 5 was initially supposed to be a culmination of the research done on all the previous scenarios where deficiencies of the model would be more easily identified and corrected. The lack of this gradual approach has resulted in modeling difficulties that arose from very complicated vehicle deformation in scenario 5. In this type of collision, almost all parts of the vehicle in the engine compartment and numerous parts from passenger compartment structure significantly influence the deformation. The modifications of the model had to be simultaneously performed on many parts in both vehicles. In addition, the collision of two vehicles has the largest number of finite elements among all the considered scenarios, and it presented computational difficulties because of the availability of supercomputers at ORNL.

After numerous modifications and simulations with the computational model, and investigations on the crashed car, a vehicle model that very accurately describes the deformation 
of the studied vehicle in collision scenario 5 has been developed. The simulated deformation of the engine compartment, subframe, and chasis up to the passenger compartment shows a very good agreement with the test. In light of the fact that the most of the energy in this particular collision scenario is consumed in the engine compartment, it may be concluded that the developed model is reasonably valid. It could also be expected that the developed model should be accurate in collision scenarios 1 through 4 . However, this assumption would need to be verified by inspection of the test vehicles involved in those collisions.

\subsection{PHASE II}

This phase was to concentrate on building a true comprehensive simulation for assessment of the effect of LWM in the automotive design. Phase II was also to focus on the development of the constitutive material model libraries to characterize the materials, such as aluminum and polymer composites. Unfortunately, Phase II was not explored indepth because of the termination of the project. 


\section{PROJECT RESULTS}

\subsection{ANALYSIS OF NHTSA VEHICLE DATABASE}

The NHTSA develops and maintains a comprehensive relational Vehicle Crash Test Database that includes engineering data measured during controlled vehicle crash tests performed for various types of research, New Car Assessment Program (NCAP), and compliance crash tests. The database was built using INGRES ${ }^{1}$ software. The document ${ }^{2}$ detailing the structure and the content of the database has been used to form SQL queries for extracting the data that were relevant for the development of the computational vehicle model. The database primarily deals with passenger safety issues (injury criteria, intrusion in the passenger compartment, etc.) and not with the structural deformation of particular vehicle components so that it was of a limited use for the model development.

The entire database has been recently made available on the World Wide Web at

http://www-nrd.nhtsa.dot.gov/nrd10/nrd11/databases.html.

The interface for creating simple queries is under development at NHTSA, and it is expected to be available in the near future. Therefore, the details on techniques used to perform database queries will not be presented in this document because they will soon become unnecessary for database browsing.

The test vehicle provided for this project was from NHTSA test number 2075. The general test information is enclosed in Appendix A. The test involved two Ford Taurus vehicles engaging in oblique $30^{\circ}$ offset frontal impact. A setup for the test is illustrated in Fig. 1. The provided vehicle is marked as target. A frame from the high-speed film of the collision with overlayed vehicle trajectories is shown in Fig. 2. The tested vehicle was placed on a rotating fixture so that it could be inspected from different angles. The underside of the tested vehicle on the rotating fixture is shown in Fig. 3. 


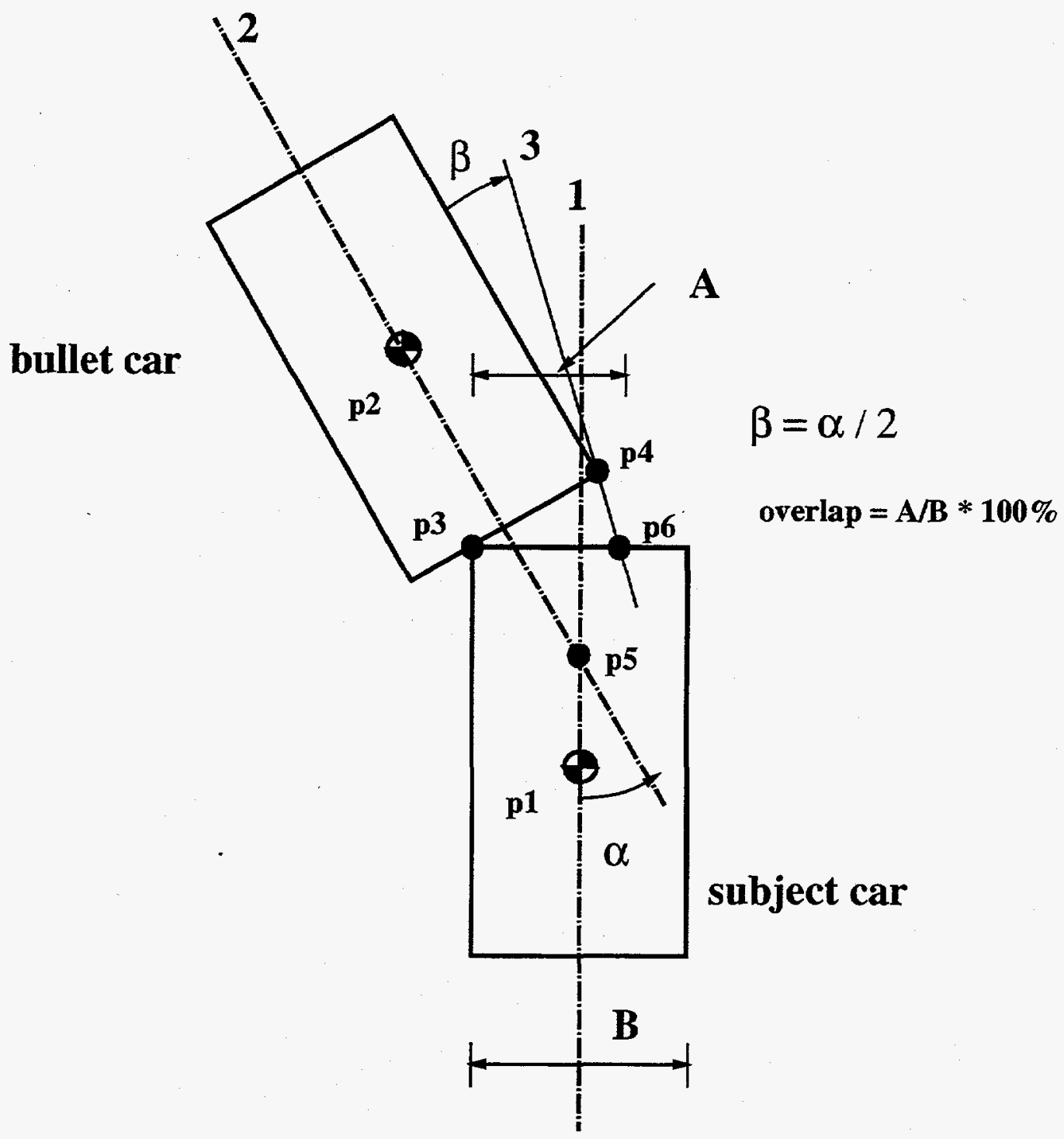

Fig. 1. Vehicle Positions for Offset Frontal Oblique Test 


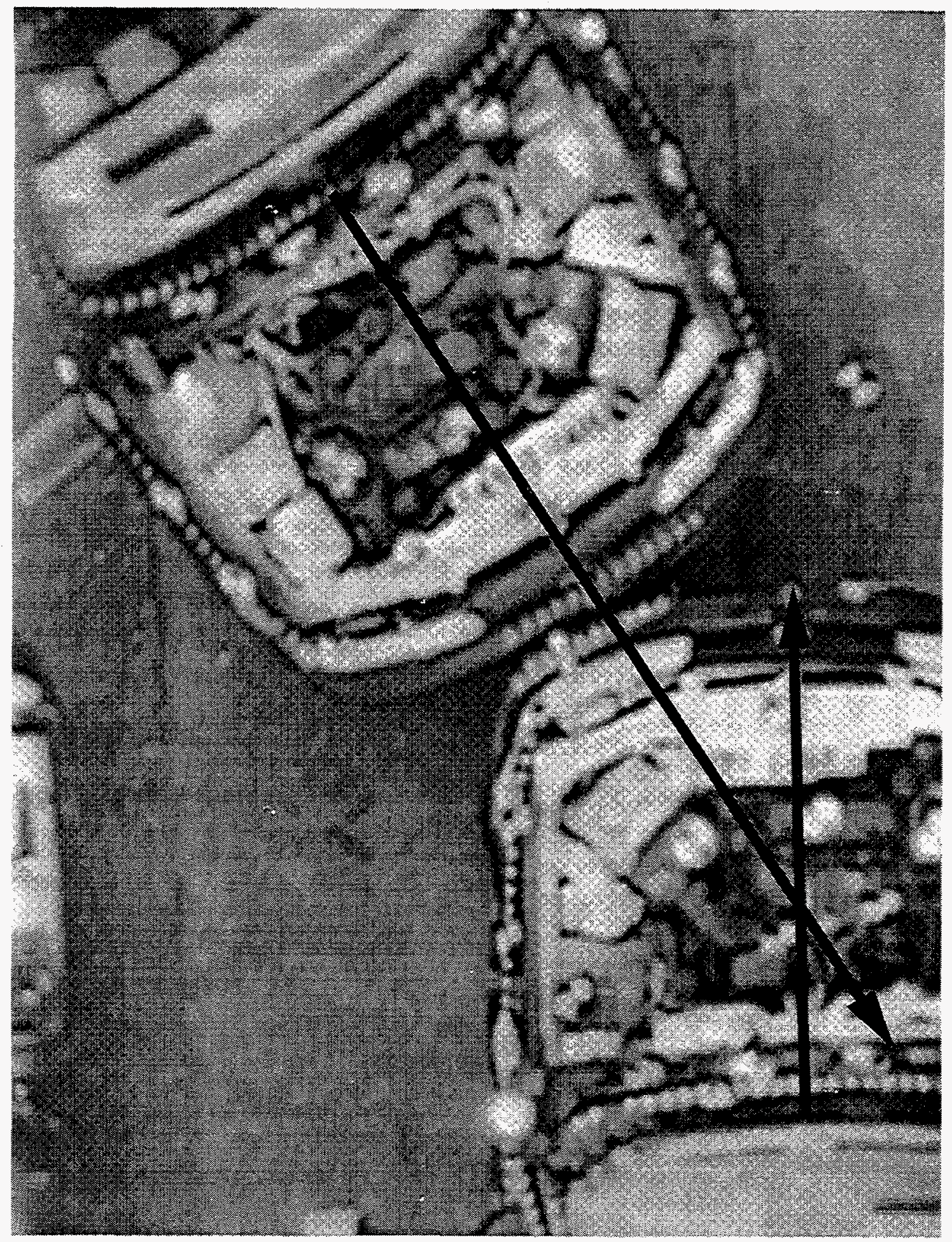

Fig. 2. Collision Point of Test Vehicles 


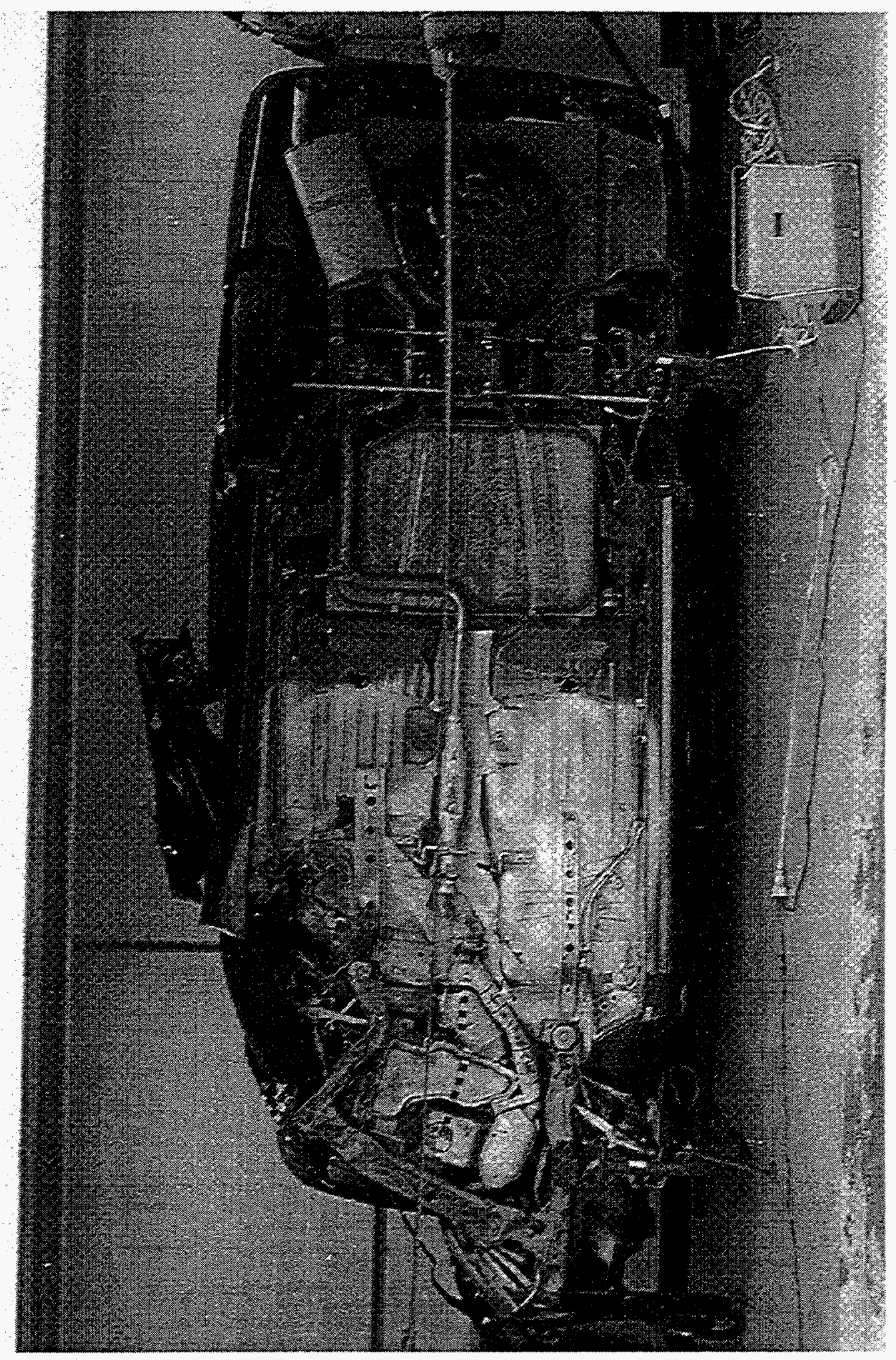

Fig, 3. Tested Vehicle on Rotating Fixture 


\subsection{ANALYSIS OF THE TEST VEHICLE}

\subsubsection{Background}

The 1992 Ford Taurus sedan, having been subjected to an instrumented, $30^{\circ}$ oblique offset impact test, was transported to the George Washington University School of Engineering and Applied Science for mapping of the deformed vehicle. The vehicle was received at a reserved garage space in the basement of GWU s Thompkins Hall. All four tires were removed from the vehicle, and the driver's side door and trunk were tied in a closed position with ropes. The vehicle was rotated $90^{\circ}$ along its longitudinal axis and locked in place on a steel tube frame steady rest, with the passenger side closest to the floor of the garage and the vehicle roof facing the back cinderblock wall of the garage. This configuration left the deformed underbody and forward-end driver's side of the vehicle exposed for measurement.

Several measurement techniques were considered to produce a general map of the deformed structure of the vehicle. Classical manual surveying techniques were considered, which required laying out a gridwork of strings against the vehicle underbody, plumbed to give a two-dimensional grid with the vertical axes plumb to the garage floor and horizontal axes leveled. This grid could then be used to provide a gross referencing plane to map the underbody geometry. However, this approach seemed to be extremely labor intensive and subject to significant error. A more modern technique was investigated, using an articulated electronic digitizing arm designed for use as a computer aided coordinate measurement machine. The potential accuracy advantages of this approach led to its selection. A digitization system was purchased under contract, and a graduate student at GWU attended a 3-day course at the digitizer manufacturer $s$ facility to be trained in the use of the equipment and software. A significant portion of the vehicle rear end, underbody, and the highly deformed regions of the forward end structure were measured using the equipment to produce three-dimensional, rectangular Cartesian geometry points. These points were captured in AutoCAD, written to an IGES file format, and provided to the Modeling and Simulation Group at the Oak Ridge National Laboratory. 


\subsubsection{Digitizing Equipment}

The selected computer-aided measurement system is an 8 - $\mathrm{ft}$ radius, Silver series articulated digitizing arm with the trade name Faro Arm, sold by Faro Technologies, Incorporated, of Lake Mary, Florida. This model of the Faro Arm consists of a heavy-duty tripod with a 3-in.-diam male thread attachment, the mounting base assembly with a mating 3 -in.-diam, female thread and 30-in.-high vertical positioning post, the articulated arm assembly with integrated digital control box, and an IBM ThinkPad 550 notebook computer and software for data acquisition. The Faro Arm has rated, 2-standard-deviation accuracies of 0.012-in. spherical point and 0.016-in. linear displacement.

\subsubsection{Hardware}

The tripod assembly has cast aluminum leg assemblies with 6-in.-diam, rubber-coated footpads for leveling and skid-resistant gripping on the floor of the garage. Although the Faro Arm also includes a tabletop mounting bracket, the mobility and added vertical positioning afforded by the tripod warranted its use. The 30 -in. vertical mount assembly threads onto the tripod assembly and is hand tightened using the knurled surface on the outer surface of the thread boss. The arm assembly slides onto the vertical mount assembly and is held in place using a hand-knob-actuated, oversized set screw to prevent both vertical and rotational movement of the arm when tightened.

The control box on the Silver series of the Faro Arm is mounted directly to the base of the arm assembly. This controller box contains signal and numerical processors that allow for the reading of raw data and conversion of these raw data into dimensional coordinates. Inside the box is an EEPROM chip that allows for controller software updating. The controller box automatically senses worldwide $\mathrm{AC}$ input $110 / 220 \mathrm{VAC}, 50-60 \mathrm{~Hz}, 50 \mathrm{~W}$. Power to the controller box is supplied through an external power supply box, which plugs into a power port in the back of the controller box. The data connection between the controller box and the notebook computer is provided by a null modem serial cable that plugs directly into the PC's serial port. A series of eight LEDs are on the front panel of the controller box to indicate power, communication error, and six error indicators for each of six positioning sensors in the arm. Temperature compensation is built into the EEPROM logic such that 
the control box will not operate until the device senses the temperature to be stabilized within $a+5^{\circ}$ Celsius bandwidth for 5 minutes.

The arm assembly has two, 4-ft-long arm segments and a probe segment. At each of the three joints (lower arm to base, lower to upper arm, and upper arm to probe segment), the arm is articulated to rotate about two axes, and the degree of rotation is monitored by built-in sensors that communicate with the controller box. The lower arm segment to base degrees of freedom are rotation about the vertical axis of the base and rotation about the current horizontal axis of the base to provide unlimited positioning within approximately $70 \%$ of the spherical space defined by the base attachment (origin) and the length of the arm. The degrees of freedom of the elbow joint between the lower and upper arm segments and between the upper arm segment and the probe segment are a hinging degree of freedom and rotation about the previous segment's longitudinal centerline. If the limits of any of the six degrees of freedom are reached, error signals are transmitted to the control box, and the data flow is stopped until all degrees of freedom are within allowable limits. This prevents erroneous data from being transmitted as a result of unwanted flexure of the arm segments.

The probe segment contains a 0.375-in.-24UNF threaded receptacle that accepts either of two styles of probe: a point probe and a 1/4-in.-diam spherical tip probe. Two buttons are located on each side of the probe segment for control of the data flow.

The global origin of the Faro Arm defaults at power up to the center of a base-mounted, magnetized spherical receptacle located at the lower front of the base assembly. This receptacle accepts either of two, close-tolerance accuracy-certification devices provided with the Faro Arm.

The computer used for data acquisition is an IBM ThinkPad 550 notebook personal computer with a 10-in. diagonal active matrix color screen, $24 \mathrm{MB}$ of RAM, and a $750 \mathrm{MB}$ built-in hard disk drive. A trackball pointing device was also supplied, which plugs into the bus port of the PC and attaches to the side of the keyboard.

\subsubsection{Software}

The software used for data acquisition was AnthroCAM, written by Faro Technologies, Inc. AnthroCAM operates as an overlay to AutoCAD release 12 AS for DOS, by AutoDesk, 
and requires the AutoCAD add on software AutoSurf release 2 for Non-Uniform Rational B-Splines (NURBS) based surfacing operations and the AutoSurf IGES Translator. AnthroCAM also requires a hardware port lock authorization key to operate the software.

The AnthroCAM software includes a large number of general coordinate measurement machine (CMM) capabilities, designed to assist in quality control inspection. Most of these capabilities were not required for this activity. Only those capabilities of the software pertinent to this effort are discussed below.

\subsubsection{Certification}

The Faro Arm is calibrated for accuracy at the factor prior to shipment. Certification of the current status of accuracy of the Faro Arm is accomplished using two different certification methods: the Ball-Bar accuracy test and the Sphere-Sphere accuracy test. The Ball-Bar accuracy test is based on the ANSI B89 1.12 standard and reports the volumetric singlepoint repeatability of the Faro Arm. The inspection hardware provided with the Faro Arm for this test is an angled bar with a highly polished, 1-in.-diam ball at one end and a coneshaped receptacle at the far end. The ball end rests in the magnetized base receptacle and allows full range of motion of the arm. The conical receptacle is used to hold the $1 / 4$-in. probe tip during the range of motion certification test. The Sphere-Sphere accuracy test uses a separate 1-in.-diam, highly polished steel ball, held in place in the magnetized base receptacle, and is used to measure the distance from the center of one sphere to the center of the second as the arm is exercised through its full range of motion. This test provides repeatability certification. Both tests are controlled by the software through a menu item selection and produce a report of the results of the certification. Certification of the accuracy of the Faro Arm was conducted once before any measurements were taken, then periodically during the data acquisition effort.

\subsubsection{Measurement}

The AntrhoCAM software, written to the AutoCAD API, provides extensive measurement options, including point reducible features, plane reducible features, and three-dimensional entities. Point reducible geometric entities (e.g., circles, cones, points, etc.) require that the 
user first define a plane onto which the feature will be projected. Planes are defined by up to 99 input (digitized) points, which are then reduced to a two-dimensional plane using a least squares fitting routine in the AntrhoCAM software. In fact, all geometric primitive entities are defined by performing least squares fit to an arbitrary number of input digitized measurement points. All geometric primitive entities are corrected internally for the offset of the 1/4-in.-diam probe tip. This is accomplished by the operator of the digitizer by including as the last data acquisition point a material side vector that varies depending on the geometric entity being measured.

In addition to the measurement of geometric primitives, several scan options are available. Scan measurements allow the operator to scan an unlimited number of general threedimensional points in a continuous stream using a variety of options. The most useful option used during this effort was parallel locked planes, in which user-defined coordinate systems were defined and planes parallel to an input principal coordinate plane are established based on user-defined spacing. As the probe tip is passed over a general three-dimensional object, data points that fall on the planes are memorized, and each of the data points on each plane are fit using cubic splines. These splines can later be used to clean up the data by reducing the number of input points (by mathematically fitting evenly spaced points along each spline), then combining them into NURBS surfaces using AutoSurf functions.

Also included in the measurement functions are inspection functions. Once surfaces are defined based on scanned input points, the operator may inspect the physical surface using the digitizer probe and compare these results with the mathematically defined NURBS surface points in the data file. In this manner, the quality of the geometric representation within the AnthroCAM model can be determined.

\subsubsection{Construction}

Besides the direct measurement features available in the AntrhoCAM software, geometric primitives may be defined by construction based on input (digitized) data points. These include lines, arcs, circles, etc. These features are useful in defining vectors for use as userdefined coordinate axes to support the direct measurement functions described previously. 


\subsubsection{Alignment}

One of the most powerful and useful features provided by AnthroCAM besides the direct measurement functions is the ability to initially align the global coordinate system then to later reacquire that coordinate system on a subsequent setup. Several alignment options are available. The initial alignment involved defining point reducible geometric entities on the Taurus then using a feature called 3-2-1 alignment to define the global origin and coordinate axes. Later, as the limits of the Faro Arm were reached from a given setup point, a Leap Frog alignment option was used to allow the arm to be moved, and the global coordinate system then reacquired by measurement of a minimum of three point-reducible features on the vehicle. The software then uses a series of least squares fitting techniques to realign the digitizer s global coordinate system with the AutoCAD/AntrhoCAM global coordinate system. Using this feature, it was possible to span the entire envelope of the Taurus within a single AutoCAD file, although the digitizer arm had a limited range of measurement from a single fixed point.

\subsubsection{NURBS Surface Construction}

Once general three-dimensional points are defined using the digitizer and the AntrhoCAM software, the functionality of AutoSurf is used to combine various cubic spline representations of the surface geometry of the vehicle into NURBS surfaces. Because of the highly deformed nature of the vehicle, this particular software function proved to be quite cumbersome to use. The NURBS surface calculation failed to obtain valid solutions unless the number of splines used for these calculations was kept small. As a result, a large amount of postprocessing of the raw data would eventually be required to obtain a fully surface-defined model of the deformed vehicle. This final part of the crashworthiness project was not completed during the contract phase, although sufficient geometry was obtained and stored in data files to permit eventual construction of NURBS surface representation of the most highly deformed regions of the external structure. 


\subsubsection{Measurement Setup}

As noted in the Sect. 3.2.1, the Taurus vehicle was installed in a garage area of Thompkins Hall at GWU. With the Taurus mounted on the Steady Rest with its passenger side facing the garage floor, and with the roof of the vehicle pushed up against one wall of the garage, there was approximately 5 - $\mathrm{ft}$ of working space on the forward and back end of the vehicle, approximately $4 \mathrm{ft}$ of working space along the underside of the vehicle, and approximately 4 -ft above the driver's side of the vehicle to the ceiling of the garage space.

The initial setup of the digitizing equipment was selected at the rear of the vehicle. This area was selected for several reasons: the working space in this area was larger than other areas; the number of undeformed entities that could be approximated by geometric primitives was the greatest of anywhere on the vehicle; and experience could be obtained by the operator in using the hardware and software in this region, where the criticality of precision was less than in the highly deformed forward end.

The tripod was initially set up within 3-ft of the rear end of the vehicle, where access to the trunk lid, rear end, and underbody was available up to the forward end of the trunk well. The global coordinate system was defined by measurement of five different point reducible circles: the trunk lock outline, two holes located on the relatively flat surface of the license plate mount, and two holes on the body that were in the vicinity of the rear brake lamp covers. The global origin was placed at the trunk lock, with the global X-axis directed in the direction defined by the two symmetric holes near the taillight covers, the $Y$-axis defined by the perpendicular from the $\mathrm{X}$-axis on the plane defined by the license plate mount, and the $\mathrm{Z}$-axis directed toward the front of the vehicle. These five features were used in subsequent rear end setups to reacquire the global coordinate system.

To maintain security of the equipment, the digitizing arm was disassembled and placed in locked storage between each data acquisition session. At the beginning of each new session, the equipment was taken out of storage and a setup procedure was then followed prior to any new data acquisition. First, the tripod assembly was set up in the area of interest for the current session. The digitizer arm assembly was then mounted to the tripod and the mounting thread tightened by hand. The range of motion of the digitizer arm was tested to ensure that the area of measurement desired could be obtained without causing any of the 
degrees of freedom of the arm to be extended to their limits. Once positioned, the power supply and serial cable were attached to the control box on the digitizer. The computer was then positioned, the software key and serial cable were attached, and the computer was powered on. Finally, the AntrhoCAM software was executed, and the working file was opened. To realign the digitizer arm global coordinate system to the CAD coordinate system, the five point-reducible features described previously were measured, and a 3-2-1 alignment was executed. Previously measured geometric features were then inspected using the inspection functions of the software to ensure proper alignment. Once it was verified that the global coordinate system had been reacquired accurately, new geometry was then digitized.

A significant amount of the rear end of the vehicle was digitized and the data reduced to NURBS surfaces to establish the data acquisition and reduction methodology. Subsequent setups were eventually used to traverse the length of the vehicle underbody and the highly deformed forward end of the vehicle. The AnthroCAM Leap Frog realignment function was used to accomplish this traversing. Fixed features along the undersides of the vehicles were selected as master features for realignment of the digitizing arm. These master features included the axle attachment points on the rear wheels, the attachment points of the rear suspension rods to the vehicle frame, drilled holes along the driver and passenger sides of the underbody, and similar axle and suspension attachment points on the forward end of the vehicle. In all cases, the same surfaces were used to define the planes for defining point reducible geometric features, and in general only point reducible circles were used (e.g., the outline of bolts, holes, or other circular features).

The changes in setup that were accomplished using the Leap Frog technique involved a three-step process. First, with the digitizer arm alignment to the global coordinate system established, either up to five master features were selected from the stored features, or new master features were defined within the reach of the digitizer arm from both the current setup and the desired new setup locations. Once these master features were established, the software was instructed to permit realignment of the hardware. The digitizing setup was then physically moved to the desired new location. Finally, the same master features were measured, and the software then performed a best fit realignment of the general three 
dimensional coordinate system based on these measurements.

\subsubsection{Measurement Strategies}

The measurement strategies selected during this effort evolved as experience was gained with the use of the hardware and software. The initial strategy centered around measurement of clearly defined geometric entities that could be adequately represented as geometric primitives. These were simple circles, connecting lines, and in the case of the spare-tire well in the trunk, a body of revolution. These basic geometric entities, widely spaced along the rear portion of the vehicle, provided key reference points for later measurement and verification of alignment of the system. These initial, simple measurements would proceed in a regular manner. If the geometric entity was an inside circle, for example a hole in the body of the vehicle, a plane was first required for projection of the circle. In the case of the rear license plate mounting surface, numerous points were defined on the surface by moving the probe tip along the surface and selecting points using the control buttons on the probe section of the arm. Once sufficient points were acquired to define the plane, a final point was selected away from the plane to define the direction in which the software should compensate for the diameter of the probe tip. A visual representation of the plane then appears on the computer screen, trimmed to the rectangular limits of the points acquired (although internal planes are represented as infinite in expanse). Once the projection plane is established, the software prompts the operator to define points on the circle. As many as 99 points may be taken, although a minimum of 3 are required. Once several points are taken on the circle, a final point is digitized, either toward the center of the circle or to the outside of the circle, again to define the direction in which the software should compensate for the radius of the probe tip. The software then performs a best fit of the data and shows a representation of the calculated circle projected to the previously defined plane on the computer screen.

Later measurements involved defining both regular as well as highly deformed surfaces. To accomplish this part of the task, use was made of two key capabilities of the software: user-defined coordinate systems and parallel lock plane scanning. In preparation for scanning points on the surface of interest, geometric features close to that surface were selected such that a user-defined coordinate system could be constructed. For example, in preparation for 
acquiring digitized data on the forward engine compartment frame, a coordinate system was defined with its origin at the front driver's side axle intersection with the rotor; this origin was defined by measuring the point reducible circle at that intersection. An appropriate principal axis was selected by measuring another point reducible circle (e.g., the passenger's side axle intersection with the rotor), and a vector was then defined between the two. One of the other principal axes was defined similarly.

Once the user-defined coordinate system (local) was defined, the surface of interest was examined, and a decision was made regarding which direction to define the parallel planes to maximize the description of the component to be measured. For example, in the case of frame members, the parallel planes were selected such that they would be normal to the major axis of the frame member. In general, these parallel planes were selected to be spaced 0.25-in. apart but could be closer or farther depending on the frequency of change in geometry. The digitizer was then placed in continuous scan mode by pressing one of the control buttons on the probe segment, and the surface of the component to be digitized was traversed with the probe tip. If the data stream needed to be paused, for example to reposition the arm, the back button on the probe segment was pressed. The data stream could then recommence once the probe tip was repositioned.

Once a series of points was defined on parallel lock planes, the data stream was discontinued, and the software then analyzed the input data. Data points that fell on individual lock planes were grouped together and sorted. Finally, cubic splines were fit to the individual data sets for each lock plane group. These sets of points could then be refined using AutoSurf functions, which took the mathematical spline information and increased or decreased the number of points that defined those splines into evenly spaced points for compactness in the data storage.

In addition to the cubic spline definitions, the general outline of the individual parts was measured by using the general three-dimensional scan option of the software. For example, the outline of the trunk was defined as a continuous, closed line by placing the digitizer in continuous scan mode and tracing the outline of the trunk lid. Care was taken to hold the tip of the probe on the surface or outline as the digitizer arm was moved to ensure contact with the part. Spurious data points could be individually removed by on-screen selection 
after completion of the continuous data stream acquisition.

\subsubsection{Postprocessing}

As individual components were digitized as sets of cubic splines and the outlines of the components were defined by general three-dimensional lines, the data were reviewed onscreen and spurious data points removed individually. The individual splines for a given component were then refined using AutoSurf's polyline options. The spline directions were then modified as required such that all splines defining a particular component had the same direction. The splines were then clipped as needed to the three-dimensional outline, again using AutoSurf functionality. Finally, where possible, NURBS surfaces were generated from groups of splines to define the final part. Because general three-dimensional scanned points are not corrected for the diameter of the probe tip, these surfaces then were offset by 0.125 in. to compensate for the probe tip. In those cases where NURBS surfaces were successfully calculated, the integrity of the surface representation was evaluated using AnthroCAM's surface inspection options.

\subsection{DEVELOPMENT OF VEHICLE MODEL}

The modeled vehicle, a Ford Taurus sedan, is a representative of rapid evolution of mass production automobile structural design during the last two decades. ${ }^{3}$ This car no longer employs separate frame and body structures, but combine them into an integral system known as a unitized body (unibody). ${ }^{4}$ The unibody consists of a large number of welded stamped metal parts and is the main energy-absorbing structure of the vehicle. Front subframe is attached to the unibody very late in the assembly process. It carries the transversly positioned engine, transmission, front suspension, and wheel assembly. The rear suspension uses strut-independent rear suspension and two parallel control arms per side. The complexity of the unibody-subframe structure does not allow for obvious simplifications in simulation models as in cases where there is a clear distinction between the structural frame and the secondary body structure. Therefore, the sheet-metal structures are essential in impact energy absorption and have to be accurately modeled. 
Over the past several years, NHTSA has been developing an FEM model of a midsize sedan. ${ }^{5-7}$ The model has been obtained by first disassembling the vehicle and then scanning the shape and measuring mass and inertia of each component. The FEM model is derived from the geometric model by discretizing each digitized part using finite elements and connecting them into the final model. The separation of geometrical representation from the computational FEM was intended to allow for flexibility in model modifications and addition of complex constraints. The FEM model has been developed for the LS-DYNA3D FEM analysis program. The details of the employed methodology and program capabilities can be found in Ref. 8 .

The original vehicle model was developed and verified by DOT for a full-frontal impact with a rigid barrier. Simulation results were in reasonable agreement with the test data. However, when the vehicle was subjected to different impact scenarios, such as a frontaloffset and oblique-offset impact, significant discrepancy with the test data was observed as documented in Ref. 6. For example, in oblique-offset, frontal two-car impact, engagement between the wheels and supporting structures results in considerable damage to the passenger compartment. Although important in real impact, the details of this damage process were not accurately represented in the original simulation. In full frontal impacts, the crash front does not critically involve the wheel structure and, thus, has not been modeled in detail. Therefore, collisions where a considerable amount of energy is dissipated in wheel and suspension structures may not be modeled accurately with the original model.

The difference between the offset simulations and the tests is mainly a result of the difference in deformation modes that vehicles undergo during impact. While producing mostly axial mode of deformation in the full-frontal impact, the offset impact introduces large shear and bending moments into the structure. ${ }^{9}$ Moreover, the component connections are not challenged in the full-frontal impact as much as they are in offset impacts. It has been observed that in impact tests the engine block and transmission behave as rigid bodies supported by deformable structure. In frontal impacts, the engine block does not change its relative position with respect to other parts to the extent it does in offset impacts. In offset impacts engine and transmission connections to the unibody and subframe become extremely important and their failure mode and breakup force determine engine kinematics 
and overall vehicle deformation. These connections are often complex and consist of multiple cradles, dampers and fasteners. Approximating their behavior with a single constraint may not be appropriate in cases where there is a significant load transfer associated with it. Other deficiencies of the model for offset impacts were also noted and were addressed in the model optimization process.

\subsubsection{Original Model Limitations}

The most practical approach in optimizing the model would be to start from a single car model and then to progressively optimize it based on impact with various rigid and deformable barriers in offset and oblique impact configurations. The impact scenarios would preferably be in increasing order of difficulty of simulation as ranked in Sect. 2.1. The initial plan was to use the P3/PATRAN ${ }^{10}$ vehicle solid model as a base for development of finite element models. The manipulations with solid models are generally easier and more versatile than working directly with FEM meshes. Once the solid model is modified, an FEM mesh is easily generated to accommodate the changes in geometry. However, numerous deficiencies in the P3/PATRAN vehicle model and program translator to LS-DYNA3D format prevented from using that approach. More specifically:

1. Geometry data were not stored, just a finite element model. In order to use the P3/PATRAN CAD environment, it would have been necessary to redevelop all the geometries from IGES files, which in itself is a considerable effort.

2. Many of the modeled parts were disconnected and had no constraints.

3. There were numerous free edges in the model.

4. Element properties that were read in from the supplied P3/PATRAN neutral file did not have information that was required by the analysis program.

The software that was used for interfacing P3/PATRAN with LS-DYNA3D was in the early stages of development and could not handle the numerous intricacies associated with contact interfaces and single and multiple point constraints. Because of the aforementioned problems, it was decided not to pursue the P3/PATRAN-to-DYNA3D model development route but 
to directly manipulate DYNA3D input files. This decision imposed practical limitations on the extent of feasible modifications and remeshing of the model.

\subsubsection{Model Modifications}

The changes to the original NHTSA vehicle model presented here are results of information collected from crash test data, vehicle inspection, and numerous computational simulations and modifications. The structural modifications include changes in the topology and in material parameters for some of the components of the model. The topological changes are confined to the front suspension of the car, engine mounts, spotweld representation, and the engine cradle structure. In addition, several changes have been made to the front seat supports. The material changes are associated with changes in material properties in the bumper and in the links that connect the stabilizer bar to the knuckle wheel assembly. There are changes associated in the method used to simulate the flexible engine mounts and the method used to release some of the reaction components that exist at the boundaries of the suspension assembly links. The engine thickness was increased to increase its rigidity. Material thickness in the upper and the lower rail was increased to reflect the physical values measured on the crashed vehicle. The hood stiffness was significantly reduced because it was removed in the physical test.

\subsubsection{Material Sets}

One additional material set has been added compared to the original model. This is a Rigid Body Set that represents the running surface for the car. This surface is used to assess the yawing and pitching of the vehicle at impact. The new number of materials is 131 .

\subsubsection{Number of Nodes and Elements in the Model}

The number of nodes is increased as a result of the addition of the rigid surface described previously. The new number of nodes is 26,777 .

The number of solid elements is increased as a result of the addition of the rigid surface to the model. The new number of solid elements is 345 . 
The number of beams has been increased compared to the original model. The beams in the front section of the car that do not connect any structural part in the model were eliminated. There are more beams of this type throughout the vehicle, but they were not removed because they are of no importance in the frontal oblique collisions. More beams were added to account for local bending of suspension and steering components. There are now 157 beams in the model.

\subsubsection{Contact Interfaces}

The number of sliding interfaces has been reduced from 26 to 1 . The initial model used 25 slide interfaces of LS-DYNA3D type 6 . This interface represents a discrete nodes tied to surface type contact. In Version 936 of LS-DYNA3D, it was required that the physical separation of the nodes to the surface has to be small. For the cases when this separation is significant, the nodes are not tied to the surface. This results in unconnected nodes relative to the adjacent surface. Because of the 1 slide surface that includes all the surfaces within a box, the nodes will not be unrestrained, and in the front part of the car they are limited in motion by the adjacent shell elements. The 25 type- 6 slide interfaces have been replaced with rigid body constraints. Such a replacement may sometimes influence the kinematics of the problem because the inclusion of a rigid link between widely separated nodes may introduce translation of one node relative to the other as a result of the rotation of the first node. However, such a behavior was not observed in the simulations performed with the modified model.

In the original version of the vehicle model contact type-13 interfaces included components from the front of the car to the area immediately behind the front seats. This definition did not include the front seats, which, therefore, became unconstrained and penetrated the base platform of the car. The updated version extends this box to a region farther behind the end of the front seats.

The automatic surface generation feature for inclusion of multiple vehicle parts in the general contact surface was used in the initial version of the model. However, the materials associated with the beams and glass elements were not included. The updated version includes all the materials except the materials that represent the components made of glass. 
Interfaces between the floor pan and the longitudinal floor channels were added to account for the spot welds and for the tearing between the floor channels and the floor panel that was observed in the tested vehicle.

\subsubsection{Nodal Constraint Sets}

The number of nodal constraint sets has been reduced from 339 to 317. Most of this reduction results from removal of the nodal constraints that existed between the back-seats and the frame that supports these parts to the vehicle floor. These constrains are now replaced by rigid body constraints.

The original model has 180 spot welds with a prescribed tensile and shear strength of $20 * 10^{20} \mathrm{~N}$. It is not very likely that this stress limit would be reached in the collision situations under consideration so that these spot welds were replaced by rigid links.

\subsubsection{Rigid Body Constraints}

The number of rigid body constraints (rigid links) has increased from 7 to 36 . The main reason for the increase is that all the type 6 slide surfaces have been converted to nodal rigid links. The nodal constraints for the front seats have also been converted to rigid nodal constraints, and the front of the rail struts has now been connected to the front bumper back plate. The initial version of the model did not connect the front bumper to the bumper supports in the rail support assembly. In addition, the front of the left strut of the engine cradle has now been attached to the left rail strut support.

\subsubsection{Front Suspension Components}

The vehicle suspension and steering mechanisms are made mostly of steel bars or components that have longitudinal direction significantly larger that their cross section. Therefore, those substructures were modeled using the beam and truss finite elements. The beam elements are capable of carrying both forces and moments. The boundary conditions that are placed on a beam element determine the character of its load transfer. Where warranted by the loading and geometry, the truss elements were used to restrict the force transfer to the axial 
direction of the element. The linear elements (beams and trusses) that were used in the vehicle model are shown in Fig. 4.

The topology of the front suspension substructure with respect to the front of the vehicle is shown in Fig. 5. The modifications made to the front suspension car model consisted mainly of the release of the moment-carrying capability of some of the links that were part of the car's front suspension. In some cases the changes involved the use of a truss element rather than a beam model. In other instances it was necessary to use zero-length 3-D beams to selectively eliminate some reaction components of the end load of the beams used in the model. The 3-D zero-length beams were used in LS-DYNA3D in combination with a beam material (number 67) to simulate a 3-D spring that connects discrete elements; arbitrary load components at the element ends are assigned or eliminated.

Figure 6 illustrates the geometry of the front engine cradle assembly and suspension of the vehicle. Figure 7 shows the modified model of this assembly. The part of the changes associated with the link forces at the element ends can not be seen in the figures as we are dealing with zero length beams.

The following model components have been modified:

1. The control arm (material 94) that connect the wheel knuckle assembly to the longitudinal member of the engine cradle (material 79 for the $Y$ member and 81 for the $+Y$ member) was changed so that the strut interface with the subframe does not transmit moments along the $\mathrm{X}$ - and $\mathrm{Y}$-axes. Rotation about the car $\mathrm{Z}$-axis is constrained. The $-Y$-axis interface of this strut to the subframe was not connected in the original model. The interface of the control arms and the wheel knuckle assembly was also modified so that no moments about the car Z-axis are allowed (wheel is free to pivot for vehicle steering). Figure 8 illustrates the interfaces discussed in this section.

2. The tension struts (material 95) connect the wheel knuckle assembly to the forward transverse crossmember (materials 82-83) of the engine cradle subframe (Fig. 8). Both ends of this tension member have been modified so that no moments are transmitted to the supports.

3. The stabilizer bar (material 97) is attached to the rear engine cradle crossmember (ma- 
terial 84) by U-brackets that allow rotation in the transverse axis (Figs. 9 and 10); both free ends are connected to the MacPherson strut by a plastic link (material 96). The original model implemented the connection of the stabilizer bar to the crossmember using spot welds at two locations; thus, rotation about the $Y-Y$ axis was constrained. The link that connects to the shock absorber was modeled as a flexible metallic component. Changes to this model include substitution of the weld supports with flexible components that allow rotation in the $Y-Y$ axis.

4. The material properties of the link (material number 96) that connects the stabilizer bar to the MacPherson strut (material 96) was changed to represent a polyamide nylon, and the beam element type was changed from a beam-type element to a truss-type element.

5. The half shafts (material 105) of the original model are beams rigidly attached to the engine at one end and to the knuckle assembly at the other end. Some of these interfaces were modeled using welds. The changes made implement a universal joint at each end of each half shaft using a 3D zero length discrete beam with no moment capacity at the half-shaft ends. Figure 11 shows the location of these half-shafts relative to subframe and other suspension links.

6. The interface between the lower end of the MacPherson strut (material 98) and the knuckle assembly (materials 99/117) uses a 3D zero length discrete beam to release the moments about the car Z-axis, see Fig. 12. 


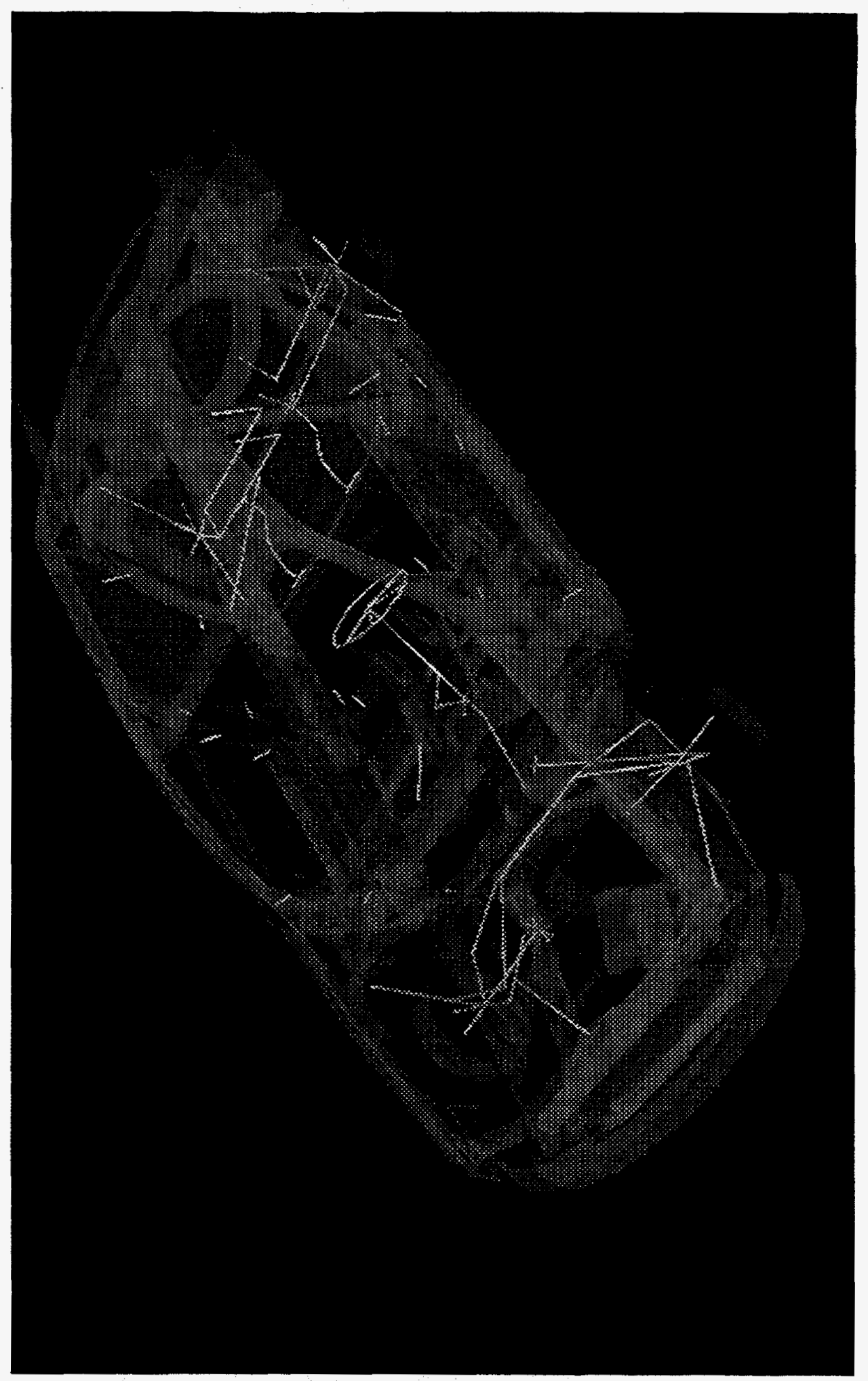

Fig. 4. Beam and Truss Elements in Vehicle Model 


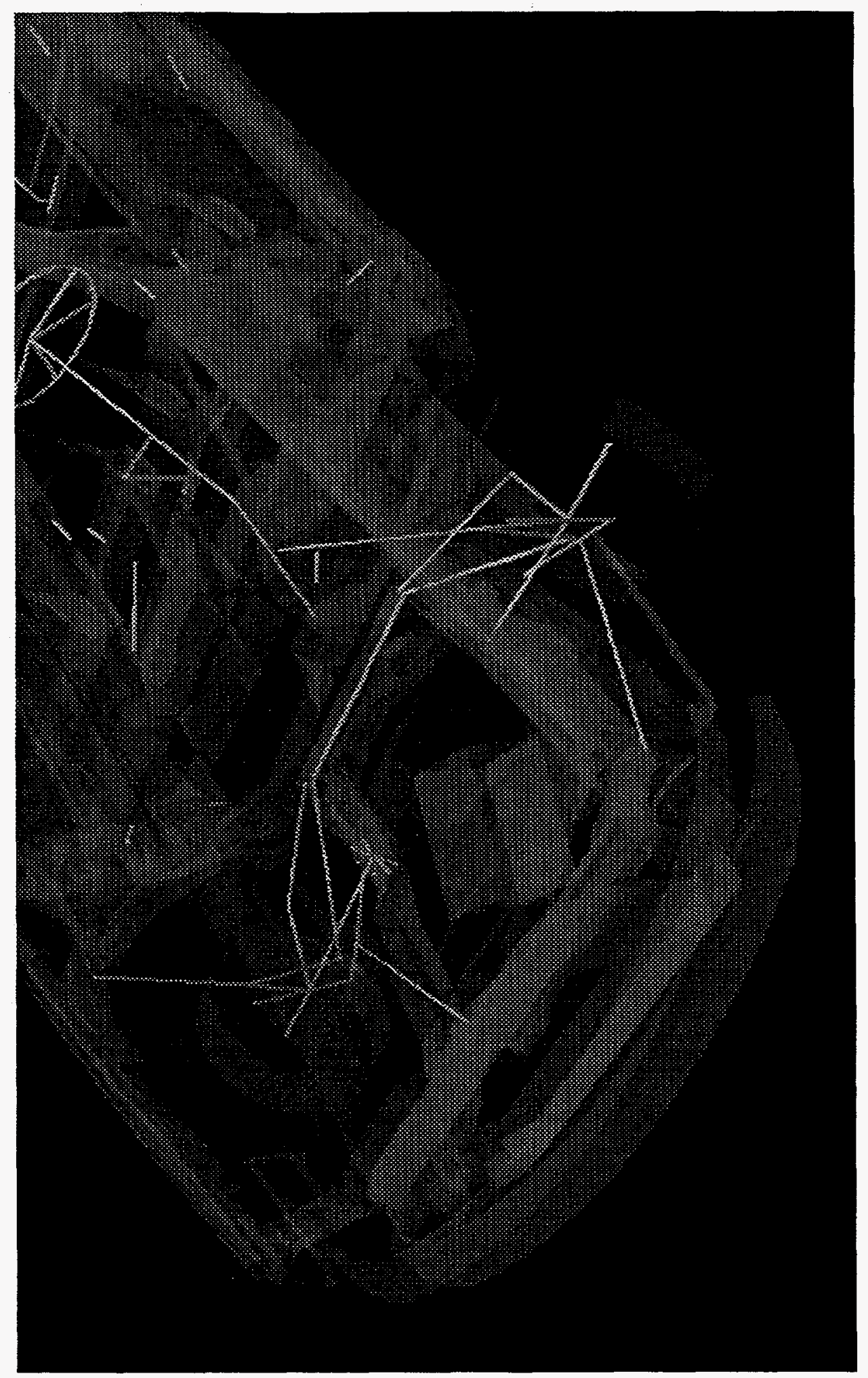

Fig. 5. Front Suspension Components in Vehicle Model 


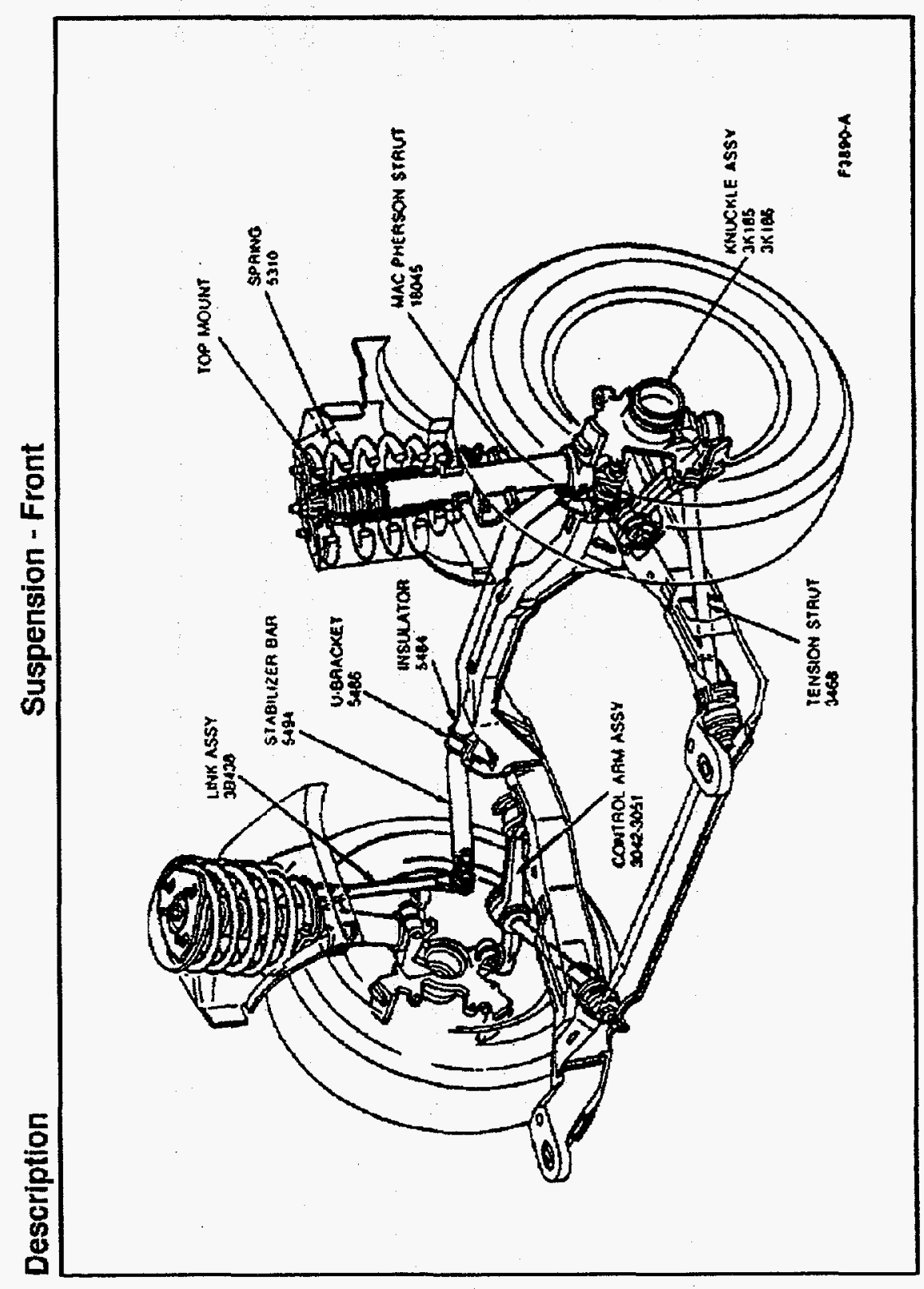

Fig. 6. Front Engine Cradle Assembly and Suspension, Technical Documentation 
7d-TAURUS-WALL-35MPH-50\% OFST-GAA-021296

L్교

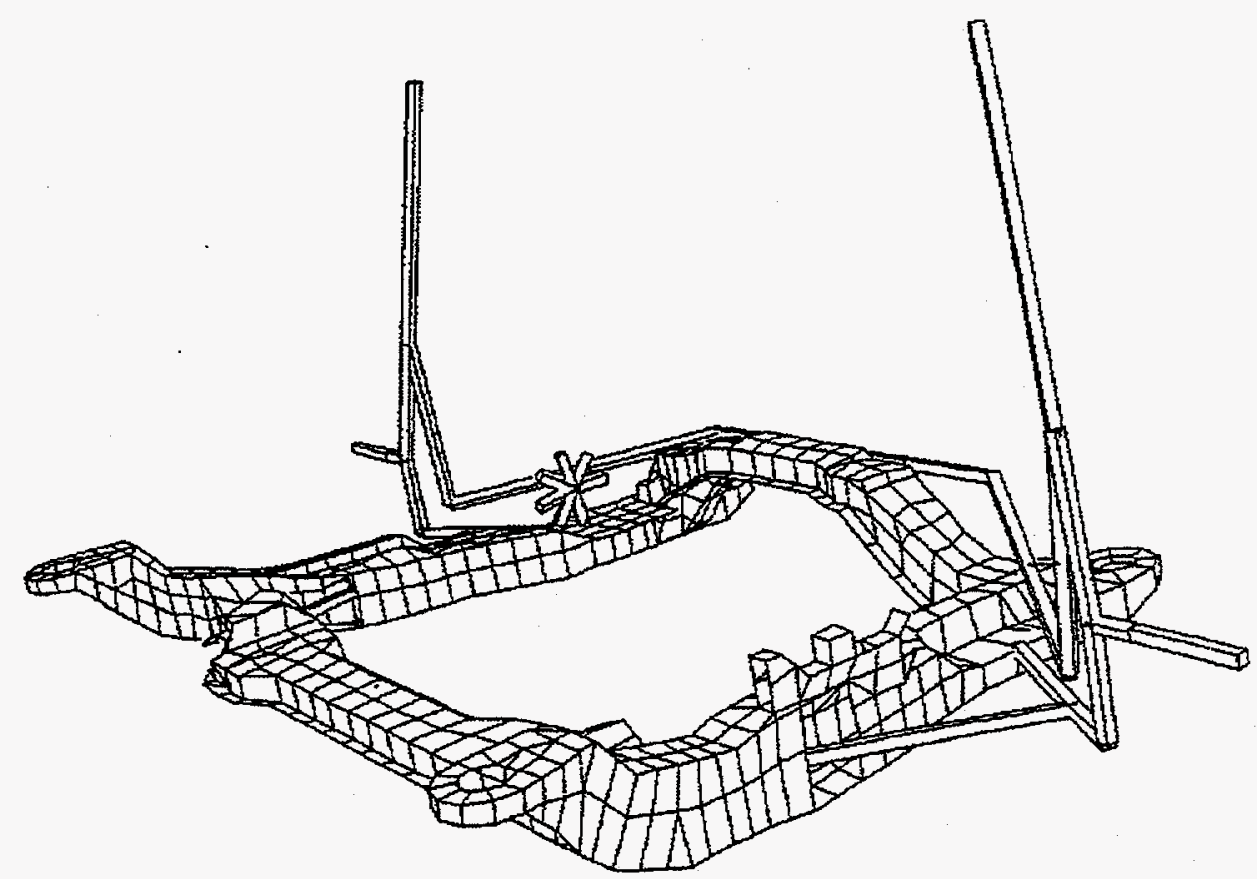

$\underbrace{2}_{-1} x$

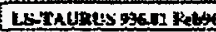

Fig. 7. Front Engine Cradle Assembly and Suspension, Revised Model 


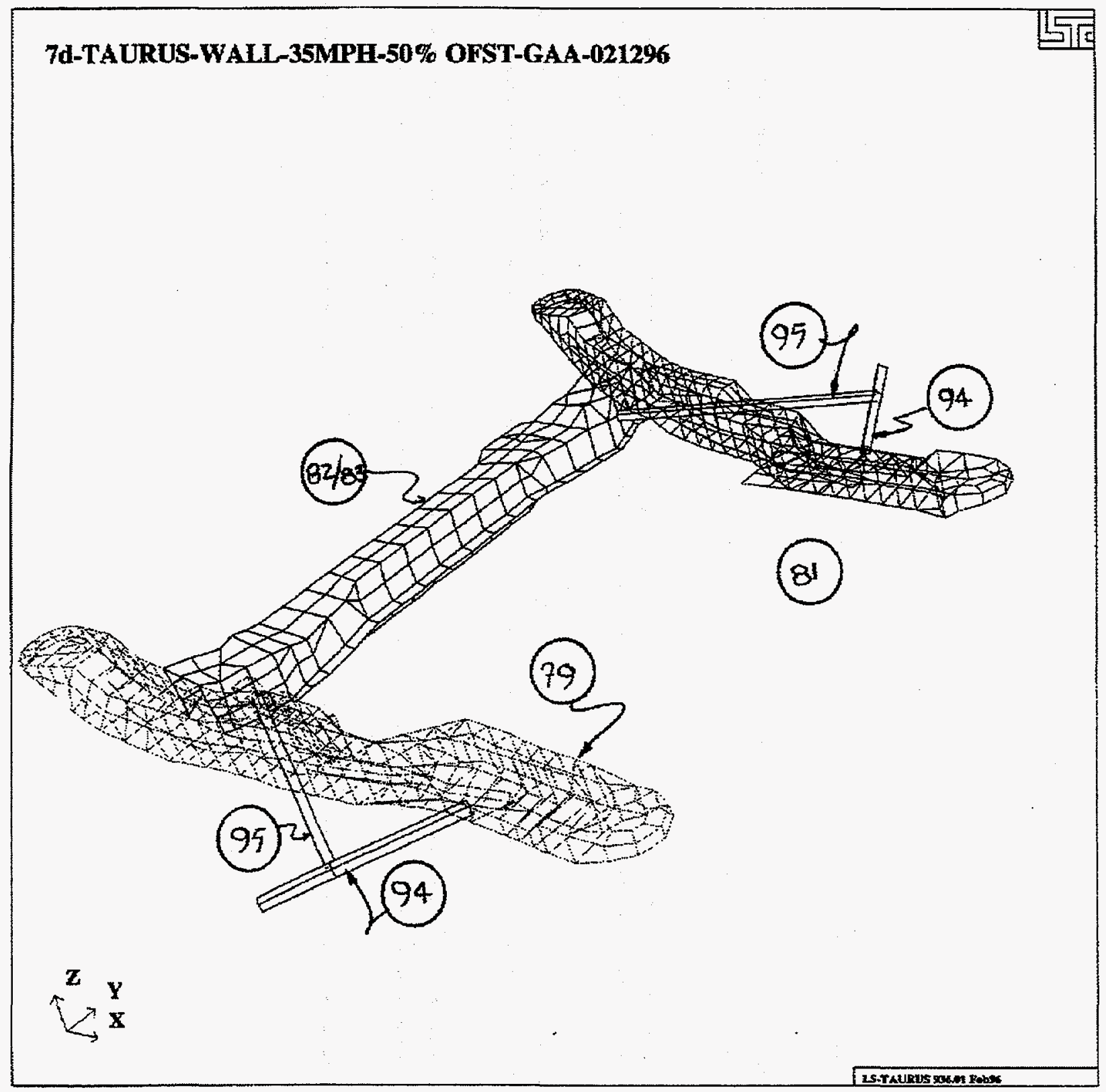

Fig. 8. Tension Struts, Model 


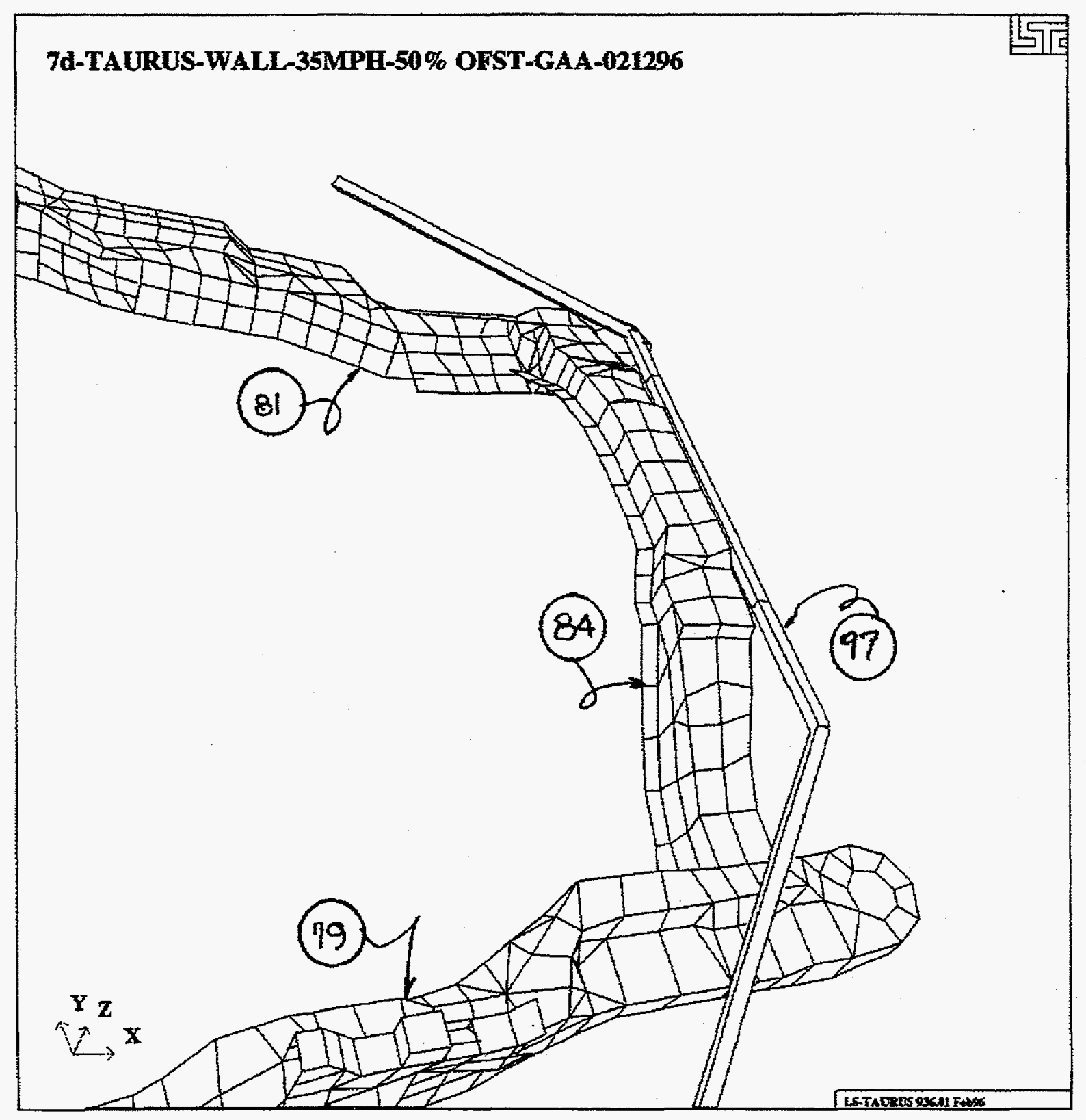

Fig. 9. Stabilizer Bar and Subframe 


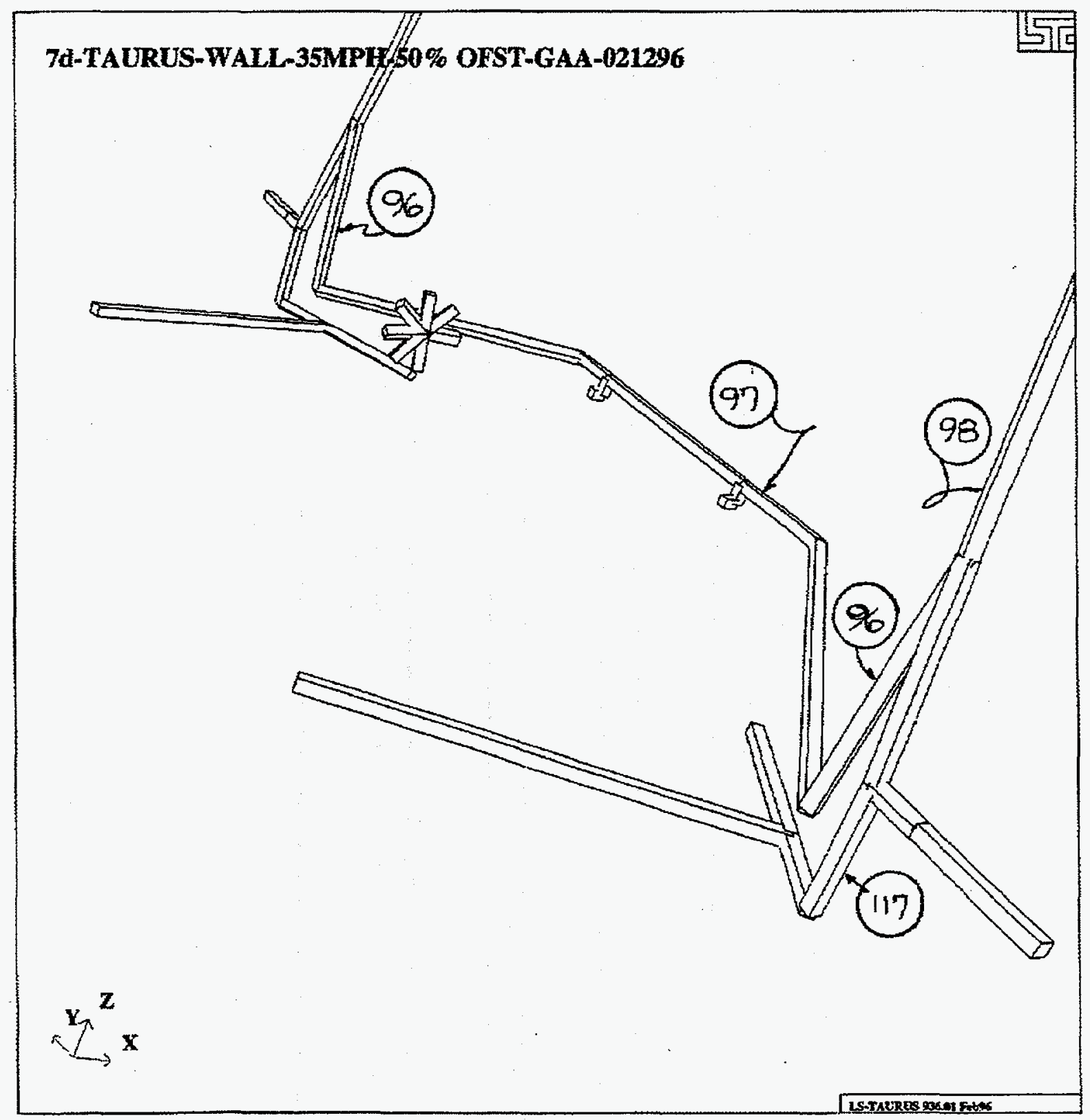

Fig. 10. Stabilizer Bar and Suspension Links 


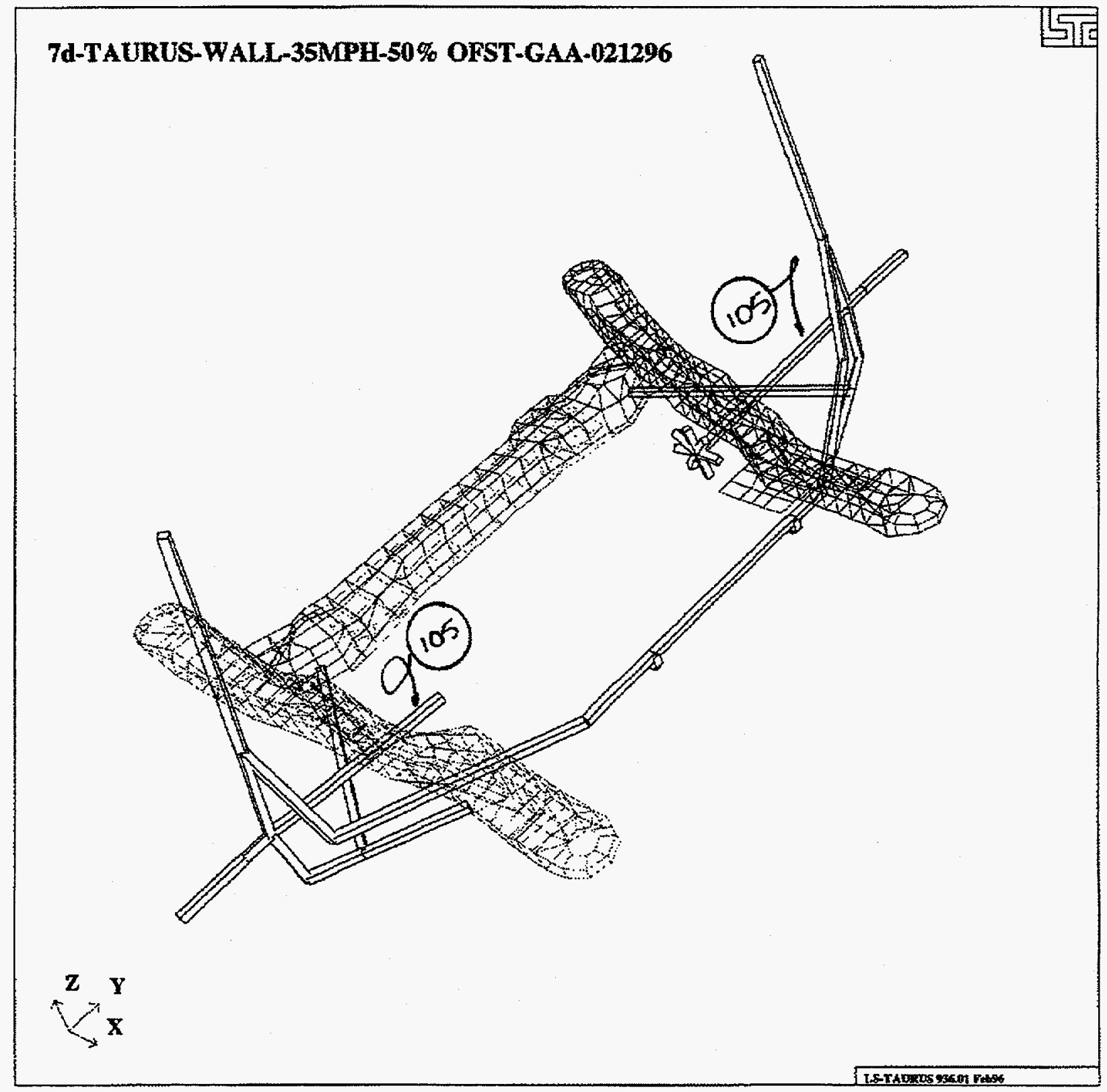

Fig. 11. Half-Shafts 


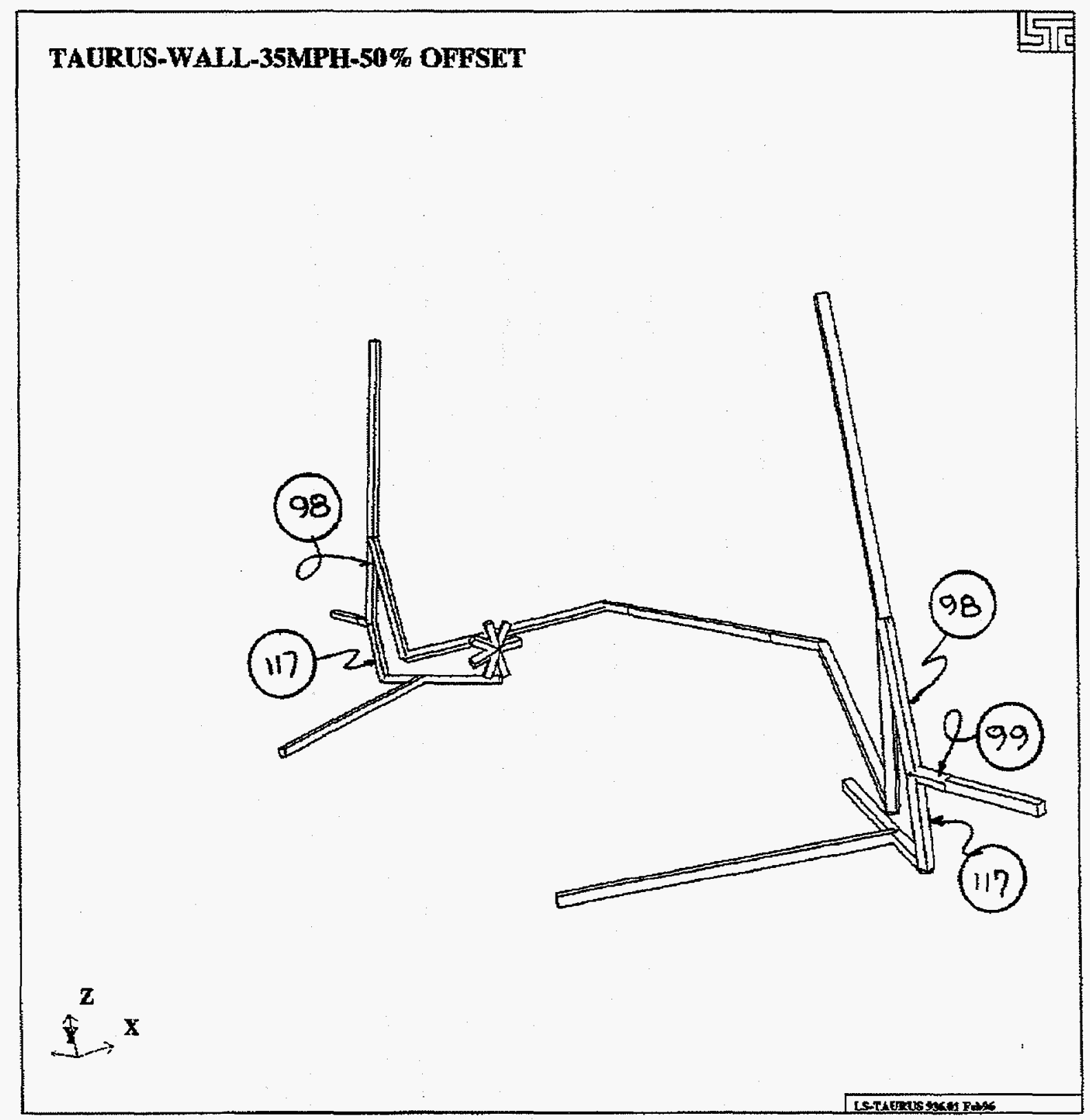

Fig. 12. MacPherson Strut and Knuckle Assembly 


\subsubsection{Engine and Transmission Mounts}

The engine and transmission (materials 89 and 122) mounts were previously modeled using rigid body links between the engine and the engine cradle. The choice of this modeling technique is attributed to the fact that the structure in the model at both ends of the interface is not coincident. This approach resulted in a model that was rigid and did not allow for local deformation between the components at the interface. Observation of the test vehicle indicated that there was significant translation of the engine and transmission relative to the supporting subframe. In fact, one of the mounts (transmission support to longitudinal member) was broken, which resulted in noticeable displacement of the engine as

a rigid body relative to the car frame. The two engine mounts and the transmission cradle are modeled using the nodal constraints and spot welds. The failure load of the weld has been estimated so that failure does occur for the event analyzed. Elastic material properties of the rubber found in these mounts were not available. This technique introduces the failure feature that is necessary to realistically model these interfaces. The interface boundaries are still not coincident, but this time a rigid link and a spot weld are attached at the interface. Figures 13 and 14 show the locations of the engine and transmission mounts.

\subsubsection{Structural Changes}

All the mounts points where the suspension links attach to the engine cradle have been stiffened (by local increase of thickness) to reduce local deformation caused by point loads applied to the shell components. The thickness of the elements that share a common node where the link was attached was increased to $3 \mathrm{~mm}$. This includes the interface of the tension struts with the forward engine cradle cross member (materials 95 and 82-83) and the interface between the control arm and the longitudinal members of the engine cradle (materials 94 and 79 for the $-Y$ interface and 81 for the $+Y$ interface, respectively).

The element thickness of the lateral members (materials 79 and 81 ) of the engine cradle has been increased to $2 \mathrm{~mm}$ (from $1.93 \mathrm{~mm}$ ).

The lower part of the forward engine cradle member (material 82) and the upper part of this member (material 83), at the point where the forward engine mount is attached, have been rigidly connected. 
The rear crossmember of the engine cradle (material 84) was changed to reflect changes observed in the crash cars and Taurus shop manual drawings. Figures 15 and 16 show this component in the original and modified configuration.

Front door connection with the hinge pillar has been completely redone to more accurately simulate the hinge behavior and load transfer through the door structure. 


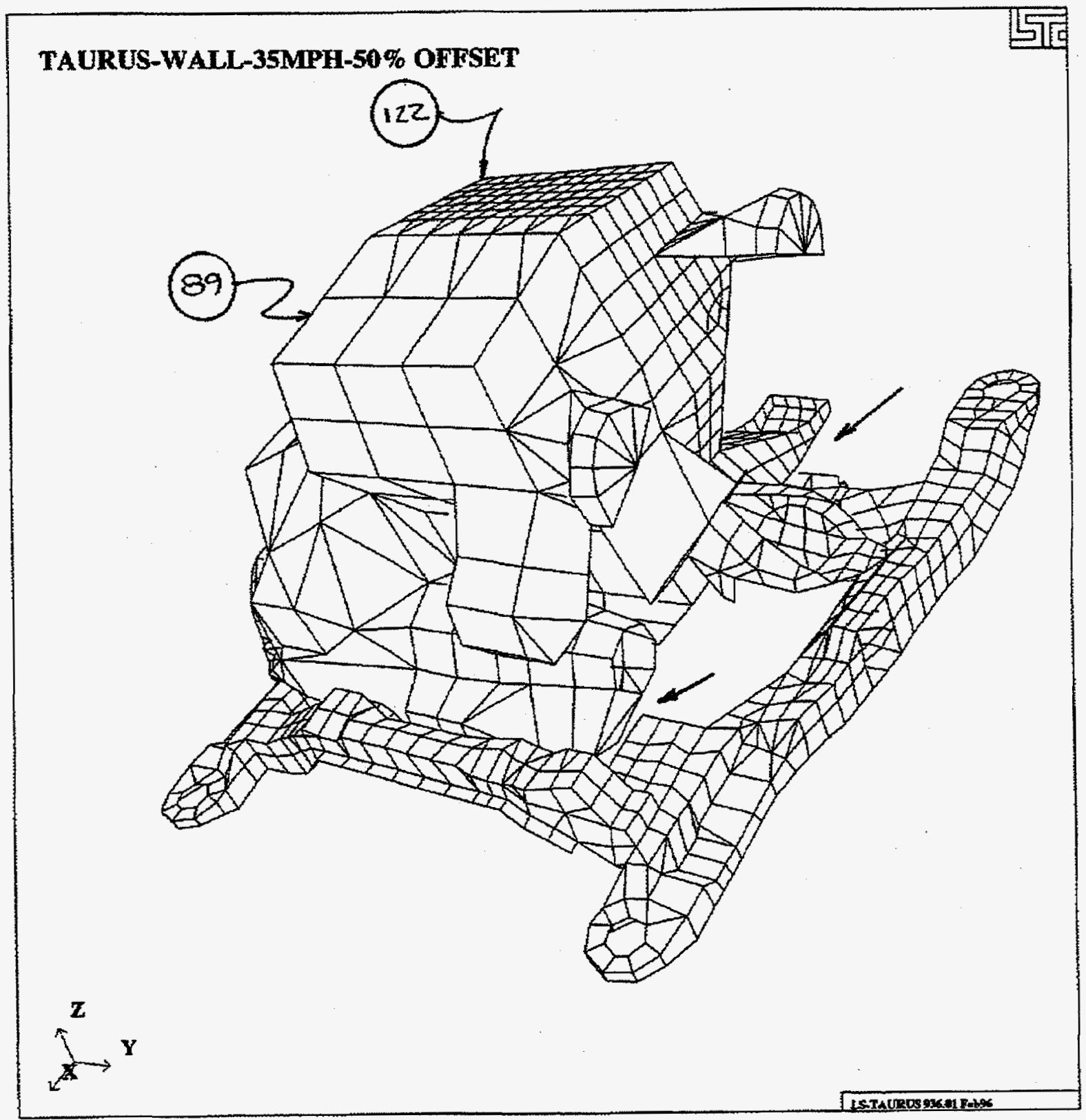

Fig. 13. Engine and Transmission Mounts, Top View 
7d-TAURUS-WALL-35MPH-50\% OFST-GAA-021296

$\sqrt[5]{5}$

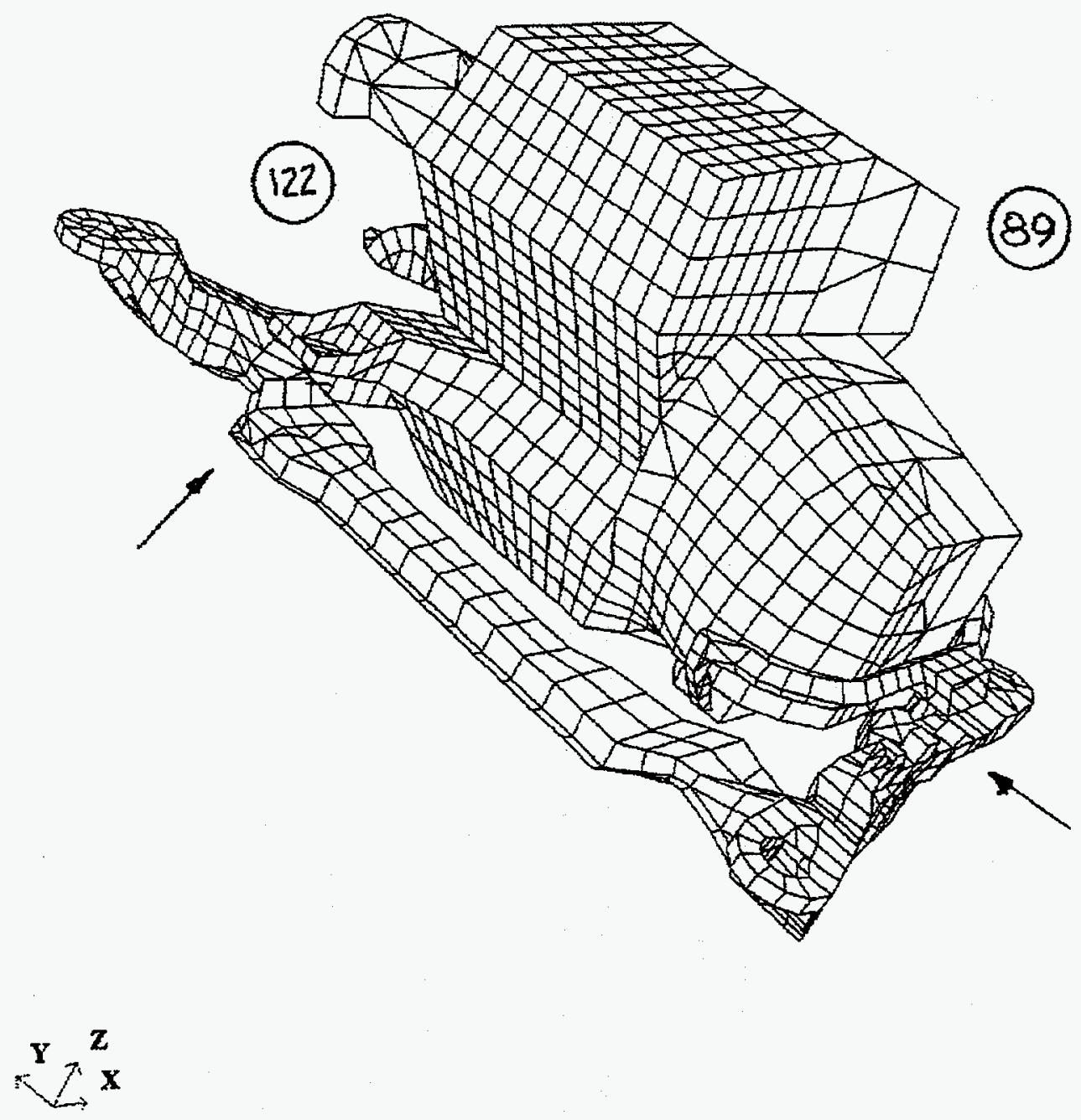

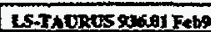

Fig. 14. Engine and Transmission Mounts, Front View 


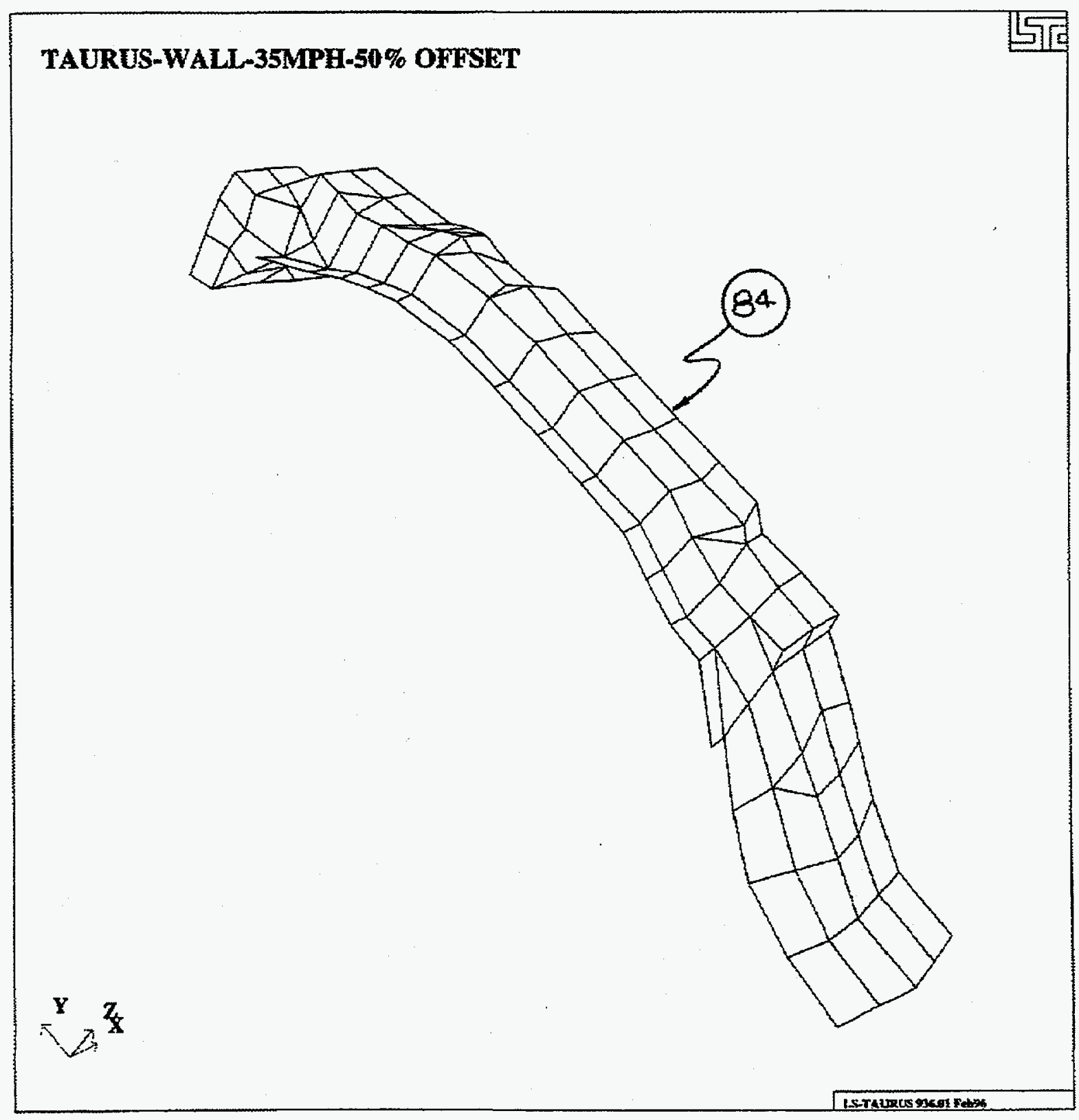

Fig. 15. Engine Cradle, Initial Rear Cross Member 


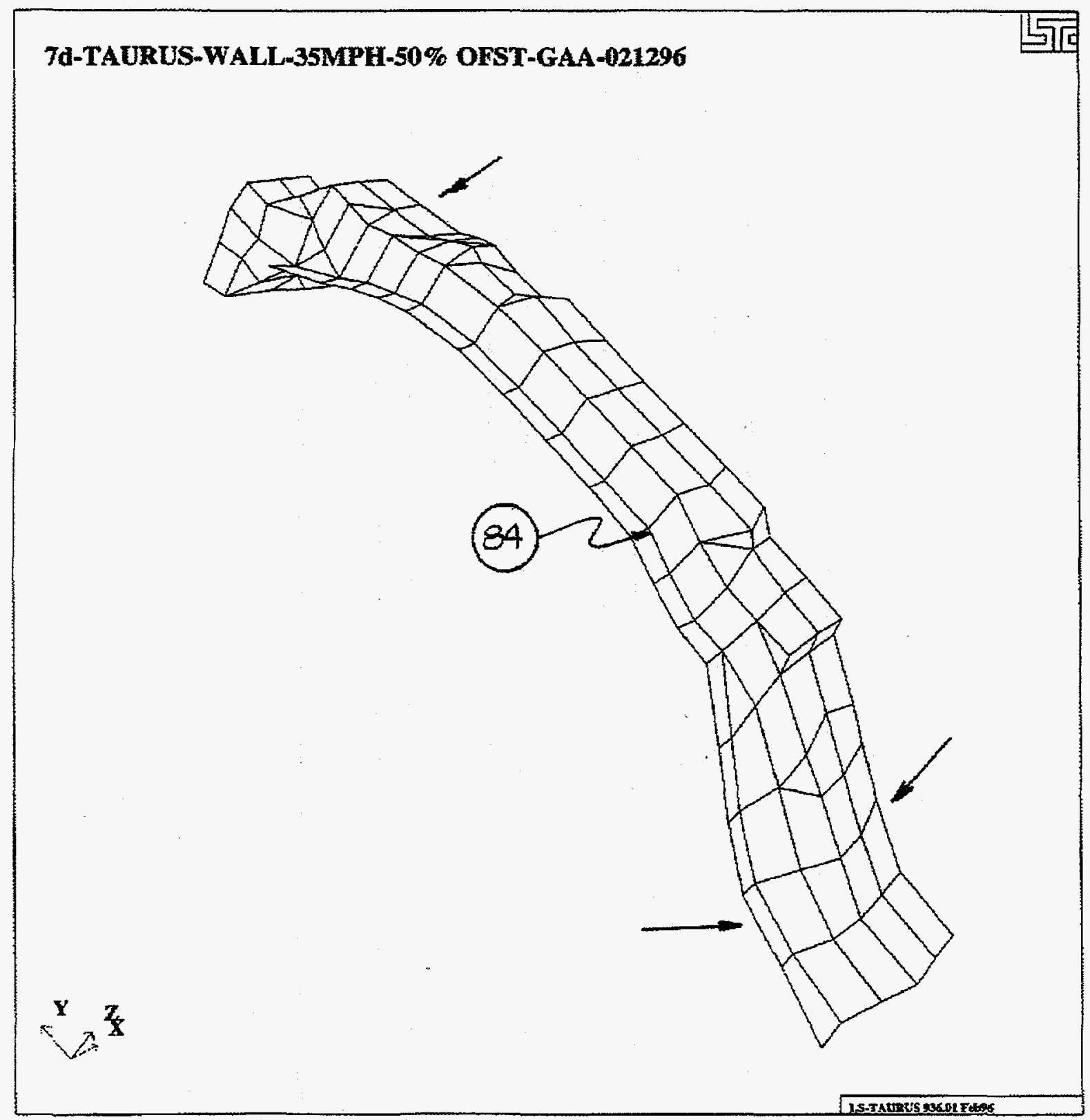

Fig. 16. Engine Cradle, Modified Rear Cross Member 


\subsubsection{Consequences of the Changes in the Model}

The input to LS-DYNA3D that incorporates these changes has been verified in a single-car offset crash against a rigid obstacle. The top and bottom views of the test configuration are shown in Figs. 17 and 18, respectively. The corresponding top and bottom views of the deformed vehicle are shown in Figs. 19 and 20. The side view of the vehicle in Fig. 21 shows the lifting of the rear wheels from the driving surface. The underside view of the front left subframe in Fig. 22 illustrates the kinematic constraints that suspension links are placing on the deformation of the subframe. No experimental data were available for this test to compare. The modeling of offset collision with a rigid barrier was used to assess the general performance of the model in offset impact and to evaluate the influences of different structural and topological changes to the model. 


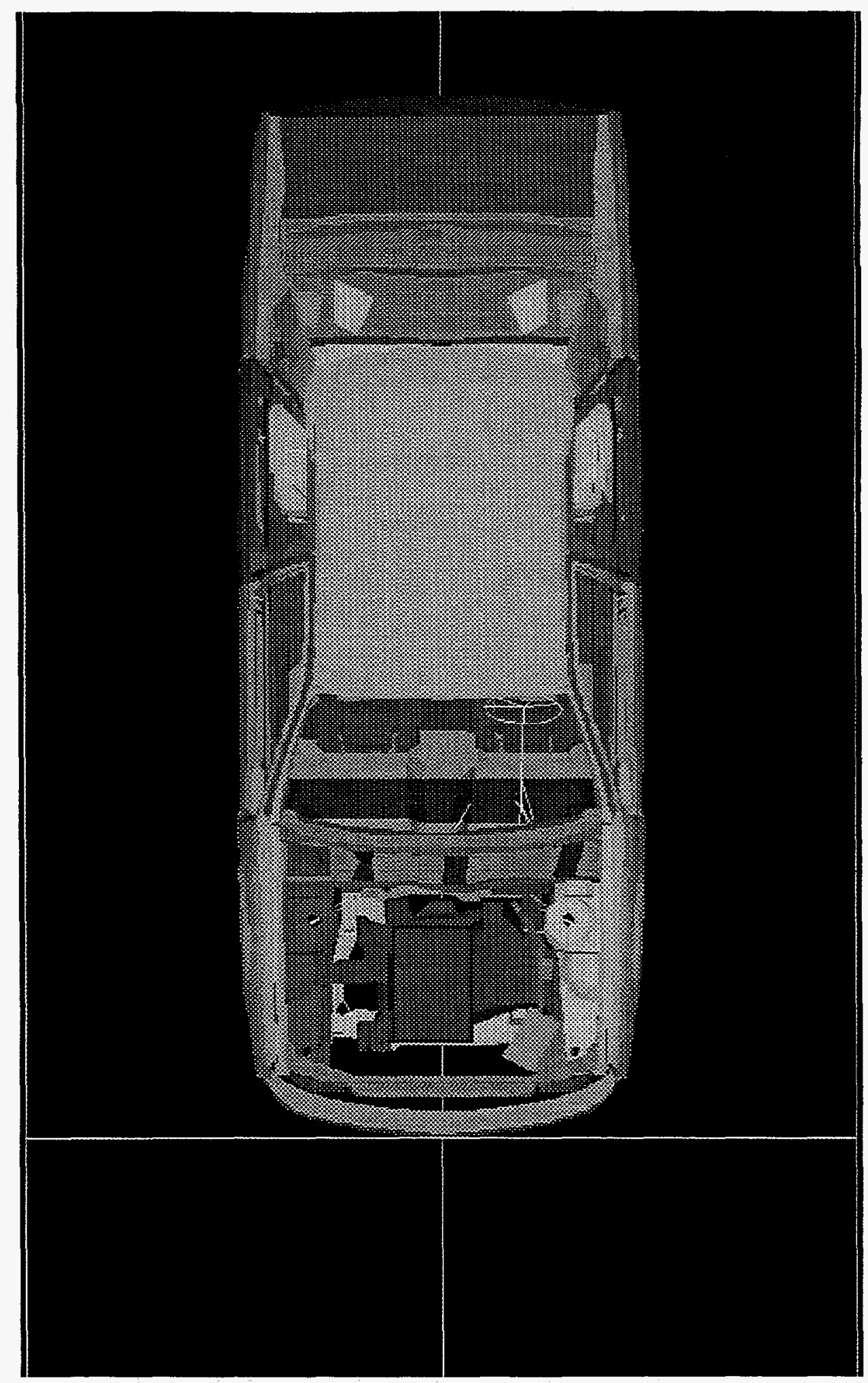

Fig. 17. Frontal Offset Impact with Rigid Barrier, Top View 


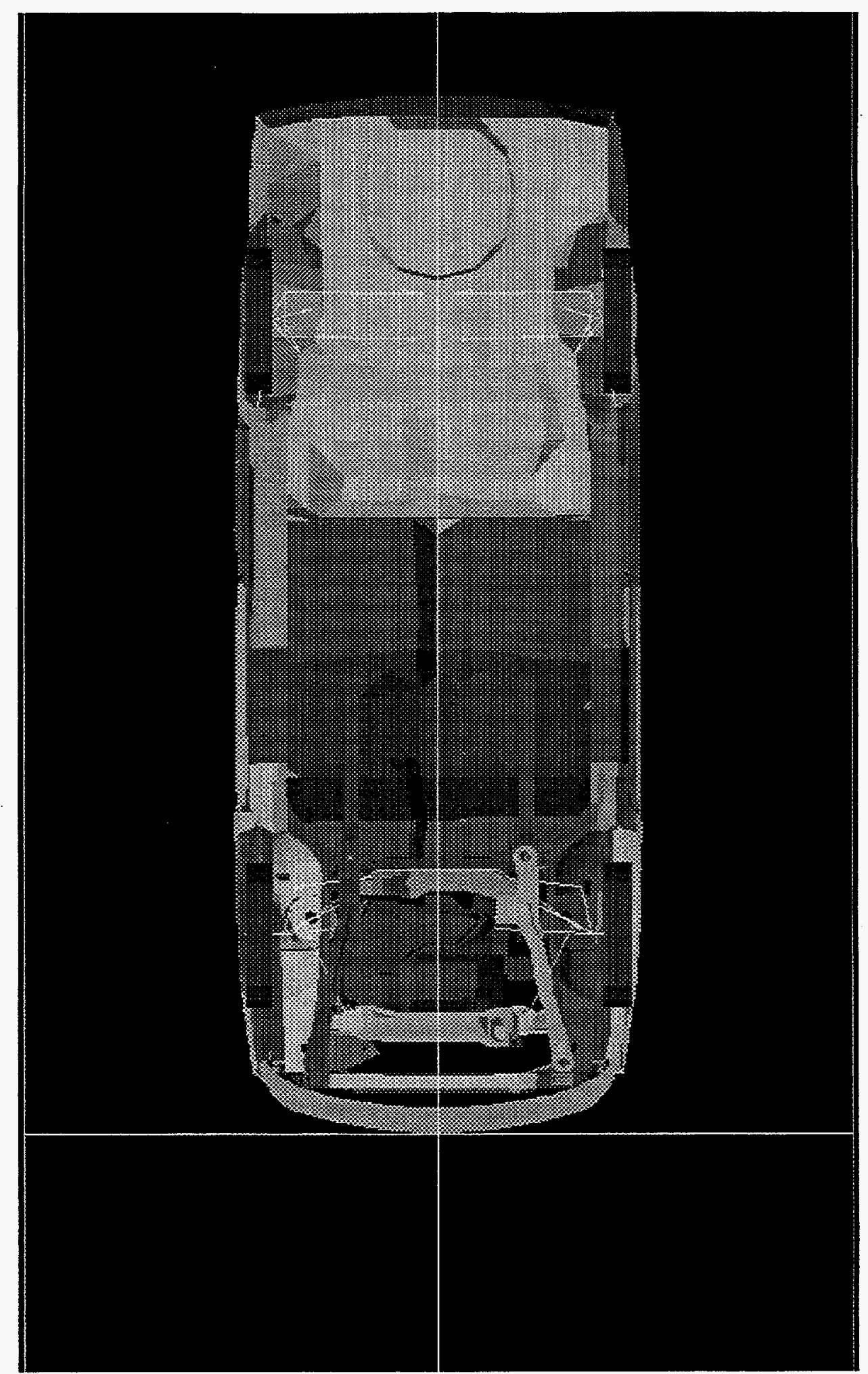

Fig. 18. Frontal Offset Impact with Rigid Barrier, Bottom View 


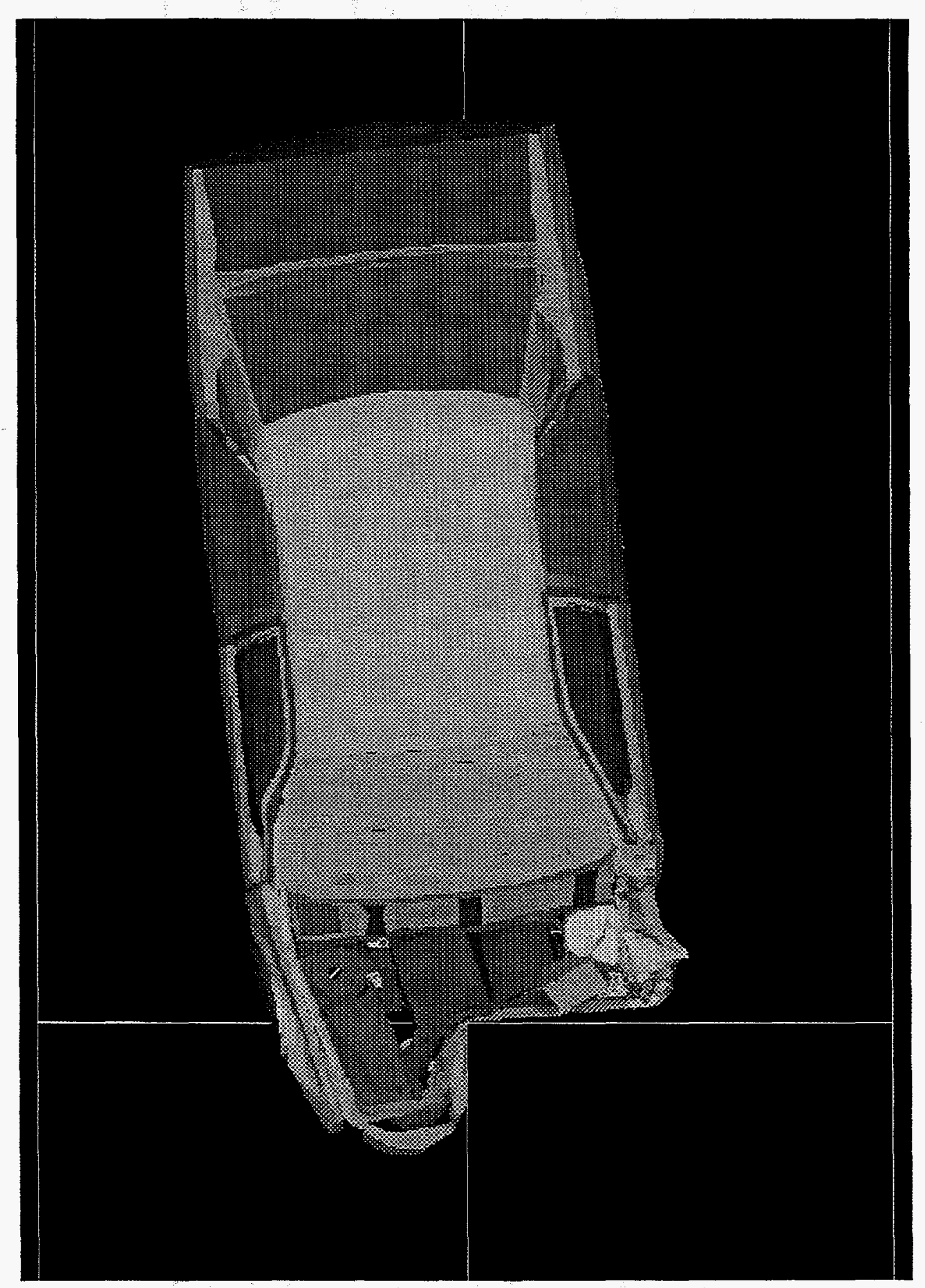

Fig. 19. Frontal Offset Impact, Deformed Vehicle, Top View 


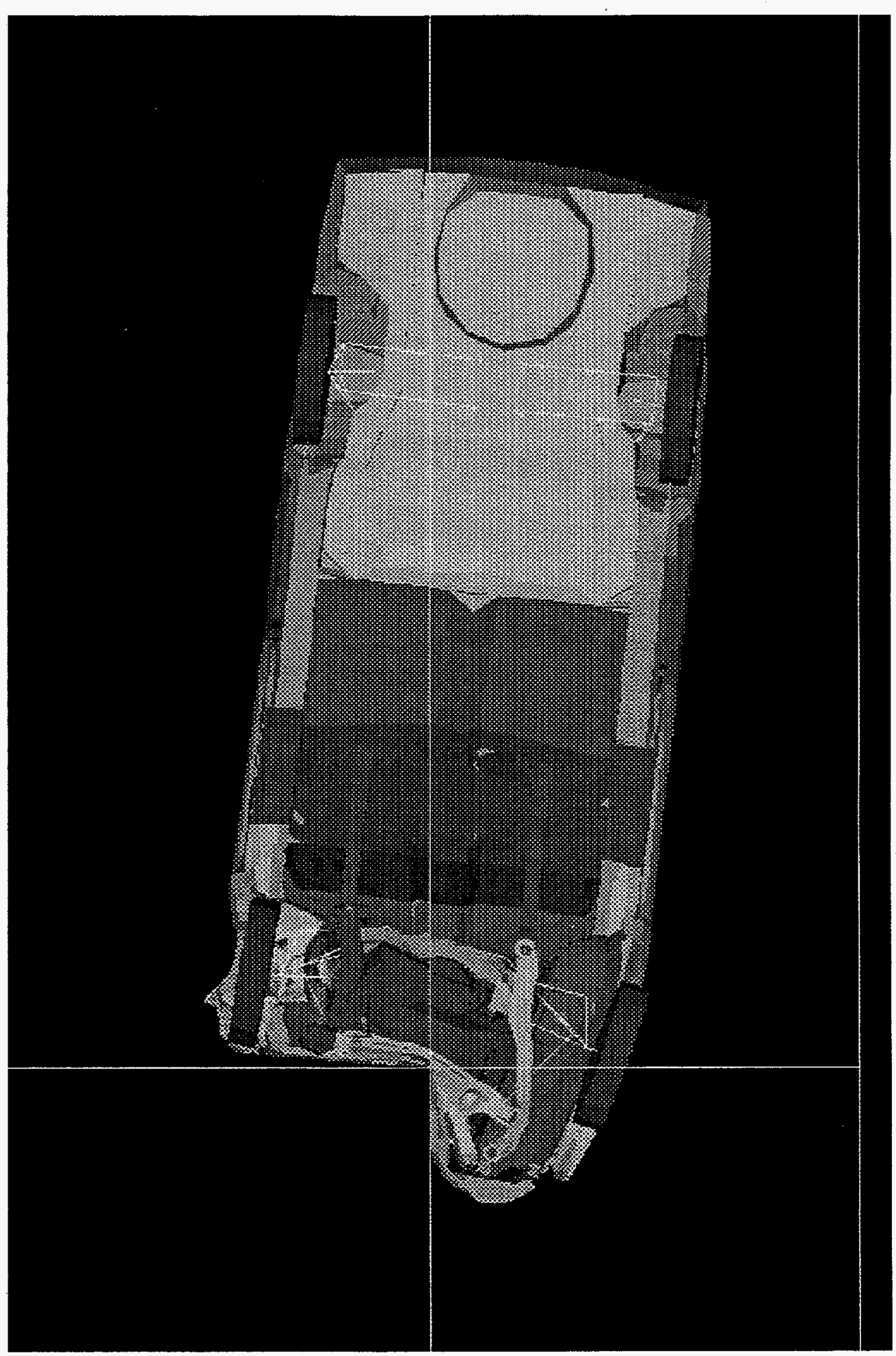

Fig. 20. Frontal Offset Impact, Deformed Vehicle, Bottom View 


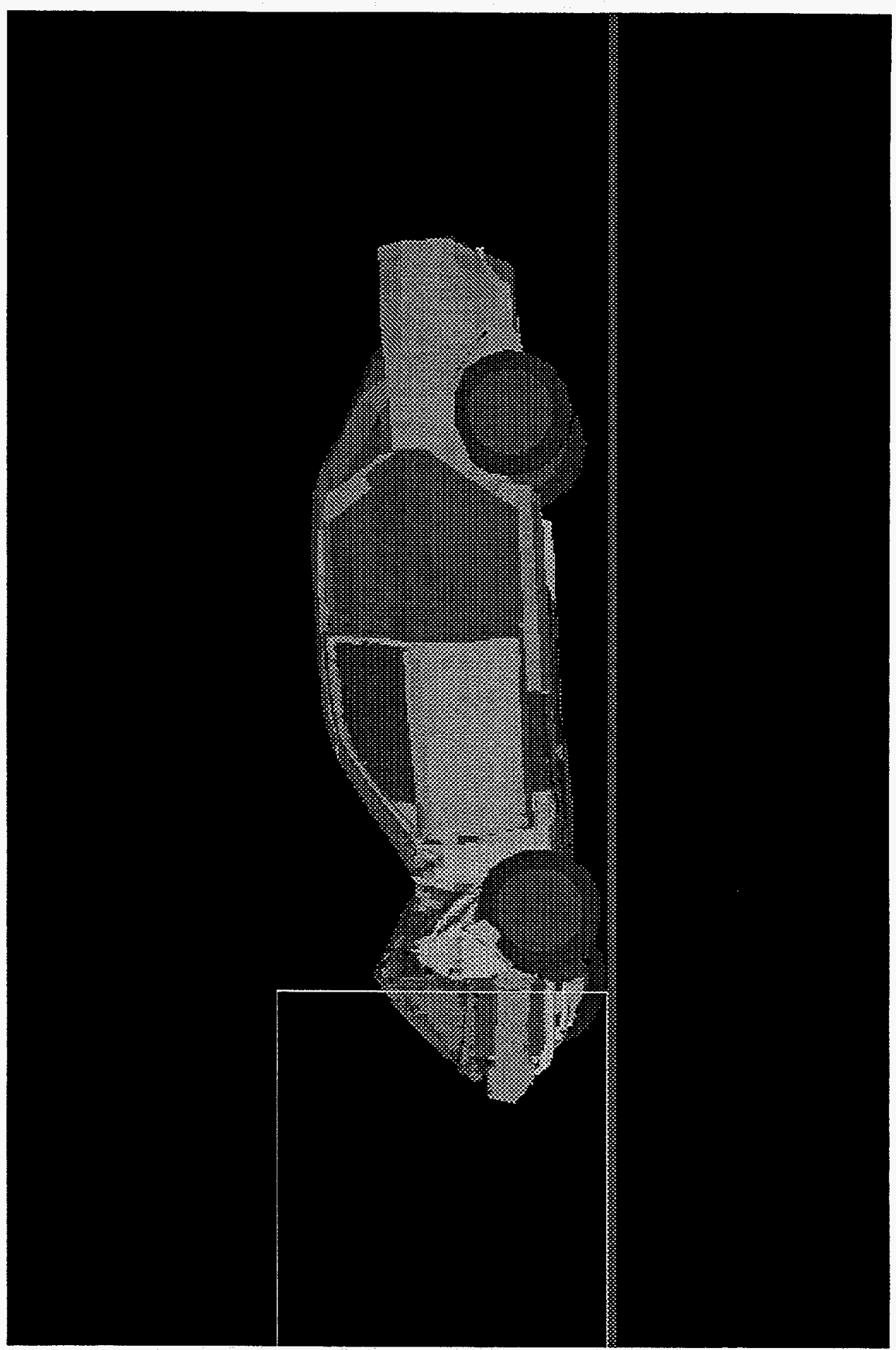

Fig. 21. Frontal Offset Impact, Deformed Vehicle, Side View 


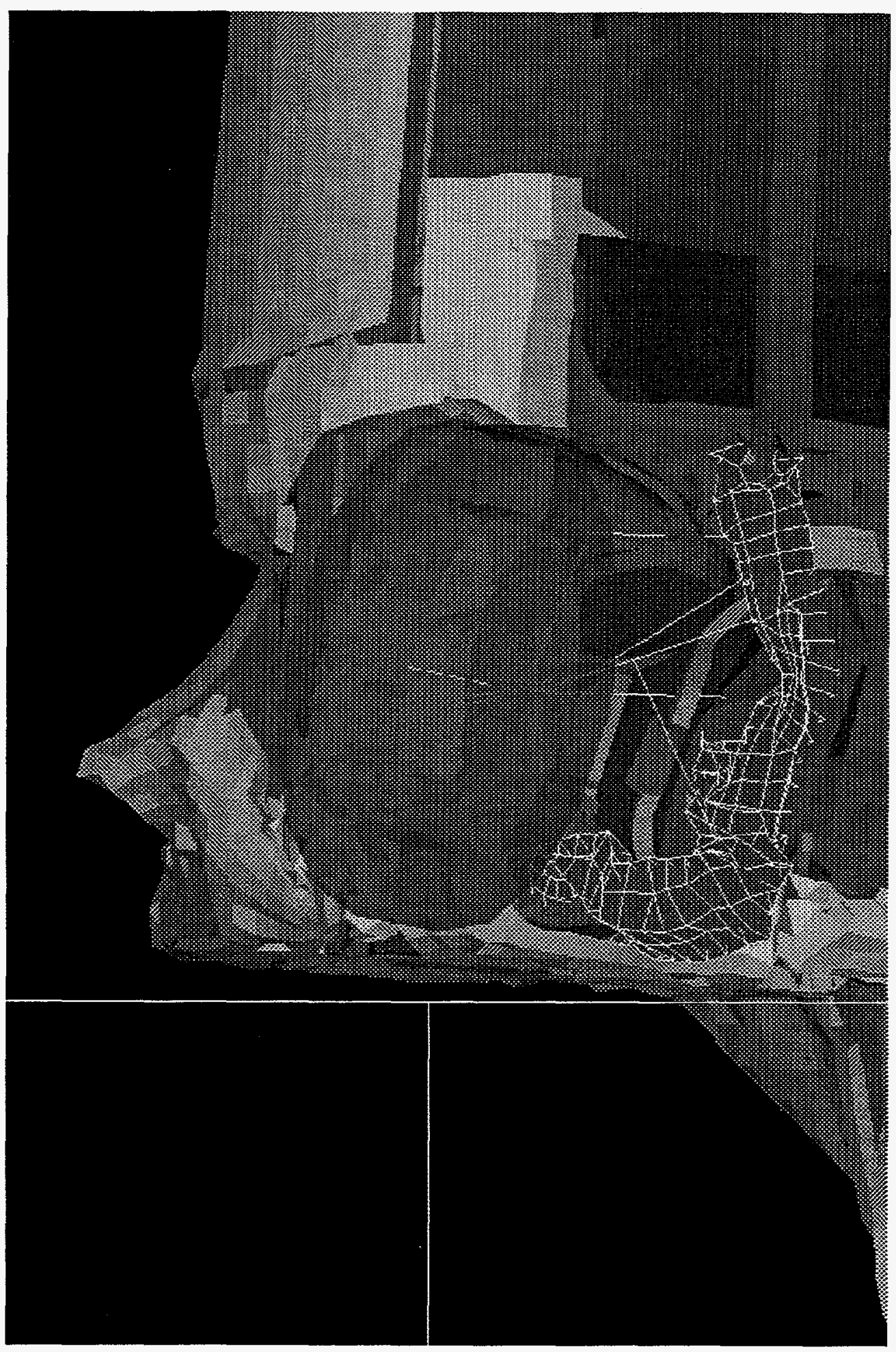

Fig. 22. Frontal Offset Impact, Left Subframe with Suspension 
The most complex collision scenario considered during this project was two-car frontaloblique-offset crash with center line offset of $50 \%$ of the vehicle width and at a $30^{\circ}$ interception (Fig. 23). The deformations at $50 \mathrm{~ms}$ and $150 \mathrm{~ms}$ are shown in Figs. 24 and 25 . The closeup view of the underside view of the front of the vehicles (Fig. 26) again illustrates the importance of suspension links for modeling of the deformation. The results obtained for the two-car crash compare very well in the undercarriage region of the target car, as can be seen in Figs. 27 and 28. The top views of the model prediction and the actual vehicle deformation are shown in Figs. 29 and 30. 


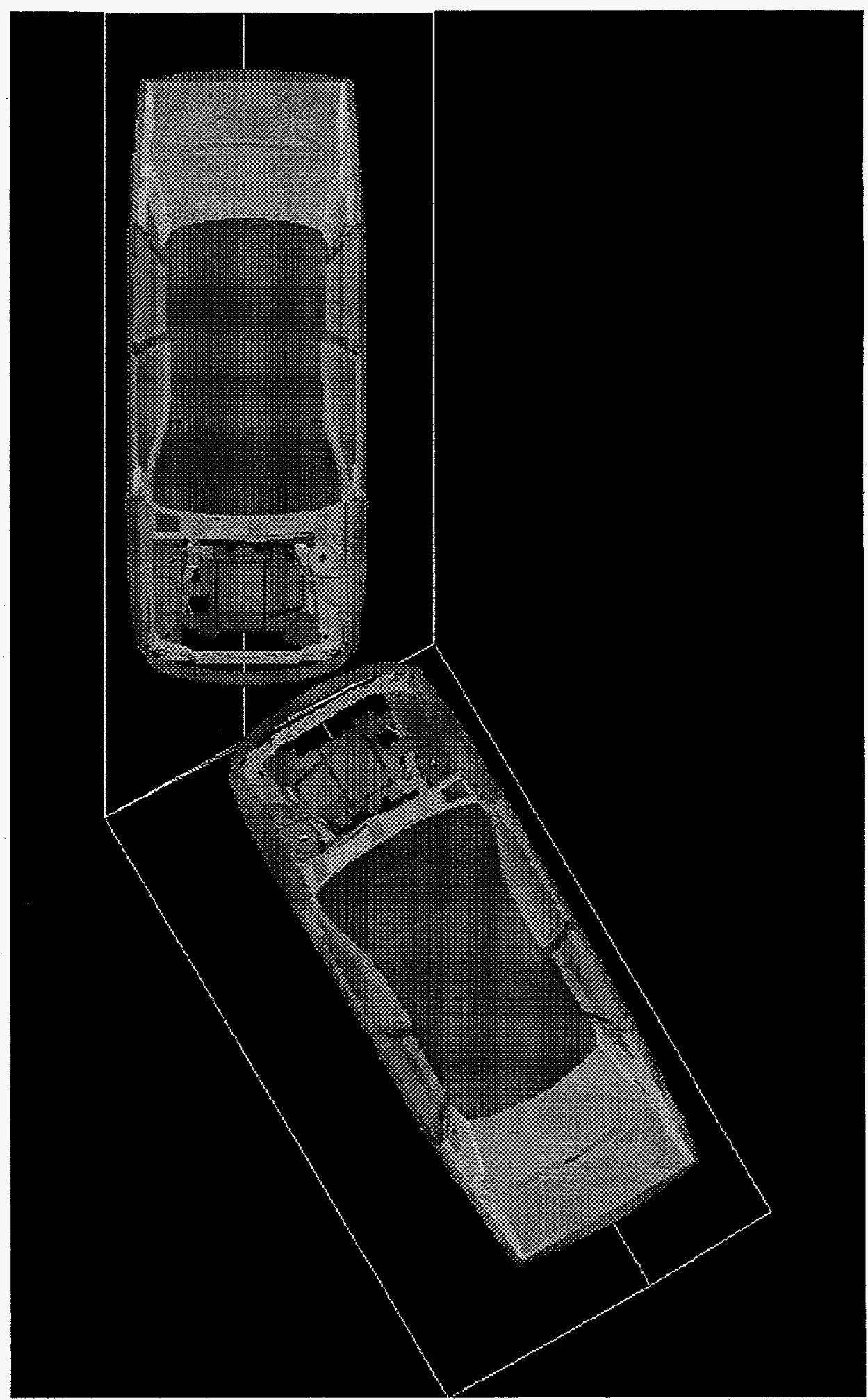

Fig. 23. Two Vehicle Frontal Oblique Offset Crash 


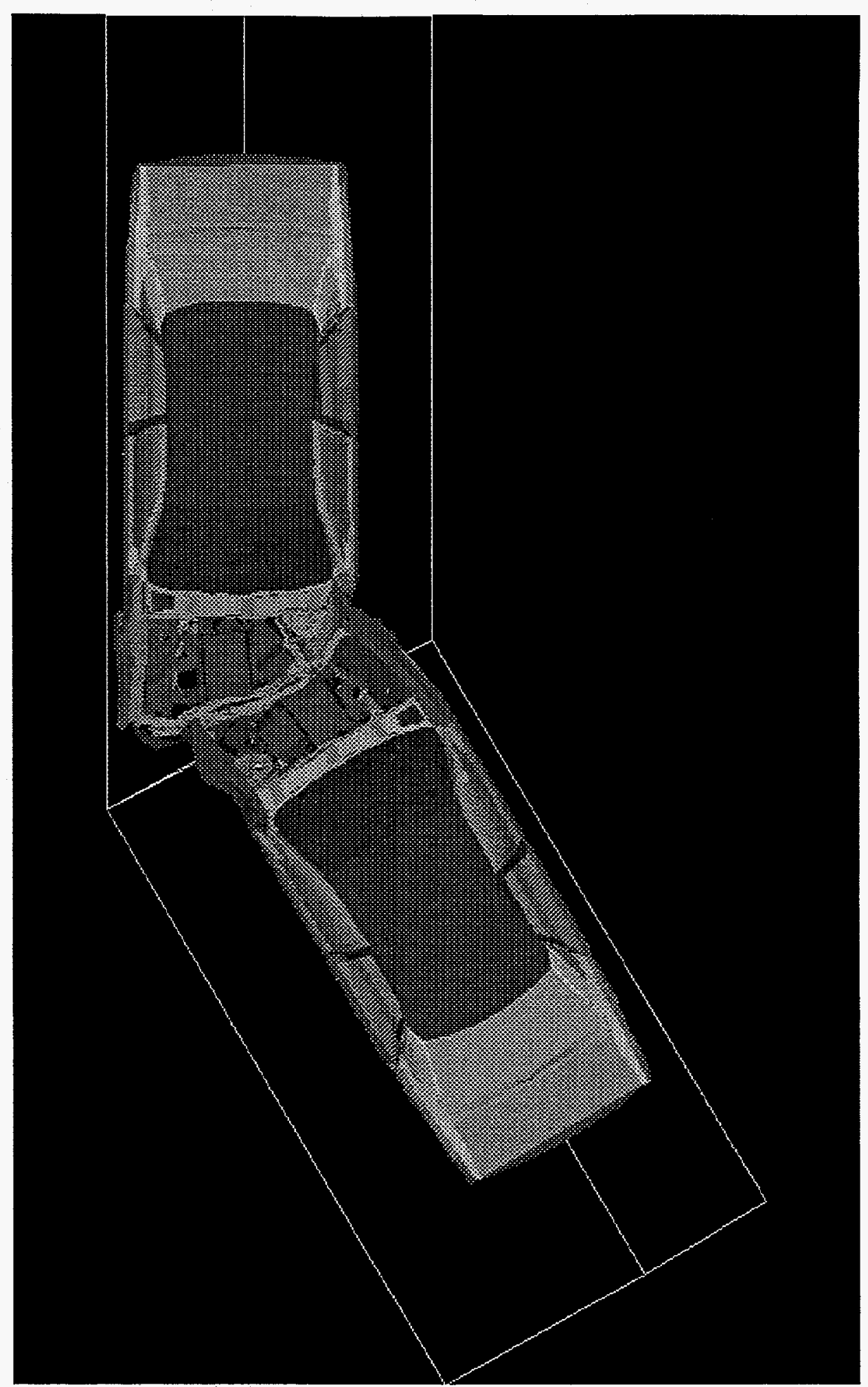

Fig. 24. Two Vehicle Crash, Deformation after $50 \mathrm{~ms}$ 


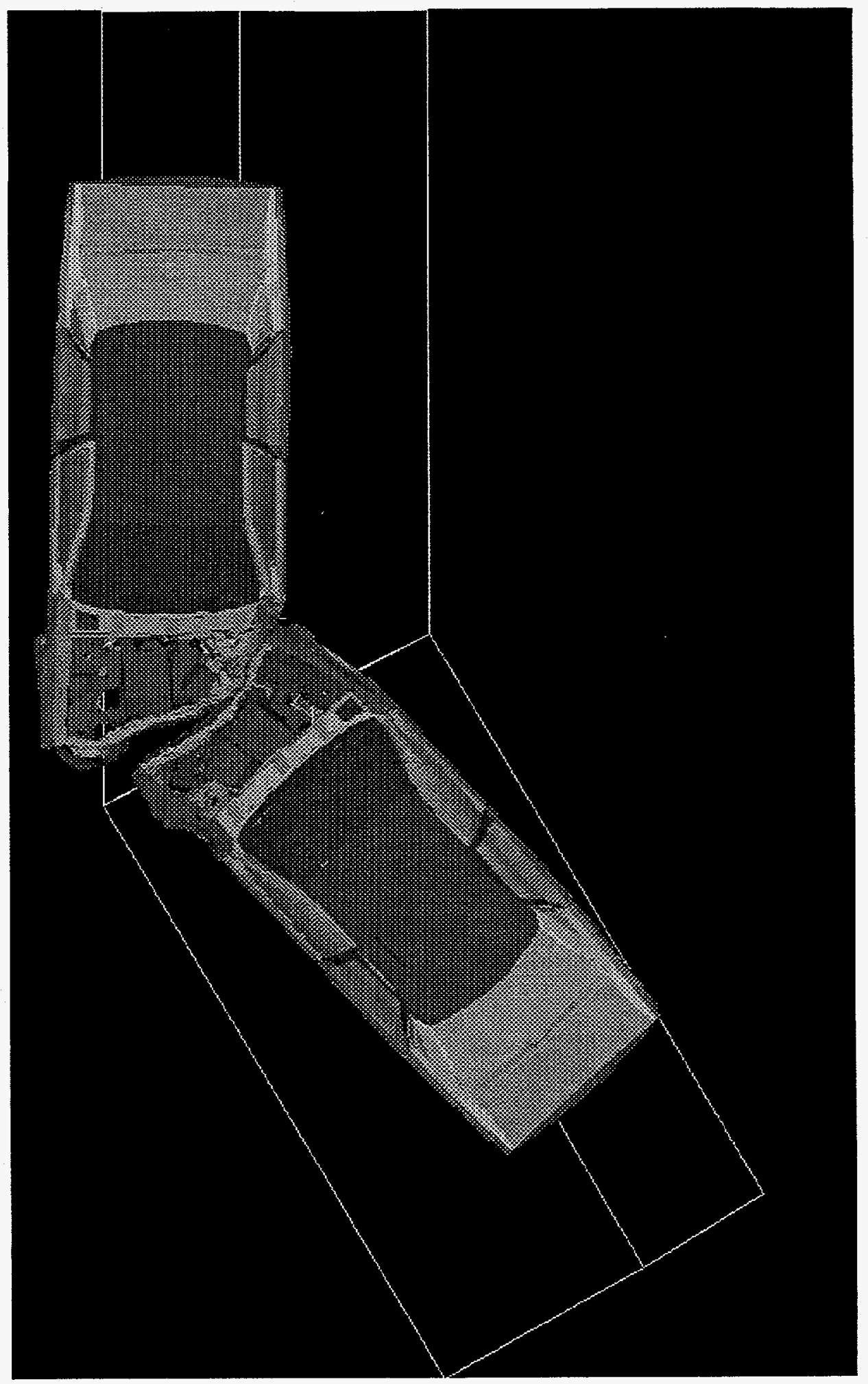

Fig. 25. Two Vehicle Crash, Deformation after $150 \mathrm{~ms}$ 


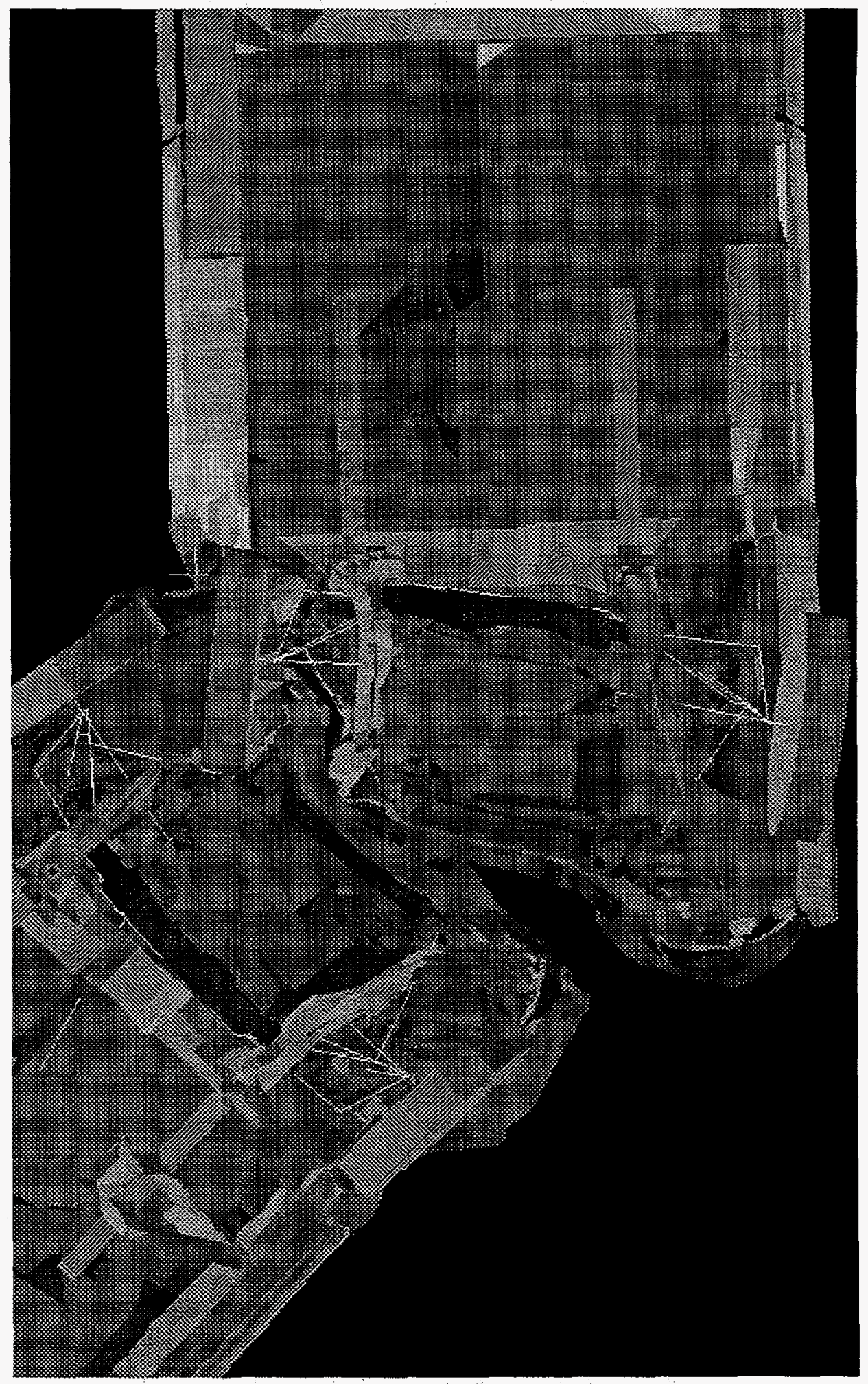

Fig. 26. Two Vehicle Crash, Suspension and Subframe 


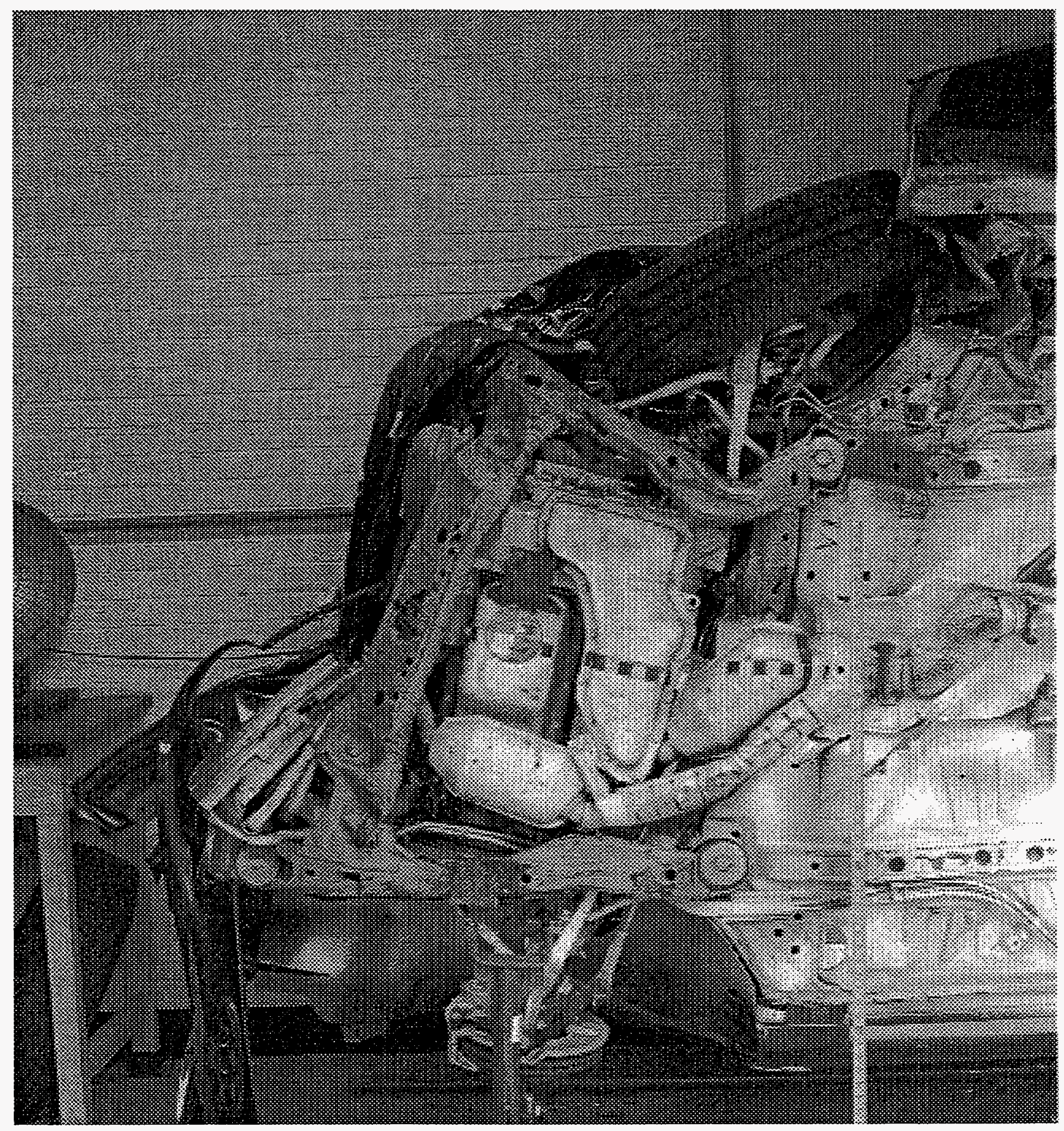

Fig. 27. Two Vehicle Crash, Test Vehicle, Bottom View 


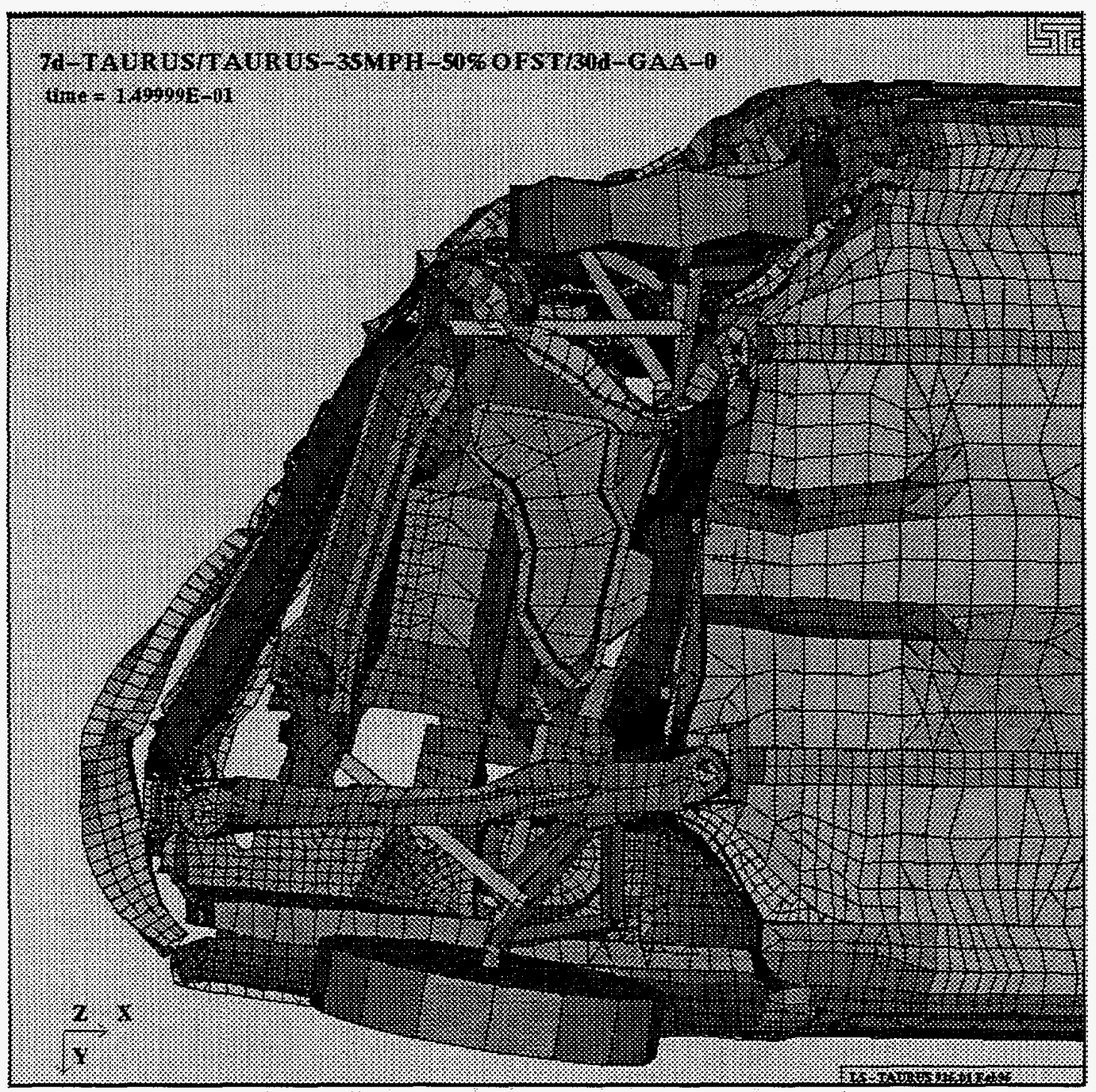

Fig. 28. Two Vehicle Crash, Model, Bottom View 


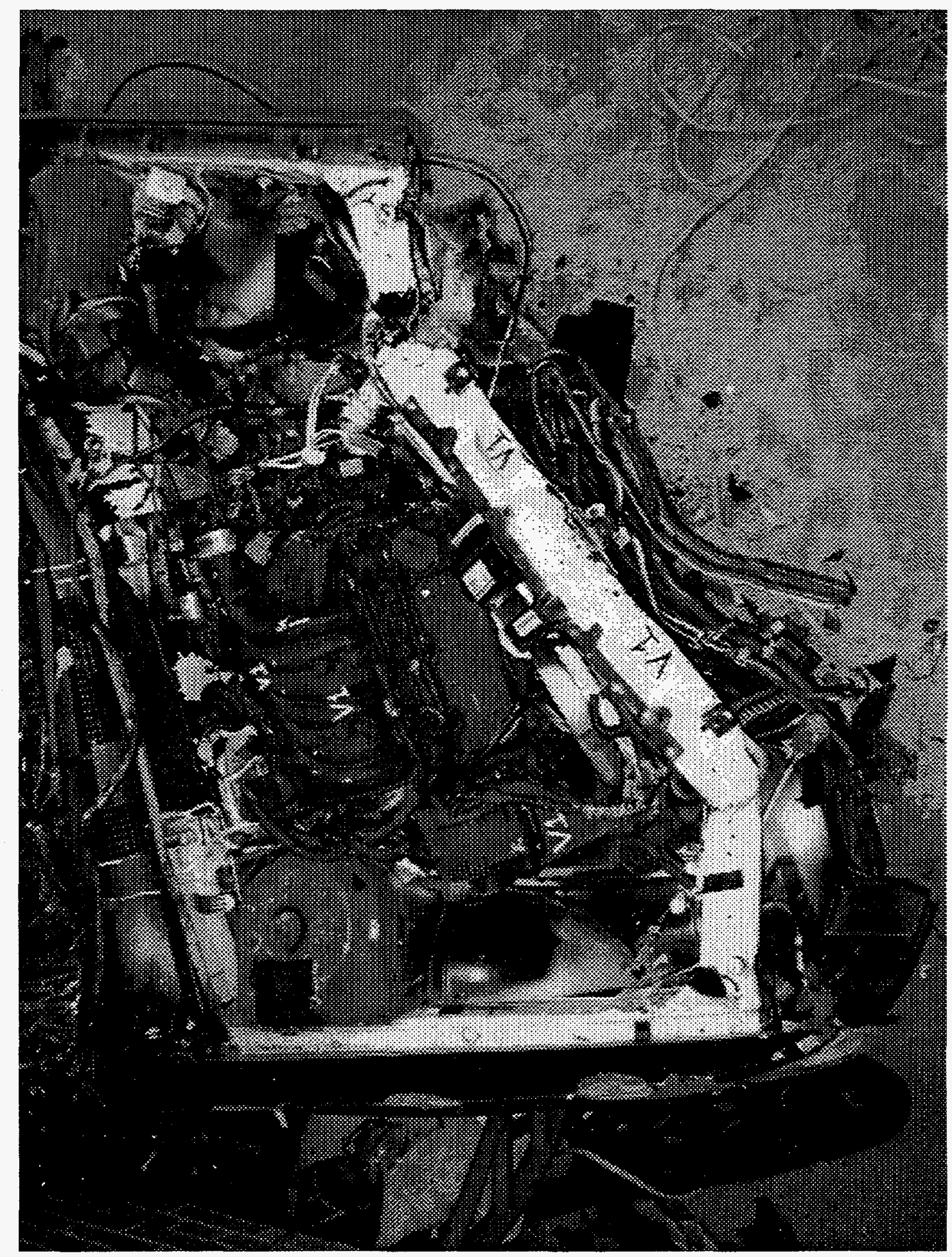

Fig. 29. Two Vehicle Crash, Test Vehicle, Top View 


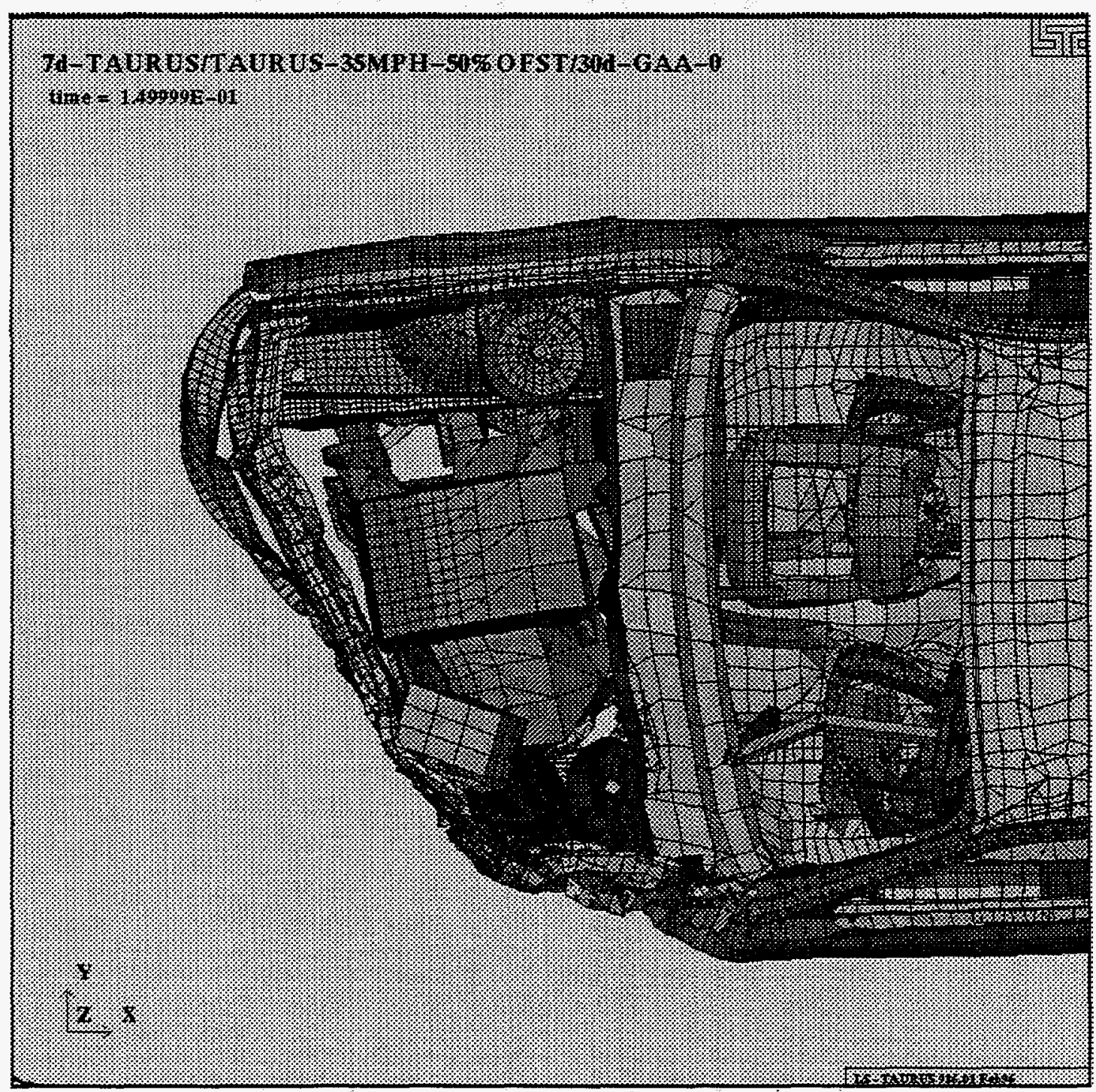

Fig. 30. Two Vehicle Crash, Model, Top View 
The changes that were made to the model have generally improved the accuracy of the vehicle suspension, powertrain supports, and sheet-metal unibody front structure. Modeling of the interaction of these components is crucial for capturing the complex deformation that occurs during collision. The crashed vehicle showed that there was no single structure in the front that remained intact and that each had contributed to some impact energy dissipation. The connections between different structures had to be more accurately modeled as they break off and engage with other structures. In the new version of the model the engine and transmission are essentially moving as rigid bodies supported by deformable links that impact the neighboring "structures, replicating the behavior that was observed in the test vehicles.

\subsection{CONSTITUTIVE MODELS FOR LWM}

Several constitutive material models ${ }^{8,11}$ for aluminum alloys were analyzed during the course of the project. The intention was to create a database of the existing constitutive material models and evaluate their behavior in crash situations. The model for main structural parts that experience large forces and deformations should consider various failure modes through the damage models. The failure modes may include tearing of the material together with characteristic folding by a mechanism of plastic hinges. Figure 31 illustrates resulting the force difference of the rectangular tube impacting the rigid surface using the material constitutive models with and without the consideration of damage. The standard elastoplastic model predicts significantly larger force associated with tube folding (Figure 32) than the model that incorporates damage. In the case of the damage-enhanced model (Fig. 33) material tears along the corner of the tube and reduces the force exerted on the rigid wall. If such a failure mode is expected in the structural part it is necessary to include damage effects in the model. However, the damage and failure models have to be carefully deployed in the model because such models may significantly increase computational time required for the analysis. 


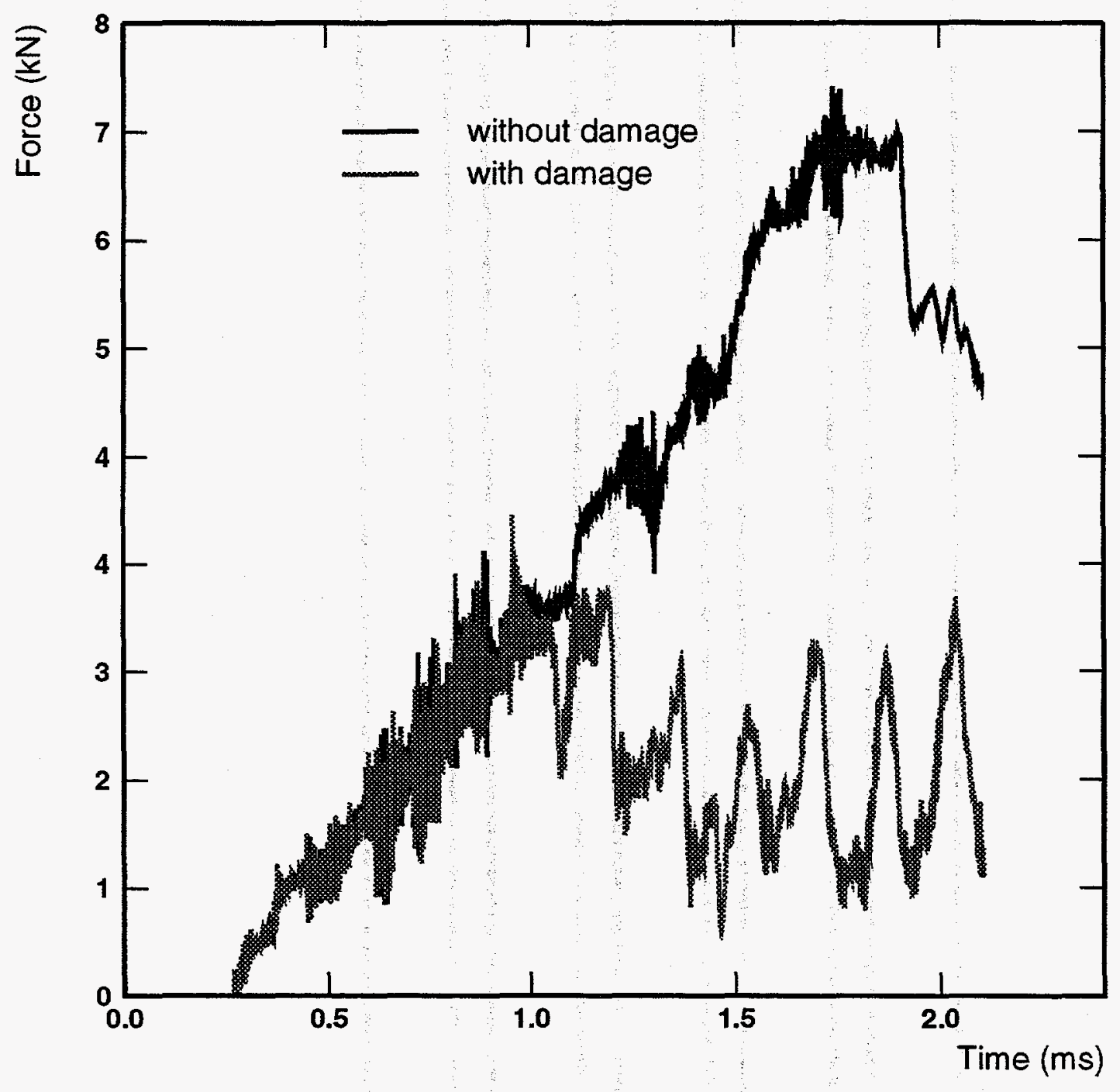

Fig. 31. Tube Impact Force 
Tube impact, elastoplastic material

$$
\text { time }=.22249 E-02
$$

fringes of eff. stress $(v-m)$

$\mathrm{min}=1.575 \mathrm{E}+04$ in element 920

$\max =4.341 \mathrm{E}+05$ in element 423

shell middle surface in global coordinates

fringe levels

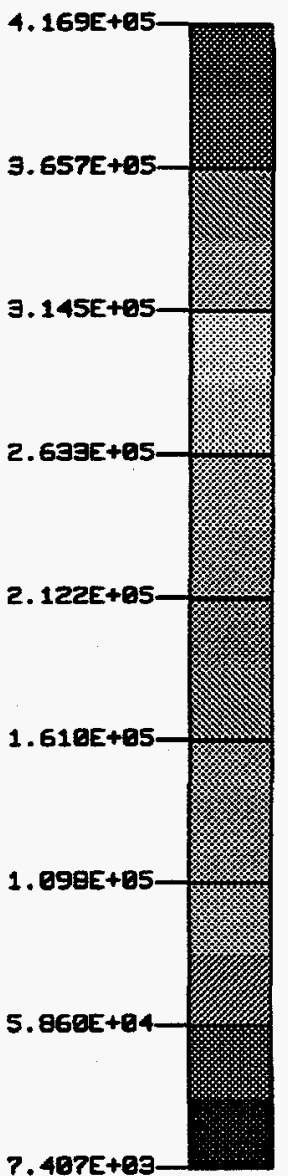

7. $48 \mathrm{RE}+$<smiles>[Y]C([14CH3])[14CH3]</smiles>
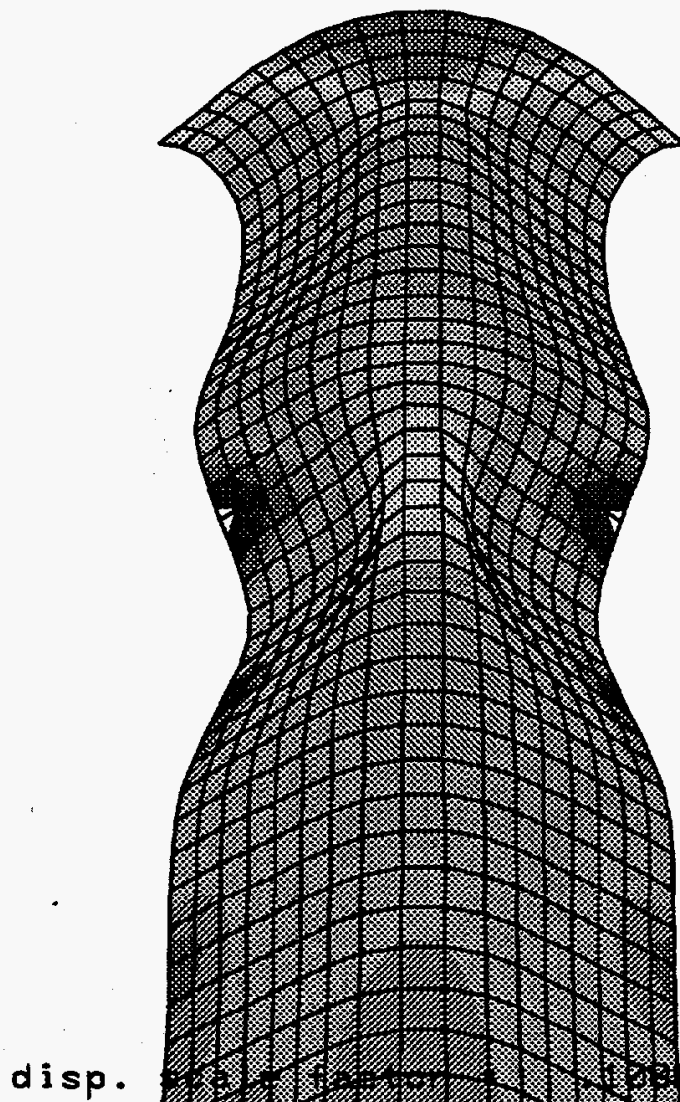

disp.

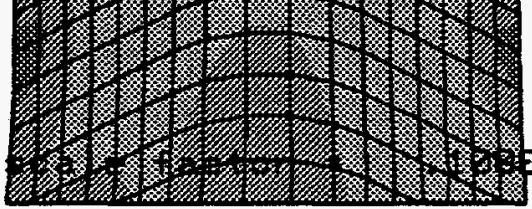

(default)

Fig. 32. Material Model without Damage Effects 
Tube impact, elastoplastic-damage material

$t$ ime $=.21066 E-02$

fringes of eff. stress $(u-m)$

$\min =0.000 E+00$ in element 443

shell $\mathrm{middle}$ surface in global coordinates

fringe levels
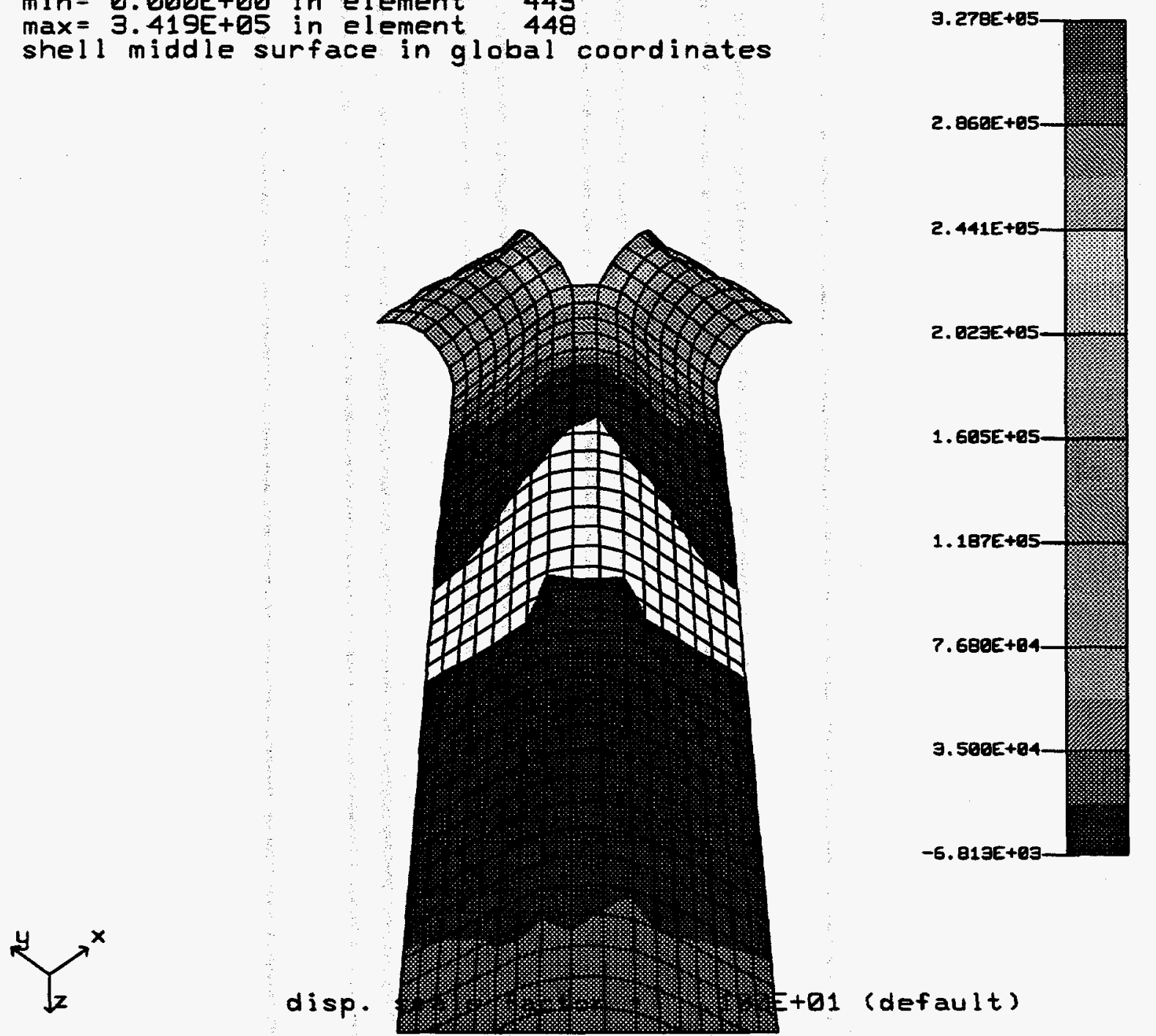

(default)

Fig. 33. Material Model wịth Damage Effects 


\subsection{MASSIVELY PARALLEL COMPUTING APPLICATIONS}

The simulations were performed using the massively parallel and multiprocessor versions of LS-DYNA3D ${ }^{12}$ software. A research collaboration has been established between ORNL and the software vendor to improve its performance on distributed memory massively parallel computers. The program calculates accelerations, velocities, deformations of components, and forces acting on vehicles, taking into consideration variables such as different materials, impact interactions, complex constraints, and spot welds. The program employs explicit time integration scheme with mass matrix diagonalization, ${ }^{13}$ thus making the matrix factorizations trivial without need for any significant interprocessor communication. The down side to this approach is that the computation is only conditionally stable. ${ }^{13}$ The stability condition requires that the time step increment within which the entire state of deformation needs to be computed be proportional to the size of the smallest element in the finite element model. For example, simulation of a 120 ms-long collision of a car with a rigid barrier requires in excess of 130,000 such time increments. The finite element model for the car used in this study involves 27,000 to 30,000 finite elements and approximately the same number of nodes. To process one finite element during a computational increment, approximately 1000 floating point operations and several hundred words of memory ${ }^{13}$ are needed.

The domain decomposition approach has been employed in the program as the principal method for exploiting concurrent distributed memory processing. Using this approach, different parts of the structure are assigned to different processors for computation of their deformation. At certain points in the program, the information has to be exchanged between processors to account for interaction between the subdomains (adjacency and contact interaction) and to synchronize computation. The efficiency of the computation is influenced by the ratio between the balanced computational load assigned to the processors and the amount of communication that is needed between them. For a given size of the problem, as the number of used processors increase, the subdomains (and therefore, computational load) decrease while communication becomes dominant. After the computation time becomes comparable to communication, the simulation time cannot be further reduced by increasing the number of processors. Three different decomposition methods can be used in the pro-

gram: (1) recursive spectral bisection (RSB) ${ }_{2}^{14}$ (2) recursive coordinate bisection, ${ }^{15}$ and (3) 
greedy algorithm. ${ }^{16}$ An example of the domain decomposition using RSB is shown in Fig. 34. The subdomain-to-processor assignment for the car on the right has been shown in exploded view to illustrate the domain decomposition approach. Usually, the average size of interfaces or "cuts" between different subdomains is directly proportional to the communication that would be required in the program. Low communication resulting from recursive spectral bisection makes it a method of choice for parallel processing on distributed-memory computers when there is no unilateral contact between the finite elements. However, in situations where structural parts interact through contact and the spatial relations drastically change, the advantages of RSB may not be so apparent.

The vehicle impact simulation involves computation of deformation of vehicle parts resulting from their contact with impacting structure as well as contact with other vehicle parts. If two interacting parts reside on different processors, this interaction needs to be carried through interprocessor communication. Because it is very difficult to determine in advance which parts will come into contact, such information cannot be embedded into domain decomposition ahead of computation. In effect, this requires application of geometrical reasoning, which is a global memory operation, on distributed-memory environment consisting of mainly independent entities (processors) having limited spatial scope. The contact algorithm employed in the program is based on frequent spatial sorting of the contact entities and redistribution of the sorted position information between processors. The problem space is divided into regular subdomains ("buckets") in $x, y$, and $z$ physical directions. The process involves extensive communication between processors, and, if performed every time step, may create a computational bottleneck. By reducing the number of 'bucket' sorts, computations can be speeded up considerably, and if errors in computation are noticed, the sorting frequency can be increased to maintain accuracy.

The timing results for different numbers of processors for simulating offset impact of a car with a rigid barrier are shown in Fig. 35 . The time axis represents average CPU time spent on the problem's time increment. In this case, the representative CPU time was averaged over a number of time steps and compared as it fluctuated depending on simulation conditions and machine load. An example of CPU time per problem time increment throughout the simulation using 128 processors is shown in Fig. 36. When the representative CPU times 
for different number of processors are normalized with CPU time needed for 16 processors (Fig. 37), it may be noticed that there was a reasonable increase in computational efficiency up to 64 processors. Further increase in the number of processors did not significantly reduce the overall computational time as the communication between processors became dominant. In the case of the two-car crash, the efficiency increased up to approximately 128 processors. This could be attributed in part to the increase in the average size of computational subdomains assigned to processors with respect to required communication. The single- and two-car impact computational simulations have been run numerous times to identify deficiencies of the existing models and to improve their performance. 


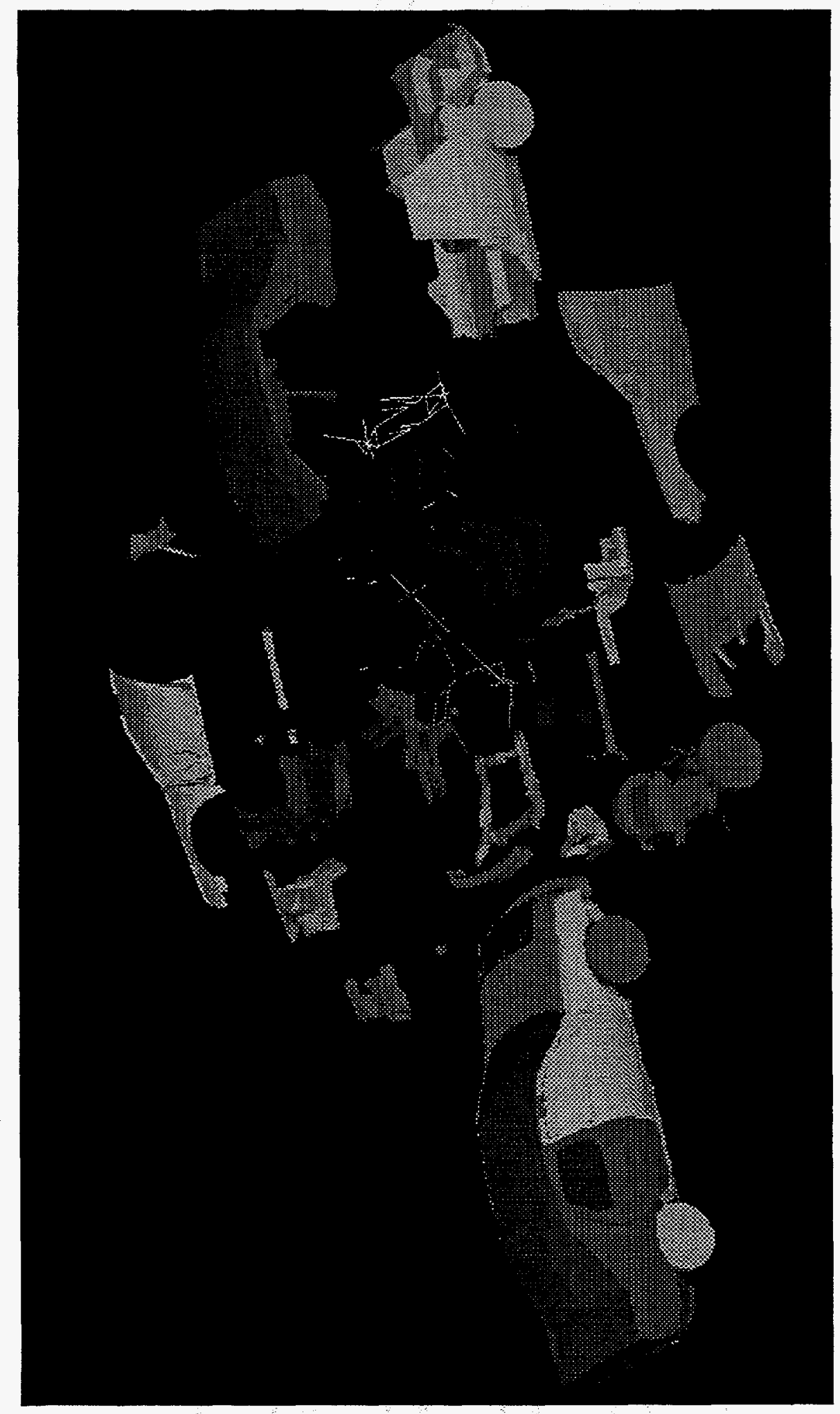

Fig. 34. Domain Decomposition for MPP 


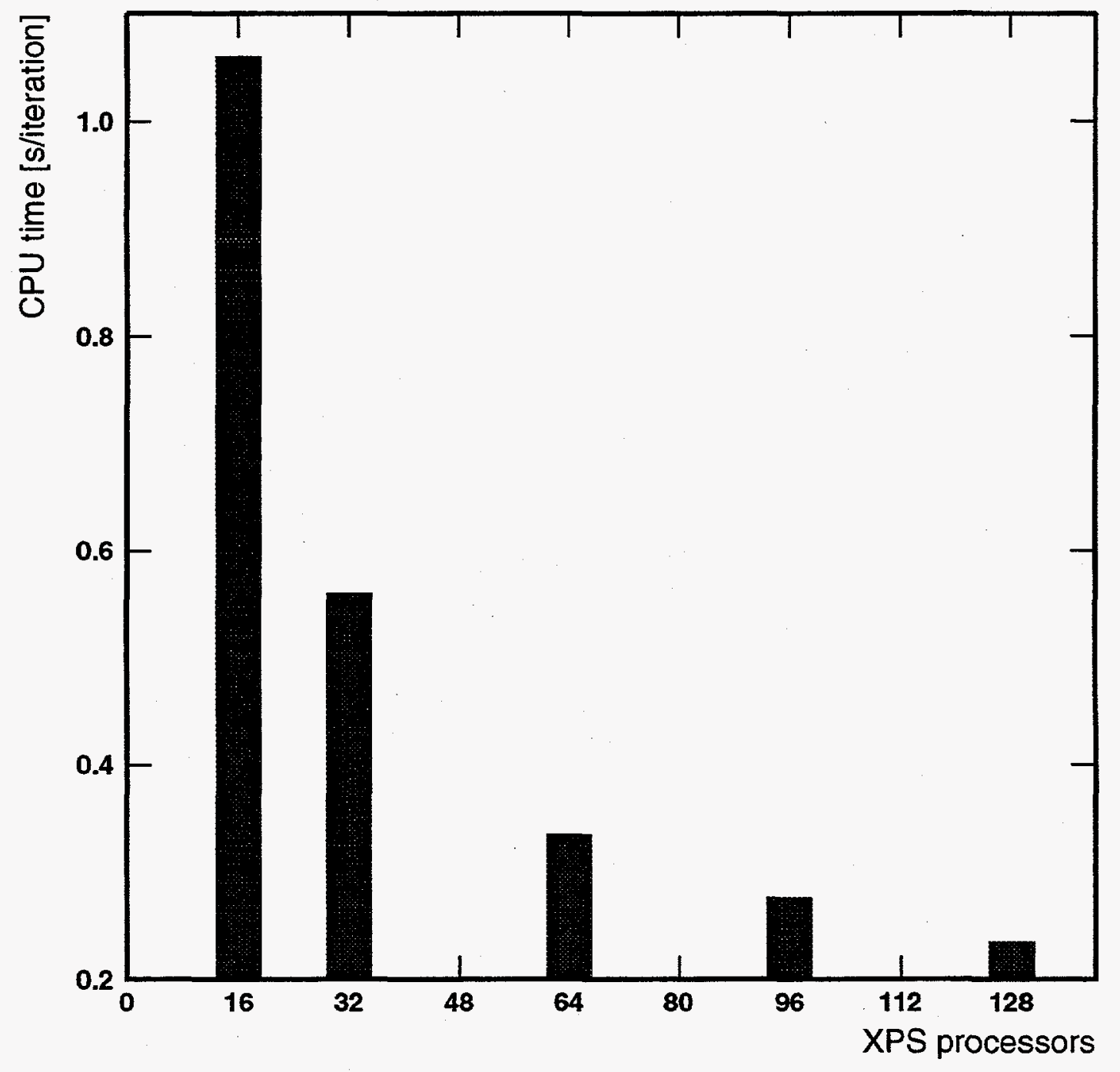

Fig. 35. CPU Time on Intel Paragon 


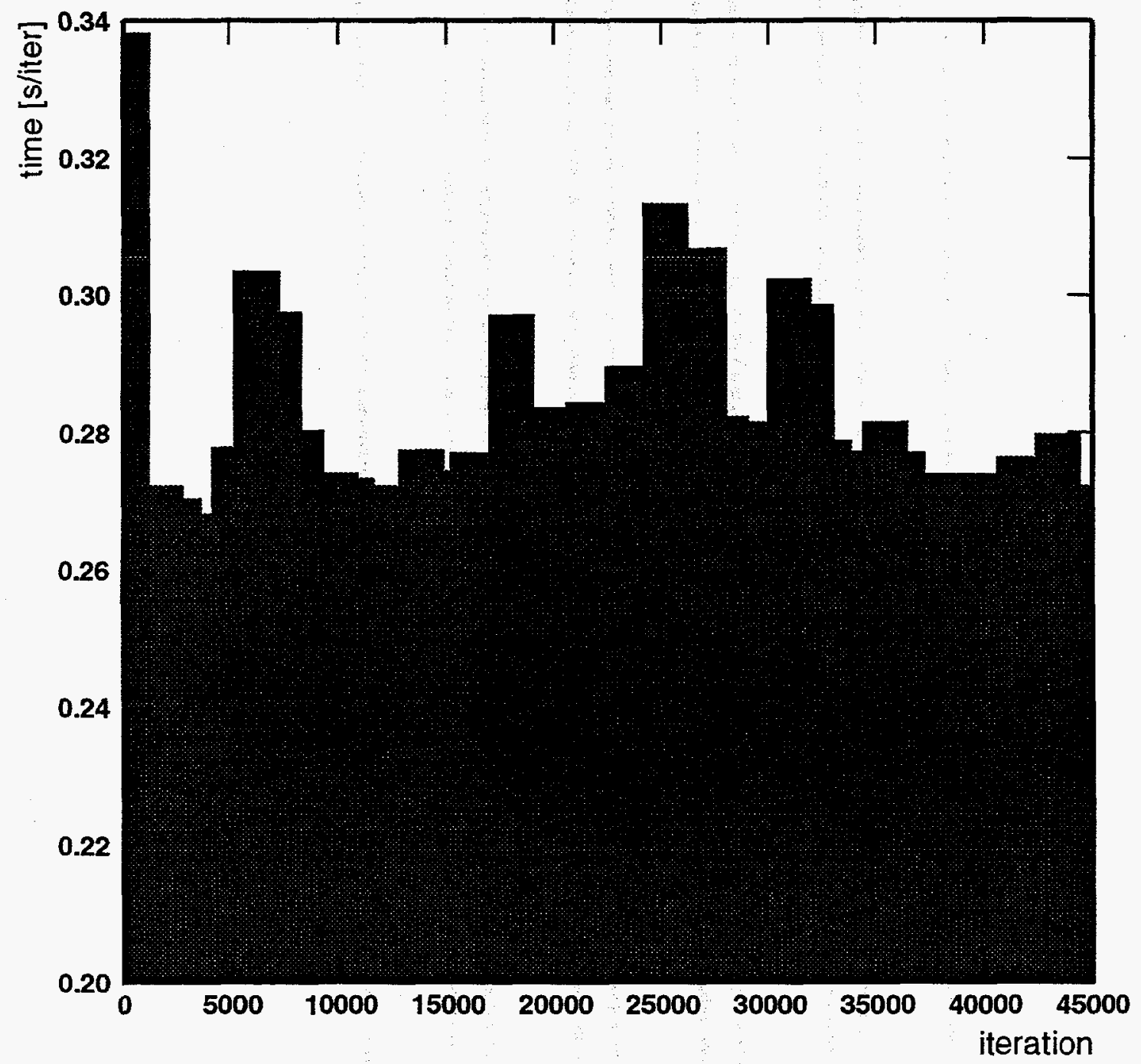

Fig. 36. CPU Time History on Intel Paragon 


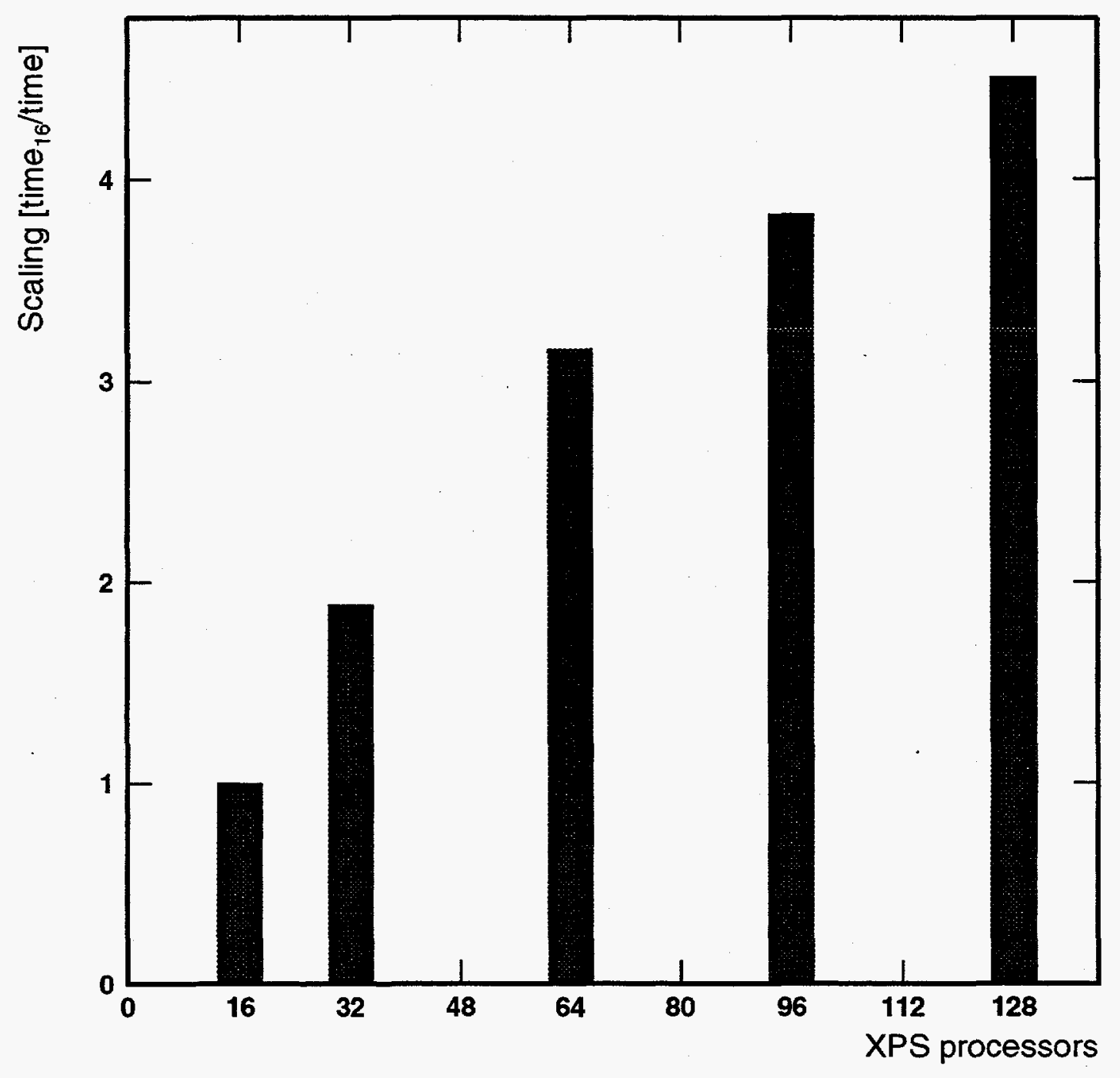

Fig. 37. CPU Time Scalling on Intel Paragon 


\section{CONCLUSIONS AND FUTURE WORK}

The computational simulation has become a standard tool in the vehicle design process. Large, detailed models can be generated directly from the CAD databases or by reverse engineering methods. Introduction of lightweight materials in vehicles can be significantly accelerated by using these computational models as test platforms to generate information that can otherwise by created only through years of service and experience. As complex material models for lightweight materials are employed in new vehicle design, computational power becomes a limiting factor. Application of massively parallel computing was an essential component in this research because it allowed for a rapid development of these models. Scalability studies on existing vehicle models indicate the existence of a threshold for number of processors that can be efficiently used for a given simulation. This threshold can be related to the average number of finite elements that are assigned per computing node of the massively parallel computer.

The vehicle models developed at ORNL can be used for a host of applications, the primary one being evaluation of lightweight materials' performance in vehicles. The model, although significantly improved, can be made more realistic by further studies. Some modifications that we feel may result in positive changes are further modification to the steering links, modification to the shotgun interface to the forward radiator mount assembly and A-pillar assembly, and modification of front floor structure near the interface with the engine cradle structure. The analysis software can certainly tolerate improvements, although it would require development of fundamentally new algorithms to use the true potential of massively parallel computers. 


\section{REFERENCES}

1. M. A. Zinky, J. W. Everett, and L. J. Hawbaker, Introduction to INGRES, PWS-KENT Pub. Co., 1992.

2. NHTSA, NHTSA Data Tape Reference Guide, vol. 1, Technical Report, National Highway Traffic Safety Administration, 1994.

3. A. Paluszny, State-of-the-Art Review of Automobile Structural Crashworthiness, Technical Report AU2301, American Iron and Steel Institute, 1992.

4. B. Henderson and J. H. Haynes, Ford Taurus and Mercury Sable Automotive Repair Manual, Haynes Publishing Group, Inc., 1994.

5. S. Varadappa, S. C. Shyo, and A. Mani, Development of Passenger Finite Element Model, Technical Report HS 808 145, Department of Transportation, 1993.

6. N. E. Bedewi, C. D. Kan, S. Summers, and C. Ragland, "Evaluation of Car-to-Car Frontal Offset Impact Finite Element Models using full scale crash data", In SAE World Congress, 1995.

7. N. E. Bedewi, T. Omar, and A. Eskandarian, "Effect of Mesh Density Variation in Vehicle Crashworthiness Finite Element Modeling", In ASME Winter Annual Meeting and Conference, 1995.

8. J. O. Hallquist, LS-DYNA3D Theoretical Manual, Technical Report 1018, Revision 3, Livermore Software Technology Coorporation, 1994.

9. H. F. Mahmood and A. Paluszny, "Analytical Technique for Simulating Crash Response of Vehicle Structures Composed of Beam Elements", In SAE 6th International Conference on Vehicle Structural Mechanics, 1986.

10. PDA Engineering, P3/PATRAN User's Manual, Technical Report 903000, National Highway Traffic Safety Administration, 1993. 
11. Y. Zhu, Contribution to the Local Approach of Fracture in Solid Dynamics, PhD thesis, University of Liege, Belgium, 1994.

12. J. O. Hallquist, D. W. Stillman, and T. L. Lin, LS-DYNA3D user's manual, Technical Report 1007, Livermore Software Technology Corporation, 1993.

13. J. O. Hallquist, LS-DYNA3D Theoretical Manual, Technical Report 1018, Livermore Software Technology Corporation, 1994.

14. A. Pothen, H. D. Simon, and K. P. Liou, "Partitioning Sparse Matrices with Eigenvectors of Graphs", SIAM Journal on Matrix Analysis and Applications, 11(3):430-452, 1990.

15. H. D. Simon, "Partitioning of Unstructured Problems for Parallel Processing", Computing Systems in Engineering, 2(3):135-148, 1991.

16. C. Farhat, "A Simple and Efficient Automatic FEM Domain Decomposer", Computers G Structures, 28(5):579-602, 1988. 
APPENDIX A

GENERAL TEST INFORMATION FOR TEST 2075 


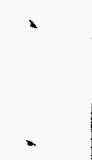


Test Report: /uds/veh/v2000/v2075/repv2075.doc

1 DATE: $23-J U N-94$

U.S. DEPARTMENT OF TRANSPORTATION

PAGE : $\quad 1$

NATIONAL HIGHWAY TRAFFIC SAFETY ADMINISTRATION

CRASH AUTOMOBILE RESEARCH SYSTEM

DYNAMIC CRASH FILE CATALOG

SELECTION CRITERION

VEHDB

VERSION 3 DATA

TABLE OF CONTENTS

HARD COPY REFERENCE NUMBER

2075

DATE : $23-$ JUN -94
CONTRACT NUMBER

DTRS57-87-C-00047
TEST PERFORMER

CAL
TEST TITLE

FY94 CRASHWORTINESS VEHICLE-TO-VEHICLE F RONTAL IMPACT

1

U.S. DEPARTMENT OF TRANSPORTATION

CRASH AUTOMOBILE RESEARCH SYSTEM

DYNAMIC CRASH FILE CATALOG

\section{SELECTION CRITERION}

VEHDE

VERSION 3 DATA

TEST INFORMATION

FOR TEST 2075

Test Title: FY94 CRASHWORTINESS VEHICLE-TO-VEHICLE FRONTAL IMPACT

Test Date: 25-MAY -94

Hard Copy Reference Number: 2075

Test Performer: CALSPAN

Test Configuration: VEHICLE INTO VEHICLE

Test TYPOE: TEST PROCEDURE DEVELOPMENT

Test objectives: OBTAIN HYBRID III DUMMY RESPONSES TO CAR-TO-CAR FRONTAL CRASHES

Closing Speed: $119.0 \mathrm{KPH}$

Test Track surface: ConcRETE

Impact Point: $99999.0 \mathrm{~mm}$

Impact Angle: 30
Entry Date: 23-JuN-94

Contract Number: DTR\$57-87-C-00047

Test Reference Number: RUN1416

Test Track Conditions: DRY

offset Distance: $\quad-102.0 \mathrm{~mm}$ 
Test Report: /uds/veh/v2000/v2075/repv2075.doc

U.S. DERARTMENT OF TRANSPORTATION

PAGE: 1 NATIONAL HICHWAY TRAFFIC SAFETY ADMINISTRATION

CRASH AUTOMOBILE RESEARCH SYSTEM

DYNAMIC CRASH FILE CATALOG

\section{SELECTION CRITERTON}

VEHDB

VERSION 3 DATA

TABLE OF CONTENTS

HARD COPY REFERENCE NUMBER

2075

DATE : $23-J U N-94$

๙ั
CONTRACT NUMBER

DTRS57-87-C-00047
TEST PERFORMER

CAL
TEST TITLE

FY94 CRASHWORTINESS VEHICLE-TO-VEHICLE F RONTAL IMPACT

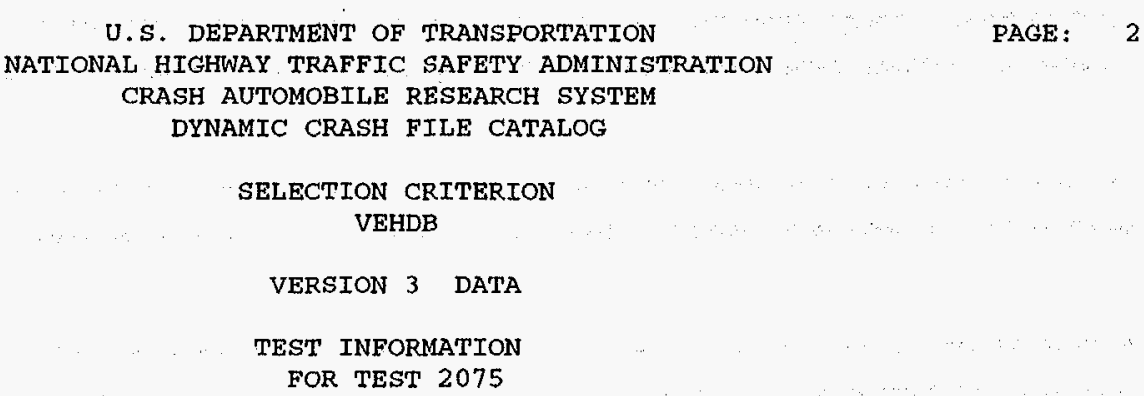

U.S. DEPARTMENT OF TRANSPORTATION

NATIONAL HIGHWAY TRAFFIC SAFETY ADMINISTRATION PAGE: 2 CRASH AUTOMOBILE RESEARCH SYSTEM DYNAMIC CRASH FILE CATALOG

$$
\begin{gathered}
\text { SELECTION CRITERION } \\
\text { VEHDB }
\end{gathered}
$$

VERSION 3 DATA

TEST INFORMATION

FOR TEST 2075

Test Title: FY94 CRASHWORTINESS VEHICLE-TO-VEHICLE FRONTAL IMPACT

Test Date: 25-MAX-94

Hard Copy Reference Number: 2075

Test Performer: CALSPAN

Test Configuration: VEHICLE INTO VEHICLE

Test Type: TEST PROCEDURE DEVELOPMENT

Test objectives: OBTAIN HYBRID III DUMMY RESPONSES TO CAR-TO-CAR FRONTAL CRASHES

Closing speed: $119.0 \mathrm{KPH}$

Test Track surface; CONCRETE

Impact point: $99999.0 \mathrm{~mm}$

Impact Angle: $\quad 30$
Entry Date: $23-\mathrm{JuN}-94$

Contract Number: DTRS57-87-C-00047

Test Reference Number: RUN1416

Test Track Conditions: DRY

offset Distance: $-102.0 \mathrm{~mm}$ 
system of Measurement: METRIC

\section{Ambient Temperature: $23.0 \mathrm{C}$}

Description of other Anomalies: VTV TEST NUMBER 7

Total Curves: 118

\section{SELECTION CRITERION \\ VEHDB}

VERSION 3 DATA

VEHICLE INFORMATION

FOR TEST 2075

Vehicle Identification Number: 1

J Make: FORD Model: TAURUS

Engine Type: V6 TRANSVERSE FRONT

Transmission Type: AUTOMATIC - FRONT WHEEL DRIVE

Vehicle Length: $4888.0 \mathrm{~mm}$ Vehicle width: $1815.0 \mathrm{~mm}$

Vehicle C.G. Distance Behind Front Axle: $1064.0 \mathrm{~mm}$

steering Column Collapse Mechanism: UNKNOWN

Year: 94

Test Weight: $1574.0 \mathrm{KC}$

Vehicle Modification Indicator: PRODUCTION VEHICLE

General Description of Vehicle Modifications: NO COMMENTs

PDOF Angle: 150 Travel Angle: 0

Vehicle Speed: $\quad 61.5 \mathrm{KPH}$ Vehicle Damage Index: 01FYEW3

Bumper Engagement: DIRECT ENGAGEMENT

Sill Engagement: NOT APPLICABLE

Total Length of Indentation: $889.0 \mathrm{~mm}$

A-Pillar Engagement: NOT APPLICABLE

Maximum Crush Distance: $\quad 724.0 \mathrm{~mm}$

Distance Between Center of Damage Area And C.G. Axis: $9999.0 \mathrm{~mm}$

Damage Profile Distances -

Point Number 1: $\quad 724.0 \mathrm{~mm}$

Point Number 4: $\quad 701.0 \mathrm{~mm}$

Angle of Moving Test Cart:
Point Number 2: $\quad 650.0 \mathrm{~mm}$ Point Number 5: $206.0 \mathrm{~mm}$
Point Number 3: $\quad 630.0 \mathrm{~mm}$ point Number 6: $0.0 \mathrm{~mm}$ 
Vehicle Orientation on Moving Cart:

DATE : $23-J U N-94$

U.S. DEPARTMENT OF TRANSPORTATION

NATIONAL HIGHWAY TRAFFIC SAFETY ADMINISTRATION
CRASH AUTOMOBILE RESEARCH SYSTEM

DYNAMIC CRASH FILE CATALOG

\section{SELECTION CRITERION}

VEHDB

VERSION 3 DATA

VEHICLE INFORMATION

FOR TEST 2075

Vehicle Identification Number: 2

Make: FORD Model: TAURUS

Engine Type: V6 TRANSVERSE FRONT

Transmission TYPe: AUTOMATIC - FRONT WHEEL DRIVE

Vehicle Length: $4875.0 \mathrm{~mm}$ Vehicle Width: $1830.0 \mathrm{~mm}$

Vehicle C.G. Distance Behind Front Axle: $1003.0 \mathrm{~mm}$

steering Column Collapse Mechanism: UNKNOWN

Year: 92

Test Weight: $1574.0 \mathrm{KG}$

Engine Displacement: 3.0 LITER

BOdY TYPe: FOUR DOOR SEDAN

Wheelbase: $2695.0 \mathrm{~mm}$

Vehicle Modification Indicator: PRODUCTION VEHICLE

General Description of Vehicle Modifications: No COMMENTS

PDOF Angle: $210 \quad$ Travel Angle: $0 . \quad$ Vehicle speed: $61.5 \mathrm{KPH}$ Vehicle Damage Index: 11FYEW3

Bumper Engagement: DIRECT ENGAGEMENT

Sill Engagement: NOT APPLICABLE

A-Pillar Engagement: NOT APPLICABLE

Total Length of Indentation: $1320.0 \mathrm{~mm}$

Maximum Crush Distance: $\quad 716.0 \mathrm{~mm}$

Distance Between Center of Damage Area And C.G. Axis: $9999.0 \mathrm{~mm}$

Damage Profile Distances -

Point Number 1: $414.0 \mathrm{~mm} \quad$ Point Number 2: $472.0 \mathrm{~mm}$ Point Number 3: $678.0 \mathrm{~mm}$

Angle of Moving Test Cart: 999

Vehicle orientation on Moving cart: 999

DATE : $23-J U N-94$

U.S. DEPARTMENT OF TRANSPORTATION

PAGE: 5

NATIONAL HIGHWAY TRAFFIC SAFETY ADMINISTRATION

CRASH AUTOMOBILE RESEARCH SYSTEM

DYNAMIC CRASH FILE CATALOG

SELECTION CRITERION 


\section{VEHDB}

VERSION 3 DATA

OCCUPANT INFORMATION

FOR TEST 2075

Vehicle Containing Occupant: 1

Seating Position: LEFT FRONT SEAT

Seat Position: CENTER POSITION

Occupant TYpe: HYBRID III DUMMY

Dummy Size Percentile: 50 PERCENTILE

Age: 99 Height: $999.0 \mathrm{~mm}$

Weight: $999.0 \mathrm{KG}$ Sex: MALE

Manufacturer of Dummy And Serial Number:

HUMANOID SN: 150

Clearance Distances:

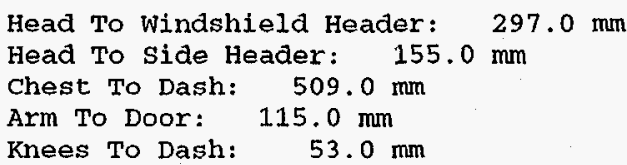

Head To Windshield Header: $297.0 \mathrm{~mm}$

Head To Side Header: $155.0 \mathrm{~mm}$

Chest To Dash: $509.0 \mathrm{~mm}$

Arm To Door: $115.0 \mathrm{~mm}$

Knees To Dash: $53.0 \mathrm{~mm}$

Primary Restraint: 3 POINT BELT

Head To Windshield: $\quad 585.0 \mathrm{~mm}$ Head To side window: $256.0 \mathrm{~mm}$ Chest To steering wheel: $295.0 \mathrm{~mm}$

Hip To Door: $138.0 \mathrm{~mm}$

Air Bag/Belt Deployment: DEPLOYED PROPERLY

secondary Restraint: AIR BAG

Head Contact Region: AIR BAG

Chest or Abdomen Contact Region: AIR BAG

Leg Contact Region: DASHPANEL

Head Injury: $\quad 410.800$.

HIC Time Interval: Low Boundary:

Thorax Peak Acceleration (CLIP3M): 51.000

Upper Boundary: $\quad 89.640$

Peak Load: Left Femur: 5199.000 Lap Belt: $\quad 9999.000$

Chest Severity Index: 552.000

occupant Comments: No commENT

DATE: 23-JUN-94

U.S. DEPARTMENT OF TRANSPORTATION

PAGE: 6 NATIONAL HIGHWAY TRAFFIC SAFETY ADMINISTRATION

CRASH AUTOMOBILE RESEARCH SYSTEM

DYNAMIC CRASH FILE CATALOG

SELECTION CRITERION

VEHDB

VERSION 3 DATA 


\section{repv2075 doc}

\section{OCCUPANT INFORMATION}

$$
\text { FOR TEST } 2075
$$

Vehicle Containing occupant: 1

Seating Position: RIGHT FRONT SEAT

Seat Position: CENTER POSITION

Occupant TYpe: HYBRID III DUMMY

Dummy Size Percentile: 50 PERCENTILE

Age: 99 Height: $999.0 \mathrm{~mm}$

Weight: $999.0 \mathrm{~kg}$ Sex: MALE

Manufacturer of Dummy And Serial Number:

HUMANOID SN 245

Clearance Distances:

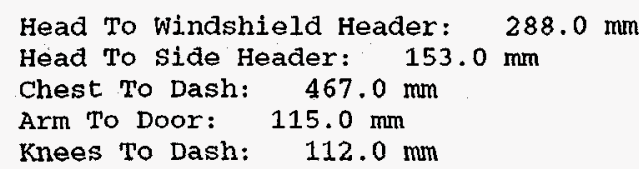

Head To Windshield Header: $288.0 \mathrm{~mm}$

Head To side Header: $153.0 \mathrm{~mm}$

Chest To Dash: $467.0 \mathrm{~mm}$

Arm To Door: $115.0 \mathrm{~mm}$

Knees To Dash: $112.0 \mathrm{~mm}$

Primary Restraint: 3 POINT BELT

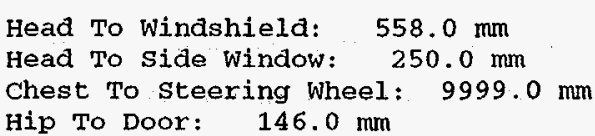

Air Bag/Belt Deployment: DEPLOYED PROPERLY

Secondary Restraint: AIR BAG

Head Contact Region: AIR BAG

Chest or Abdomen Contact Region: AIR BAG

Leg Contact Region: DASHPANEL

Head Injury: 257.000

HIC Time Interval: Low Boundary: 53.160

Upper Boundary: $\quad 80.760$

Thorax Peak Acceleration (CLIP3M): 48.390

Chest Severity Index: 414.200

Peak Load: Left Femur: 4965.000 Lap Belt: $\quad 9999.000$

Right Femur: 1648.000 Shoulder Belt: 9999.000

Occupant comments: NO COMMENT

DATE: $23-J U N-94$

U.S. DEPARTMENT OF TRANSPORTATION

PAGE : 7

NATIONAL HTCHWAY TRAFFTC SAFETY ADMTNTSTRATTON

CRASH AUTOMOBILE RESEARCH SYSTEM

DYNAMIC CRASH FILE CATALOG

\section{SELECTION CRITERION}

VEHDB

VERSION 3 DATA

OCCUPANT INFORMATION FOR TEST 2075 
Vehicle Containing occupant: 2

Seating Position: RIGHT FRONT SEAT

Seat POsition: CENTER POSITION

Occupant TYpe: RART 572 DUMMY

Dummy size Percentile: 50 PERCENTILE

Age: 99 Height: $999.0 \mathrm{~mm}$

Weight: $\quad 999.0 \mathrm{KG}$

SeX: MALE

Manufacturer of Dummy And Serial Number:

HUMANOID S/N 819

Clearance Distances:

Head To Windshield Header: $362.0 \mathrm{~mm}$
Head To Side Header: $132.0 \mathrm{~mm}$
Chest To Dash: $530.0 \mathrm{~mm}$
Arm To Door: $124.0 \mathrm{~mm}$
Knees To Dash: $\quad 112.0 \mathrm{~mm}$

Primary Restraint: 3 POINT BELT

Secondary Restraint: AIR BAG

Head Contact Region: AIR BAG

Chest or Abdomen Contact Region: AIR BAG

Leg Contact Region: DASHPANEL

Head Injury: 9999.000

HIC Time Interval: Low Boundary: 999.999

Upper Boundary: 999.999

Thorax Peak Acceleration (CLIP3M): 999.900

Chest Severity Index: 9999.000

Peak Load: Left Femur: 999.900

Lap Belt: $\quad 9999.000$

ight Femur: 999.900

Shoulder Belt: 9999.000

Occupant Comments: No COMMENT

DATE : 23-JUN-94

U.S. DEPARTMENT OF TRANSPORTATION

PAGE : 8
Head To Windshield: $\quad 563.0 \mathrm{~mm}$

To steering wheel: $9999.0 \mathrm{~mm}$

Air Bag/Belt Deployment: DEPLOYED PROPERLY

NATIONAL HIGHWAY TRAFFIC SAFETY ADMINISTRATION

CRASH AUTOMOBILE RESEARCH SYSTEM

DYNAMIC CRASH FILE CATALOG

SELECTION CRITERION

VEHDB

VERSION 3 DATA

INSTRUMENTATION INFORMATION

FOR TEST 2075

\begin{tabular}{|c|c|c|c|c|c|c|c|c|c|c|c|c|c|c|c|}
\hline & $I$ & $I$ & & $\mathrm{I}$ & & I & I & I & & I & & $I$ & I & I & \\
\hline Sensor & I Veh. & $I$ & Occupant & I & Region & I Axis & I Crve & I & NFP & $I$ & NLP & I DAS. & I Pref. & I & Data \\
\hline Type & I No & I & Attachment & $I$ & Attached & I & I No. & I & & $I$ & & I & I Freq. & I & Quality \\
\hline
\end{tabular}




I I ACCELEROMETER
I
I 1 I LEFT FRONT SEA I HEAD CG

PAGE : 9

SELECTION CRITERION

VEHDB

VERSION 3 DATA

INSTRUMENTATION INFORMATION

FOR TEST 2075

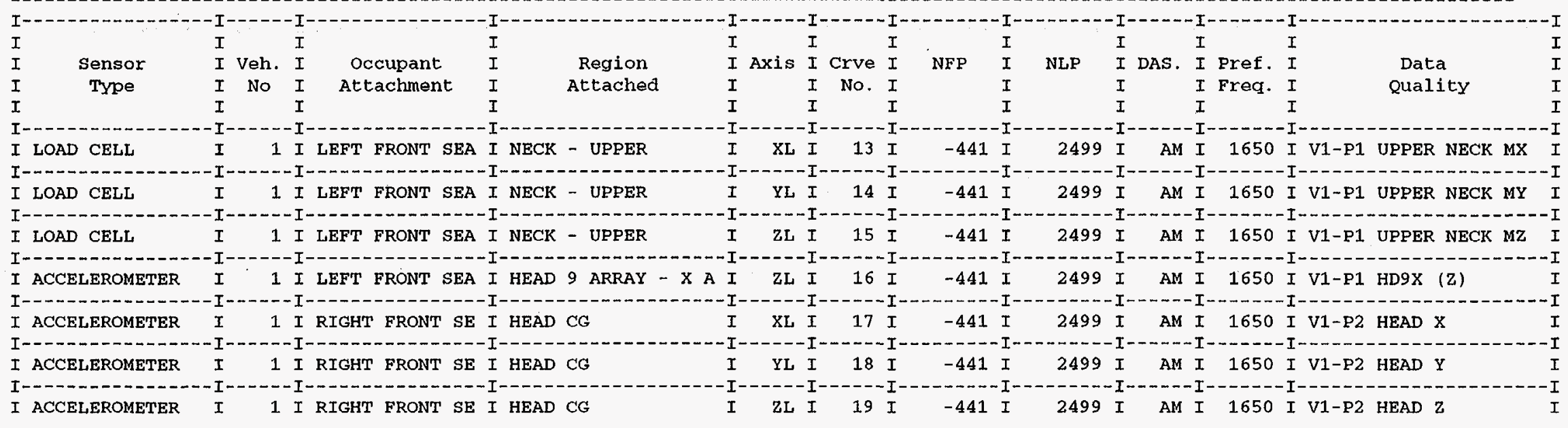




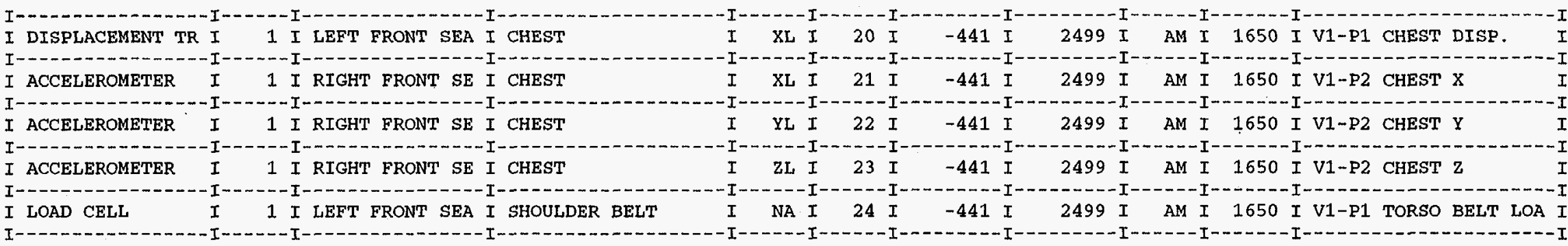

\section{SELECTION CRITERION}

VEHDB

VERSION 3 DATA

INSTRUMENTATION INFORMATION FOR TEST 2075

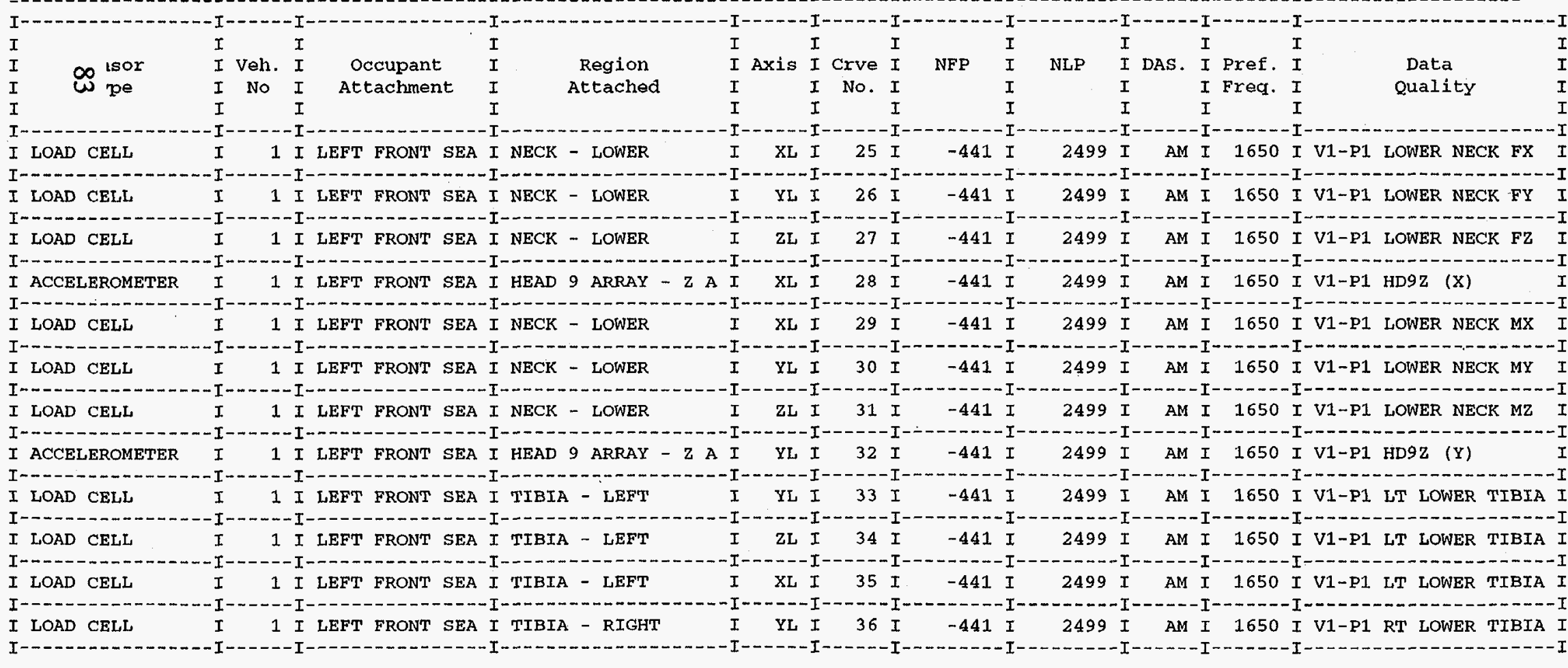


CRASH AUTOMOBILE RESEARCH SYSTEM

DYNAMIC CRASH FILE CATALOG

SELECTION CRITERION

VEHDB

VERSION 3 DATA

INSTRUMENTATION INFORMATION

FOR TEST 2075

\begin{tabular}{|c|c|c|c|c|c|c|c|c|c|c|c|c|c|c|c|c|c|c|}
\hline I & & $I$ & & I & & I & & $I$ & $\mathbf{I}$ & & $\mathbf{I}$ & & $I$ & & I & $I$ & $I$ & \\
\hline I & Sensor & $I$ & Veh. & I & Occupant & I & Region & I Axis & $\mathbf{I}$ & Crve & $\mathbf{I}$ & NFP & $I$ & NLP & I DAS. & I pref. & I & Data \\
\hline I & Type & I & No & I & Attachment & $I$ & Attached & $I$ & $\mathrm{I}$ & No. & I & & I & & I & I Freq. & I & Quality \\
\hline I & & I & & I & & $I$ & & I & I & & I & & I & & I & I & I & \\
\hline
\end{tabular}

I LOAD CELL II 1 I LEFT FRONT SEA I TIBIA - RIGHT
I LOAD CELL 1 I 1 I LEFT FRONT SEA I TIBIA - RIGHT I ZL I 37 I -441 I 2499 I AM I 1650 I V1-P1 RT LOWER TIBIA I I LOAD CELL 1 I 1 I LEFT FRONT SEA I TIBIA - RIGHT I IL I 37 I -441 I 2499 I AM I 1650 I V1-P1 RT LOWER TIBIA I

I I LOAD CELL I 1 I LEFT FRONT SEA I TIBIA - RIGHT I XL I 38 I -441 I 2499 I AM I 1650 I V1-P1 RT LOWER TIBIA I I-D..-

I LOAD CELL I 1 I LEFT FRONT SEA I FEMUR - LEFT I

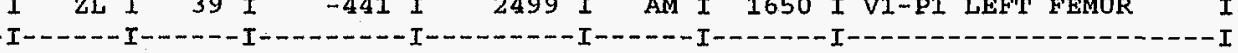
I I LOAD CELL $\quad$ I 1 I LEFT FRONT SEA I FEMUR - RIGHT I LOAD CELL $\quad$ I 1 I RIGHT FRONT SE I FEMUR - LEFT I LOAD CELL I LC ILL I 1 I RIGHT FRONT SE I FEMUR - RIGHT I-- $\infty$. I LC ILL I 1 I RIGHT FRONT SE I TIBIA - LEFT I LOAD CELL $\quad$ I 1 I RIGHT FRONT SE I TIBIA - LEFT I LOAD CELL 1 I 1 I RIGHT FRONT SE I TIBIA - LEFT I LOAD CELL $\quad I \quad 1$ I RIGHT FRONT SE I TIBIA - LEFT I LOAD CELL $\quad$ I 1 I RIGHT FRONT SE I TIBIA - LEFT I $\quad \mathrm{L} I \mathrm{I}-40$ I I $\quad-441$ I 2499 I AM I 1650 I V1-P1 RIGHT FEMUR I II $\mathrm{ZL}$ I $41 \mathrm{I} \quad-441$ I 2499 I AM I 1650 I V1-P2 LEFT FEMUR I I ZL I $42 \mathrm{I} \quad-441 \mathrm{I} \quad 2499 \mathrm{I}$ AM I $1650 \mathrm{I}$ V1-P2 RIGHT FEMUR I I XI I 43 I

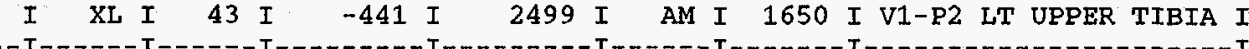
I YL I 44 I -441 I 2499 I AM I 1650 I V1-P2 LT UPPER TIBIA I I-- II YL I 45 I -441 I 2499 I AM I 1650 I V1-P2 LT LOWER TIBIA I 1 I RIGHT FRON'T SE I TIBIA - LEFT I $\quad-441$ I 2499 I AM I 1650 I V1-P2 LT LOWER TIBIA I

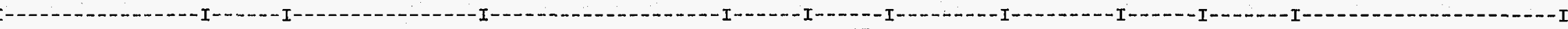
I ACCELEROMETER I 1 I NOT APPLICABLE I OTHER I YG I 47 I -441 I 2499 I AM I 1650 I V1 RICHT SHOCK TOHER I II ACCELEROMETER I I 1 I NOT APPLICABLE I OTHER

U.S. DEPARTMENT OF TRANSPORTATION

PAGE : 12 NATIONAL HIGHWAY TRAFFIC SAFETY ADMINISTRATION

CRASH AUTOMOBILE RESEARCH SYSTEM DYNAMIC CRASH FILE CATALOG

\section{SELECTION CRITERION} VEHDB

VERSION 3 DATA

INSTRUMENTATION INFORMATION FOR TEST 2075

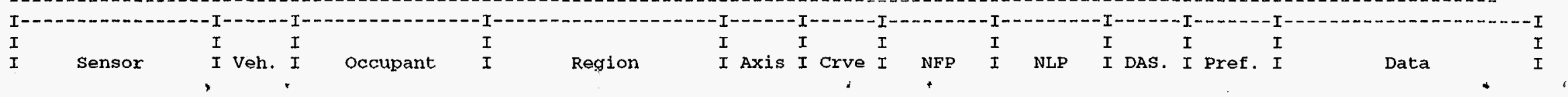


HHHHHHHHHHHHHHҢHHHHHHHHHHHH

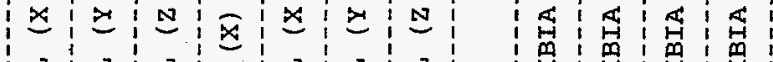

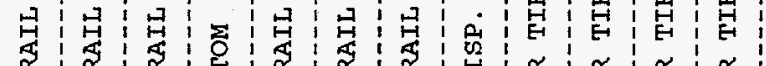
武

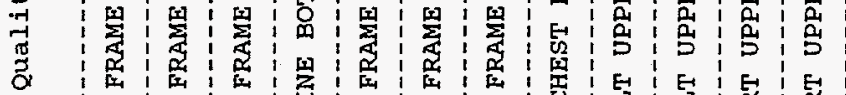

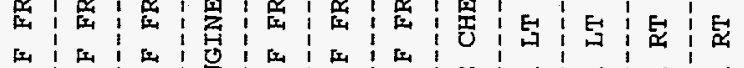

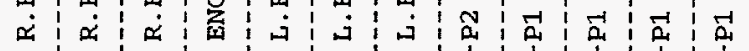
\begin{tabular}{l|l|l|l|l|l|l|l|l|l|l|l|l|l|}
5 & 5 & 5 & 5 & 5 & 5 & 5 & 5 & 5 & 5 & 5
\end{tabular}

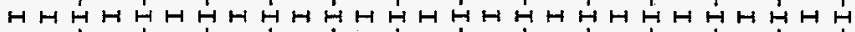

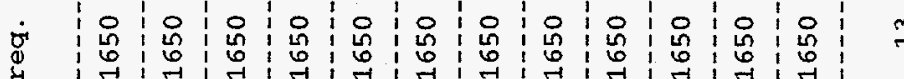
落

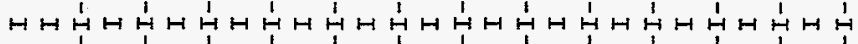

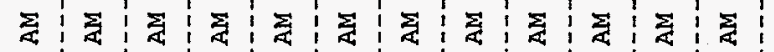

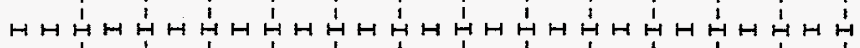

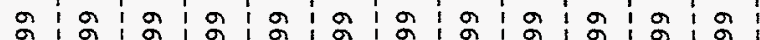
హิ

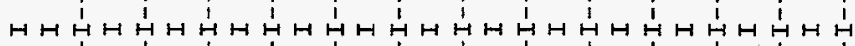

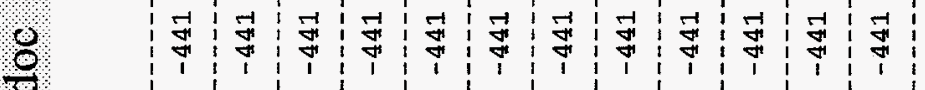
है НH

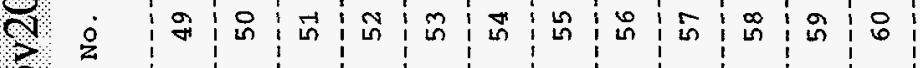
这

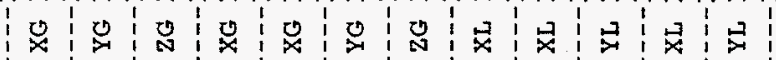

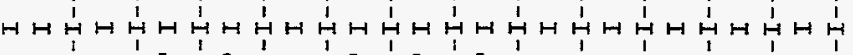
密

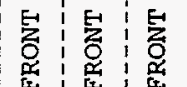

$\underset{\substack{0 \\ 0}}{0}$

吕: 包:

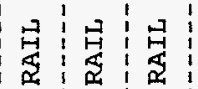

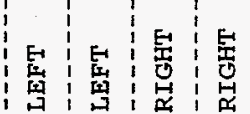
象 Нカ

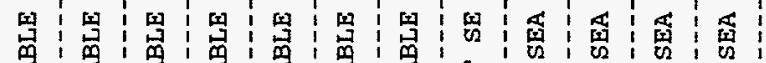

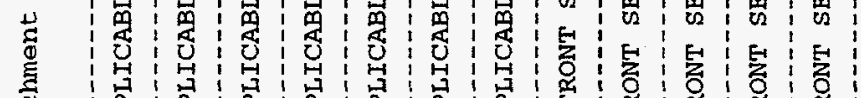
氙 㤐

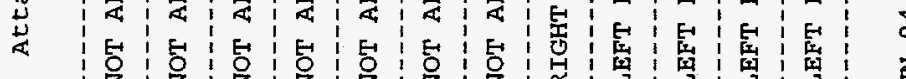
НH HНH

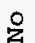

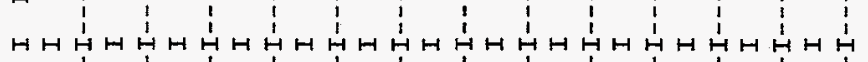
出

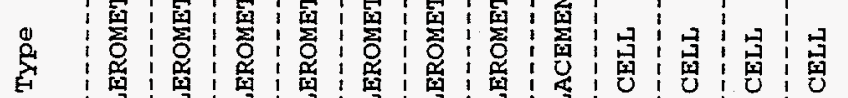

焉

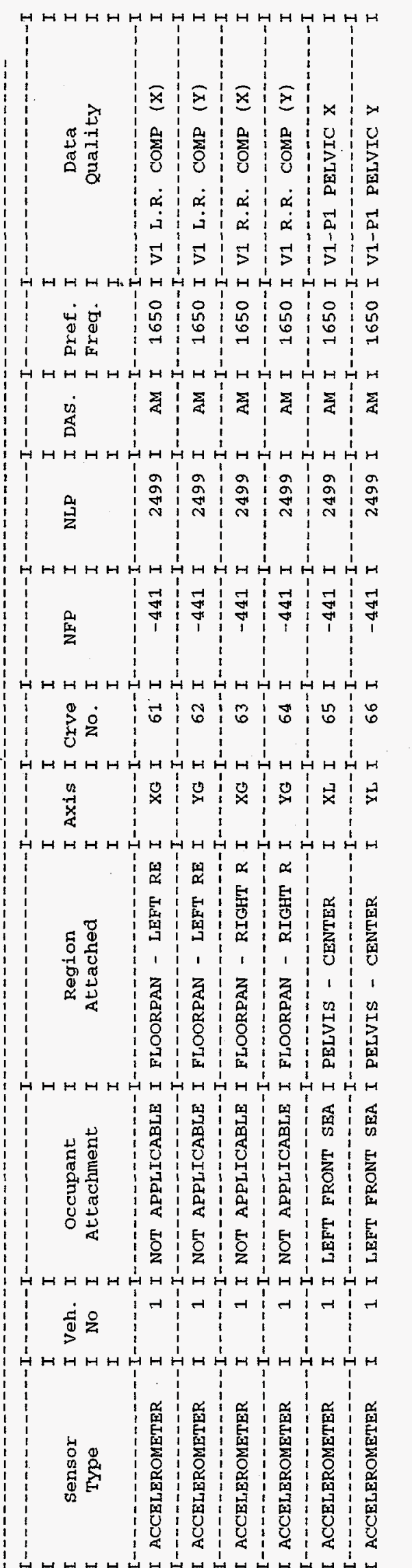




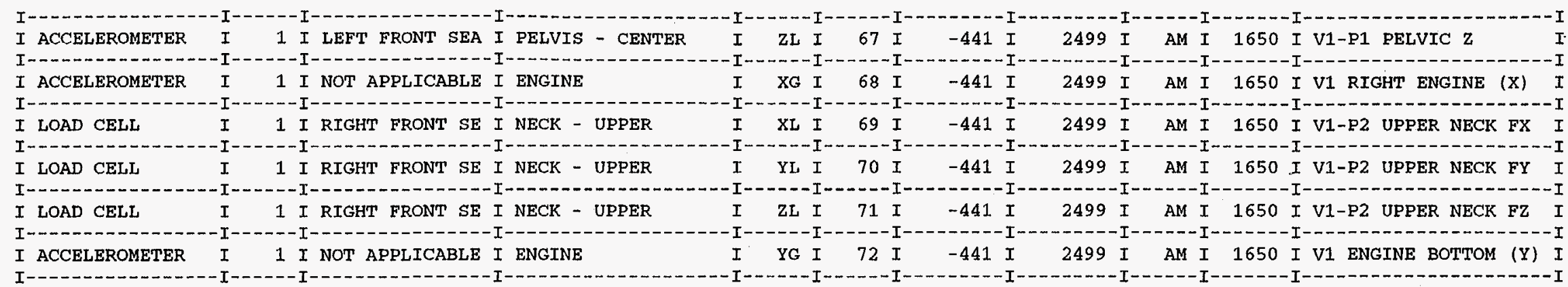
DYNAMIC CRASH FILE CATALOG

\section{SELECTION CRITERION}

VEHDB

VERSION 3 DATA

INSTRUMENTATION INFORMATION

$$
\text { FOR TEST } 2075
$$

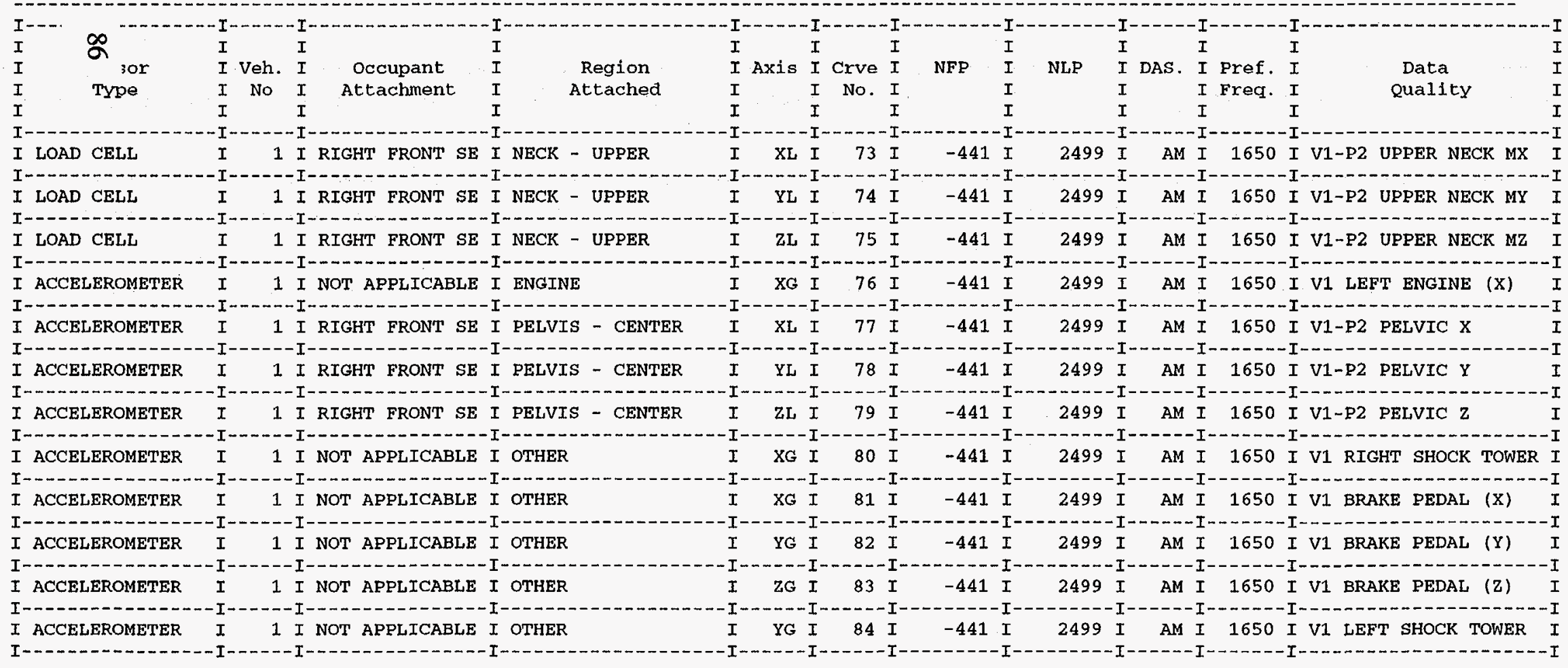




\section{repv2075.doc}

U.S. DEPARTMENT OF TRANSPORTATION NATIONAL HIGHWAY TRAFFIC SAFETY ADMINISTRATION CRASH AUTOMOBILE RESEARCH SYSTEM DYNAMIC CRASH FILE CATALOG
PAGE: 15

\section{SELECTION CRITERION}

VEHDB

VERSION 3 DATA

INSTRUMENTATION INFORMATION

$$
\text { FOR TEST } 2075
$$

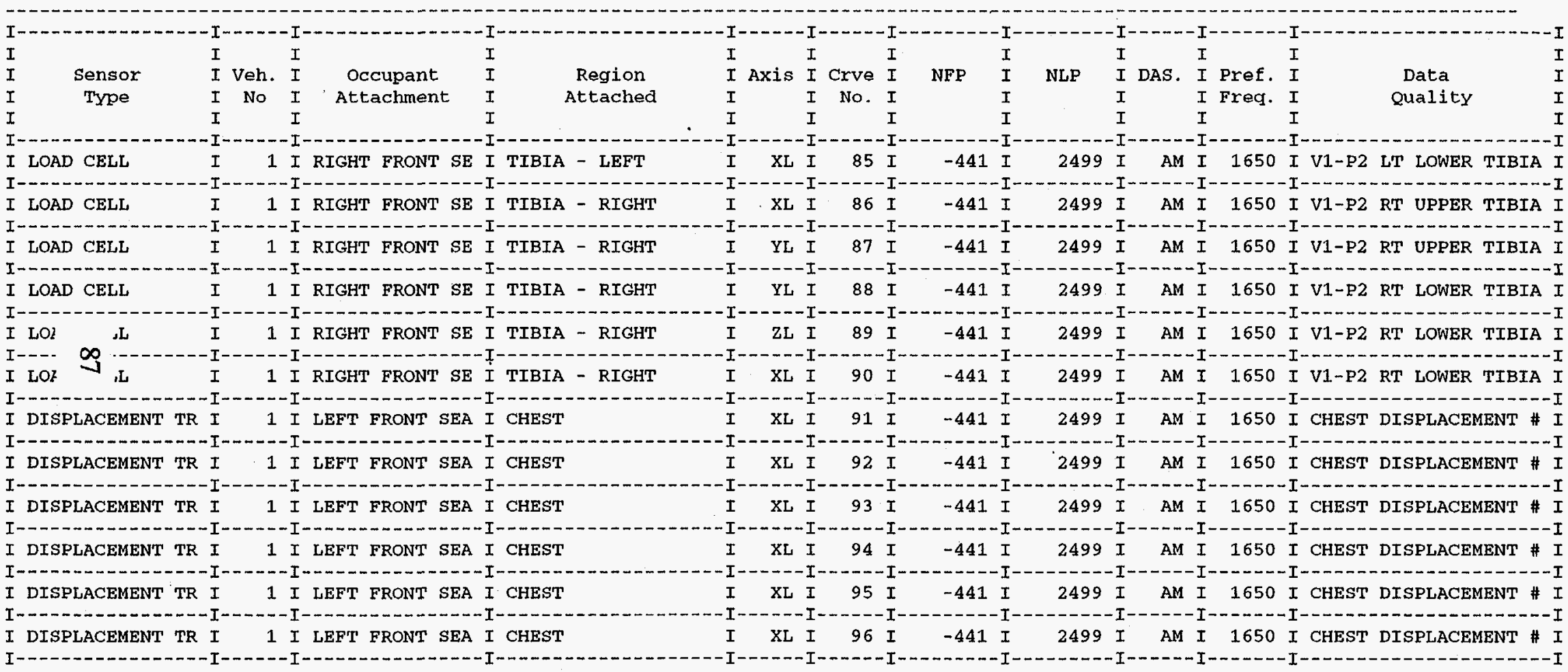

\section{SELECTION CRITERION}

VEKDB

VERSION 3 DATA 


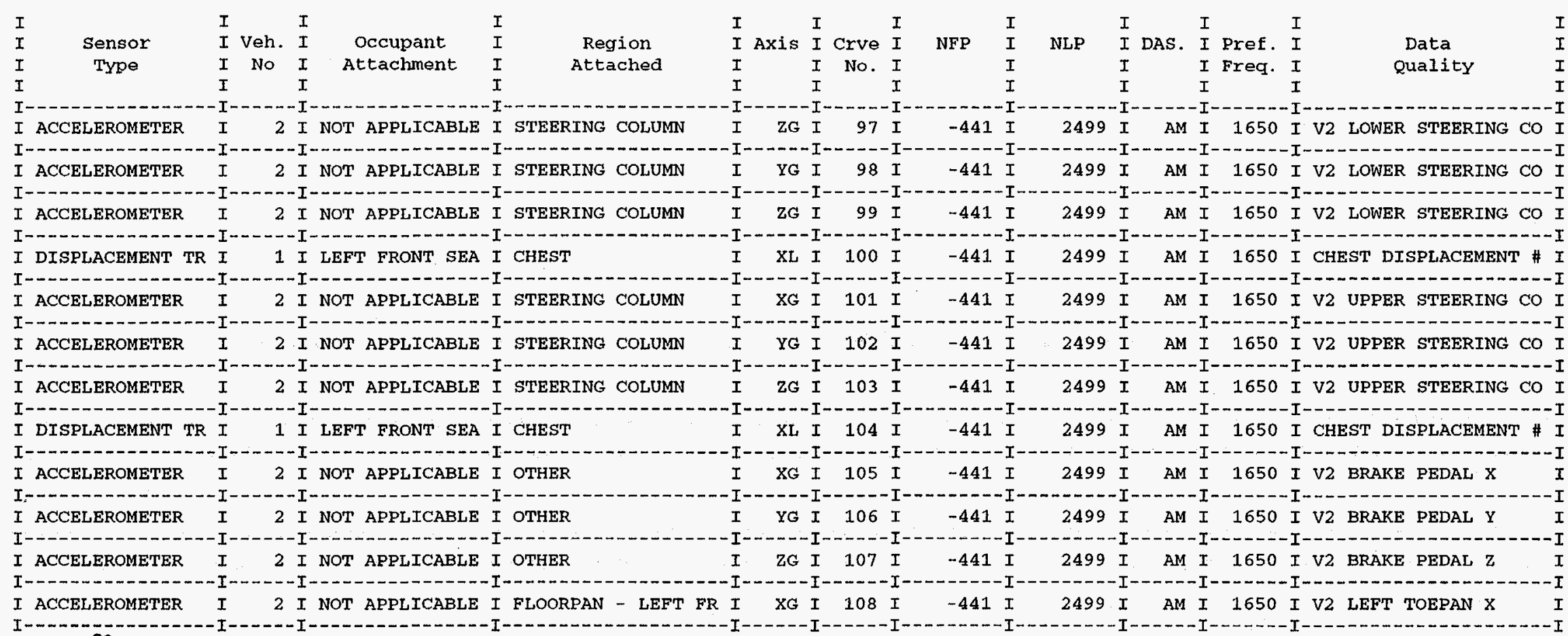
DYNAMIC CRASH FILE CATALOG

\section{SELECTION CRITERION}

VEHDB

VERSION 3 DATA

INSTRUMENTATION INFORMATION FOR TEST 2075

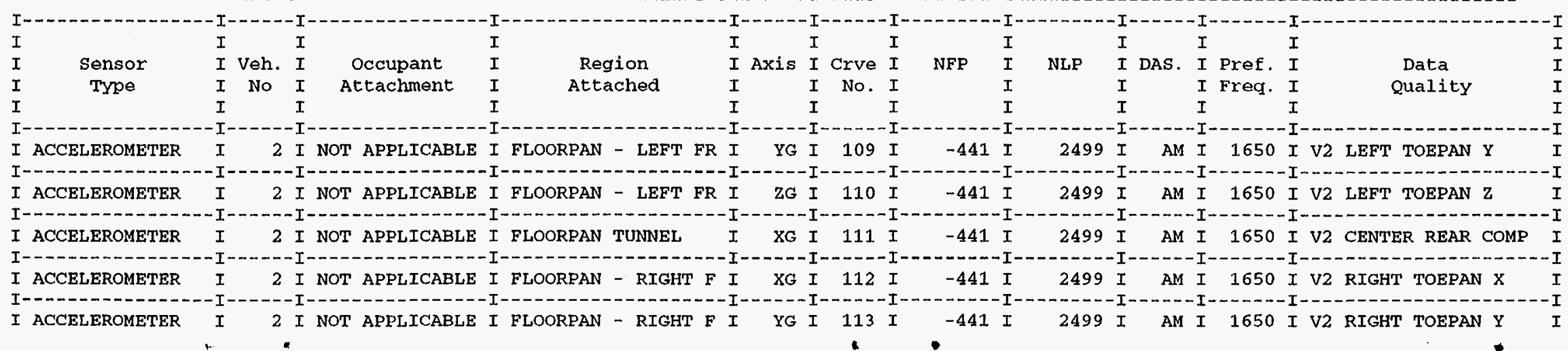




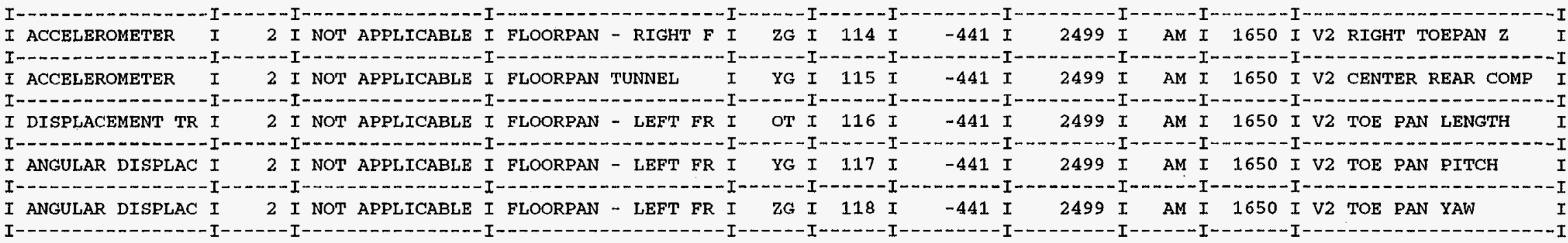

Back to the NRD home page

Send mail to the Web Master

Last Updated: Fri Mar 21 15:18:09 1997 


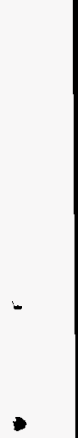

$\checkmark$ 
ORNL/TM-13407

\section{INTERNAL DISTRIBUTION}

1-2. Central Research Library

3. Document Reference Section

4-5. Laboratory Records Department

6. Laboratory Records, ORNL PC

7. ORNL Patent Section

8-9. M\&C Records Office

10. P. Angelini

11. G. A. Aramayo

12. R. A. Bradley
13. D. F. Craig

14. H. Gray

15. H. W. Hayden

16. G. M. Ludtka

17. B. Radhakrishnan

18. S. Simunovic

19. P. Sklad

20. D. Warren

21. T. Zacharia

22. R. E. Zeigler

\section{EXTERNAL DISTRIBUTION}

23. DOE, OFFICE OF SCIENTIFIC AND TECHNICAL INFORMATION, P.O. Box 62, Oak Ridge, TN 37831-0062

24. DOE, OAK RIDGE OPERATIONS, P.O. Box 2001, Oak Ridge, TN 37831-6269

25. DOE, OFFICE OF HEAVY VEHICLE TECHNOLOGY, VEHICLE MATERIALS TECHNOLOGY PROGRAM, EE-RE, Forrestal Building, 1000 Independence Avenue S.W., Washington, DC 20585

S. Diamond

26. DOE, OFFICE OF ADVANCED AUTOMOTIVE TECHNOLOGIES, LIGHTWEIGHT VEHICLE MATERIALS, EE-32, Forrestal Building, 1000 Independence Avenue S.W., Washington, DC 20585

T. Marechaux

27. THE GEORGE WASHINGTON UNIVERSITY, Department of Civil, Mechanical, and Environmental Engineering, Washington, DC 20052

T. G. Toridis

28. DOT, DIVISION OF BIOMECHANICAL RESEARCH, 400 7th Street S.W., Room 6221A, Washington, DC 20590

F. Bandak

29. DOT, NATIONAL HIGHWAY TRAFFIC SAFETY ADMINISTRATION, NRD-11, 4007 th Street, S.W., Washington, DC 20590

T. Hollawell

C. Ragland

S. Summers 